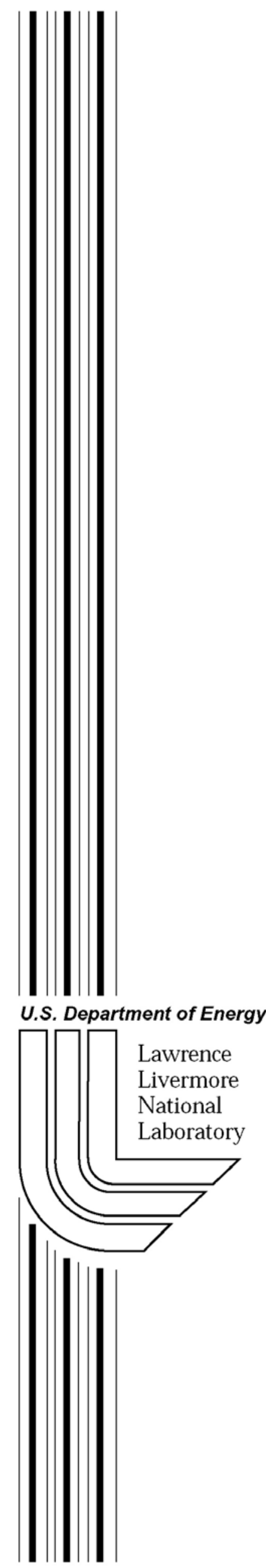

\title{
Concrete Model Descrip- tions and Summary of Benchmark Studies for Blast Effects Simulations
}

C. Noble

E. Kokko

I. Darnell

T. Dunn

L. Hagler

L. Leininger

Structural and Applied Mechanics Group, LLNL

Defense Systems Analysis Group, LLNL

Computational Physics Group, LLNL

Advanced Engineering Analysis Group, LLNL

U.S. Department of Energy

Lawrence

Livermore

National

Laboratory

July 2005 
This document was prepared as an account of work sponsored by an agency of the United States Government. Neither the United States Government nor the University of California nor any of their employees, makes any warranty, express or implied, or assumes any legal liability or responsibility for the accuracy, completeness, or usefulness of any information, apparatus, product, or process disclosed, or represents that its use would not infringe privately owned rights. Reference herein to any specific commercial product, process, or service by trade name, trademark, manufacturer, or otherwise, does not necessarily constitute or imply its endorsement, recommendation, or favoring by the United States Government or the University of California. The views and opinions of authors expressed herein do not necessarily state or reflect those of the United States Government or the University of California, and shall not be used for advertising or product endorsement purposes.

This work was performed under the auspices of the U.S. Department of Energy by University of California, Lawrence Livermore National Laboratory under Contract W7405-Eng-48. 


\section{Table of Contents}

K\&C Concrete Material Model

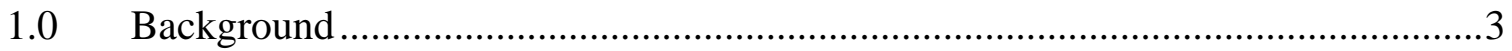

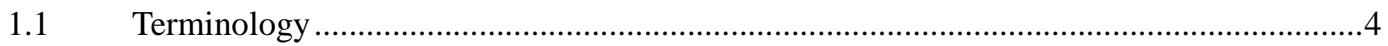

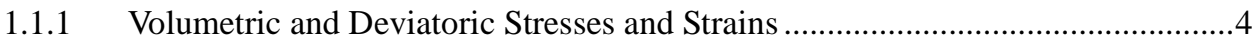

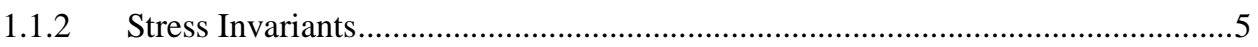

1.1.3 Triaxial Compression and Extension...............................................................

2.0 Nonlinear Concrete Model Description ......................................................... 7

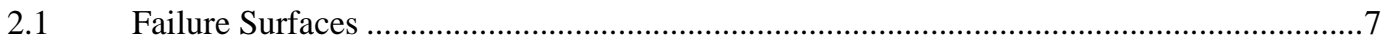

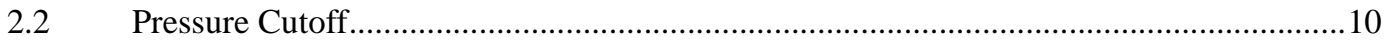

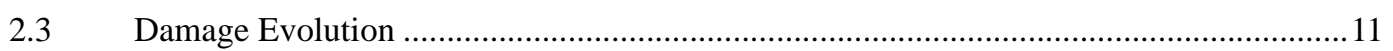

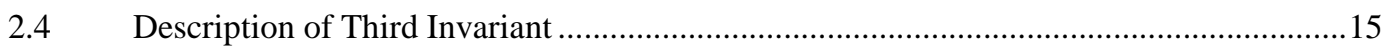

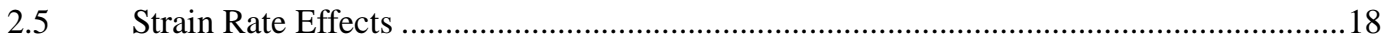

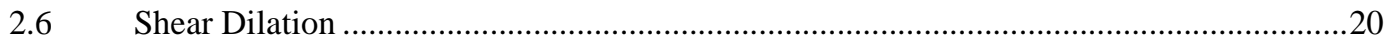

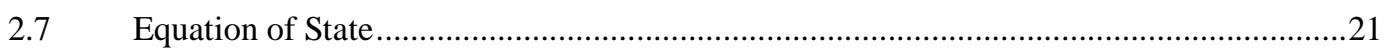

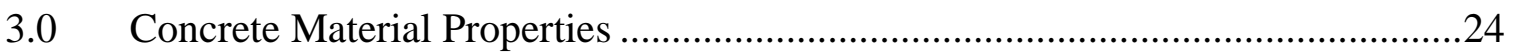

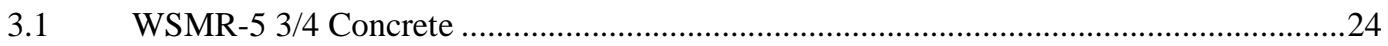

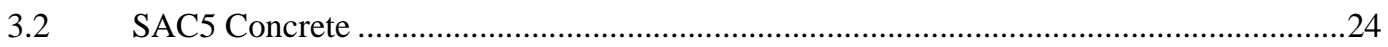

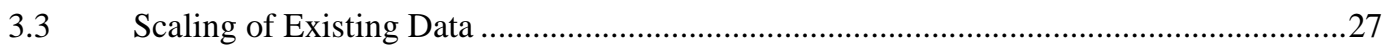

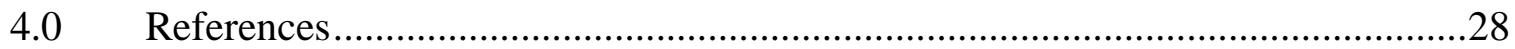

Porous Crush Material Model

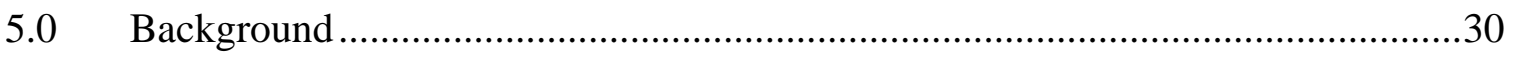

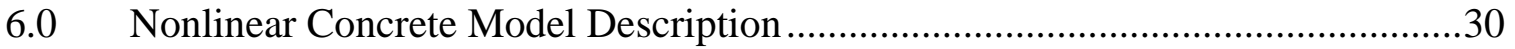

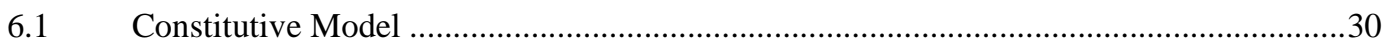

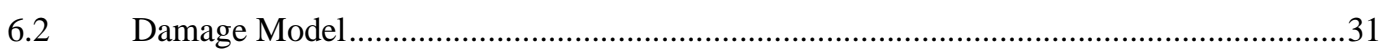

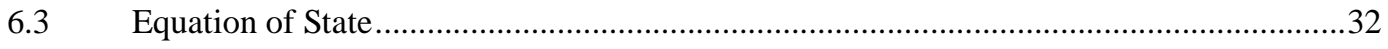

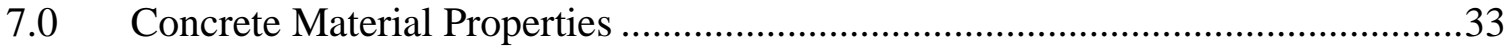

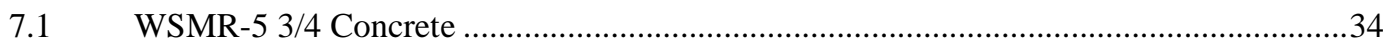

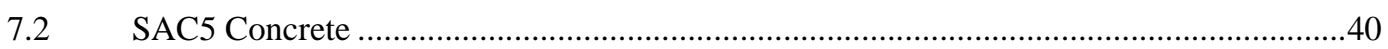

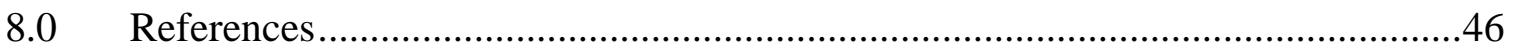

9.0 CALE Concrete Material Model Verification ......................................................46

Homogenized Rebar Model

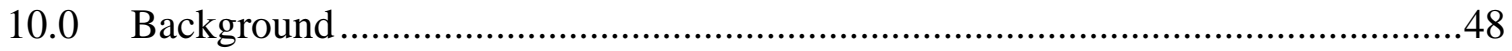

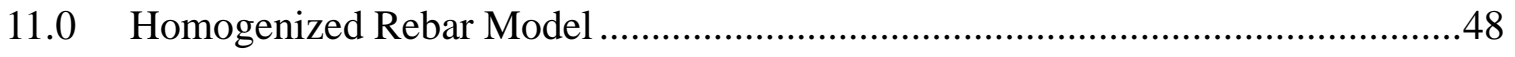

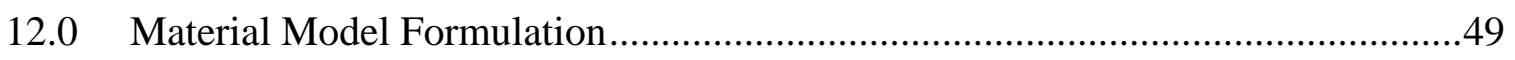

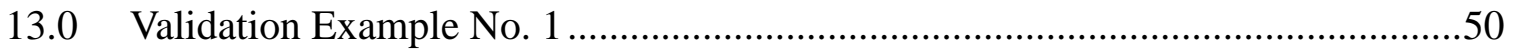

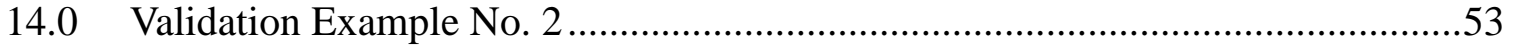

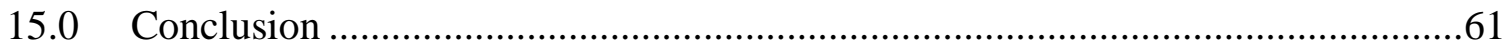

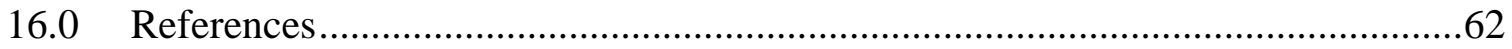


Benchmark Studies

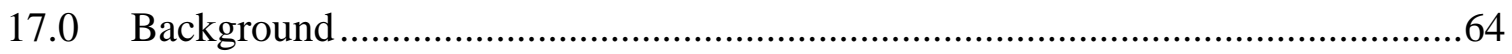

18.0 Shell Element Validation Studies ...................................................................64

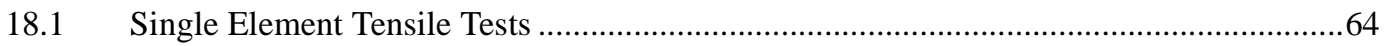

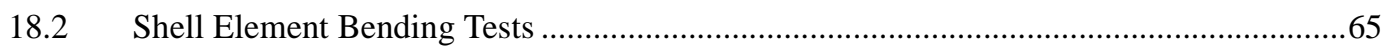

18.3 Underwater Explosions Near Thin-Walled Structures ......................................................66

18.3.1 6061-T6 Aluminum Test Cylinder ........................................................................66

18.3.2 Deformation and Rupture of Thin Plates Subjected to Underwater Shock..........67

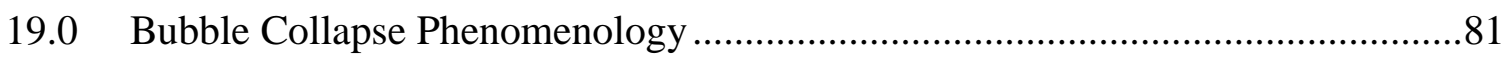

20.0 Concrete Benchmark Experiment ..............................................................93

21.0 Explosively Formed Projectile Validation Experiment ....................................99

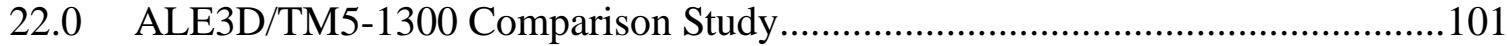

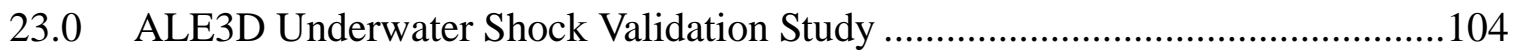

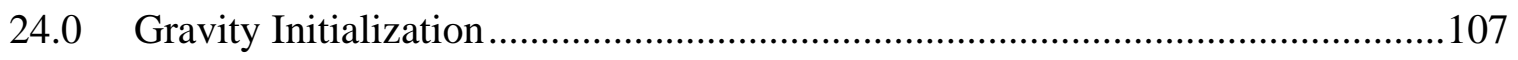

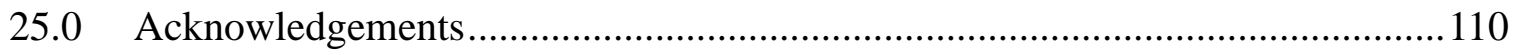




\section{List of Figures}

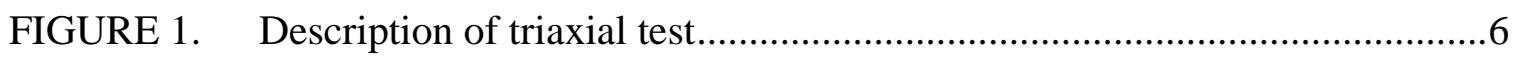

FIGURE 2. Model failure surfaces and uniaxial stress-strain response ..........................

FIGURE 3. Description of pressure cutoff and tensile paths ........................................11

FIGURE 4. Effects of parameters and on softening for a single element tensile test. 14

FIGURE 5. Three-dimensional state of stress and space diagonal ..............................15

FIGURE 6. Von Mises yield surface (plan view of -plane). .......................................15

FIGURE 7. a) Concrete deviatoric sections for increasing pressure; b) William and

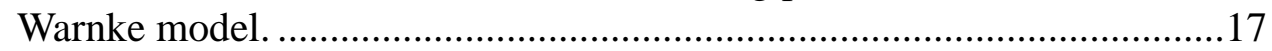

FIGURE 8. Strain rate effects on tensile and compressive strengths ([Ref 3] and

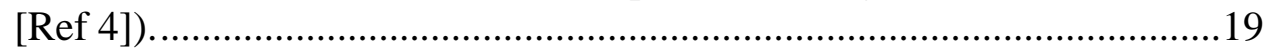

FIGURE 9. Description of strength enhancement calculation...................................20

FIGURE 10. graphical representation of shear dilation; b) yield surface with associated flow rule; c) description of associative, non-associative, and partial associative flow rules............................................................................21

FIGURE 11. Pressure vs. volumetric strain curve for equation-of-state Form 8 with compaction (similarly Form 12).

FIGURE 12. WSMR-5 3/4 concrete properties: a) plot of compressive meridians; b) single element uniaxial tensile test with and without rate dependence (tensile strength $=464 \mathrm{psi}$ ); $\mathrm{c}$ ) description of unconfined uniaxial compressive test and plot of damage parameter $\mathrm{d}$ after compressive failure; d) stress-strain plot of UUC test with and without rate dependence (compressive strength $=6500 \mathrm{psi}$ ).

FIGURE 13. SAC5 concrete properties: a) plot of compressive meridians; b) single element uniaxial tensile test with and without rate dependence (tensile strength $=363 \mathrm{psi}) ; \mathrm{c}$ ) description of unconfined uniaxial compressive test and plot of damage parameter $d$ after compressive failure; $d$ ) stress-strain plot of UUC test with and without rate dependence (compressive strength $=5500 \mathrm{psi}$. .

FIGURE 14. Model failure surfaces and uniaxial stress-strain response.........................31

FIGURE 15. Compressive meridians for WSMR-5 3/4 concrete based on DYNA3D

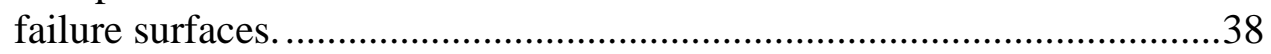

FIGURE 16. Crush pressure vs. density plot. ..............................................................

FIGURE 17. Evolution of damage for unconfined uniaxial compression test in which the pressure load curve specified compressive yield should occur after $2000 \mathrm{msec}$.

FIGURE 18. Compressive meridians for SAC5 concrete based on DYNA3D failure

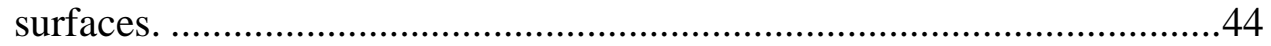

FIGURE 19. Crush pressure vs. density plot. ...........................................................4

FIGURE 20. Evolution of damage for unconfined uniaxial compression test in which the pressure load curve specified compressive yield should occur after $2000 \mathrm{msec}$. 
FIGURE 21. CALE TEPLA-F Porous Material EOS w/ Arbitrary Crush Curve. .46

FIGURE 22. CALE stress and strain time history plots for concrete in an unconfined compression test.

FIGURE 23. CALE damage parameter plot for concrete in an unconfined compression test.

FIGURE 24. Precision test wall study description and computational comparison of concrete damage at mid-section of wall.

FIGURE 25. Precision test wall study computational comparison of concrete damage at back-face of wall.

FIGURE 26. Test setup for contact charges placed at different locations on varying thicknesses of RC bridge piers.

FIGURE 27. Comparison between experiment and simulation for RC bridge pier experiments.

FIGURE 28. Computational results of $1 \mathrm{lb}$ above water and at water surface charges on 10 " thick bridge piers.

FIGURE 29. Computational results of $1 \mathrm{lb}$ below water surface charge on 10" thick bridge piers.

FIGURE 30. Computational results of $2 \mathrm{lb}$ above water and at water surface charges on 6" thick bridge piers.

FIGURE 31. Postshot views of above water and at water surface bursts for 10" thick bridge pier.

FIGURE 32. Postshot views of below water and above surface bursts for 6" and 10" thick bridge piers.

FIGURE 33. Damage comparison between model with rebar brick elements, homogenized rebar, and homogenized rebar using FiberGrid.

FIGURE 34. ALE3D and DYNA3D single shell element tensile test comparison........65

FIGURE 35. ALE3D and DYNA3D shell element bending test comparison.

FIGURE 36. 6061-T6 aluminum test cylinder underwater blast experiment conducted by NSWC.

FIGURE 37. 6061-T6 aluminum test cylinder deformation comparison between experiment and ALE3D simulation.

FIGURE 38. Pressure time-history and bubble evolution of an underwater explosion. Figure taken from Ref. NSWC/WOL TR 76-116.

FIGURE 39. Pressure time-history for an underwater spherical explosion. Pressures data taken $121 \mathrm{~cm}$ from the center of the HE.

FIGURE 40. Bubble radius for an underwater spherical explosion with bubble collapse.

FIGURE 41. Experimental setup of underwater explosion bubble collapse against a flat plate. Figure taken from Ref. NSWCDD/TR-92/482. .86

FIGURE 42. Computational setup and initial mesh of underwater explosion bubble collapse against a flat plate.

FIGURE 43. Stages in a bubble collapsing near a flat plate. 
FIGURE 44. Pressure time history taken at the surface of the plate at the centerline. A) Computational Prediction, B) Experimental Data (Ref. NSWCDD/TR-92/ 482).

FIGURE 45. Pressure time history taken on the surface of the plate at a radial location 1 inch away from the centerline. A) Computational Prediction, B)

Experimental Data (Ref. NSWCDD/TR-92/482). .88

FIGURE 46. Computational setup and initial mesh for the Bubble-Cylinder Interaction test case.

FIGURE 47. Experimental data for bubble-cylinder interaction. Shows outlines of bubble shapes obtained from high-speed camera images. Figure taken from Ref. NSWCDD/TR-93/162.

FIGURE 48. Computational grid and material geometry along bubble centerline showing bubble-cylinder interaction. Taken at $0 \mathrm{msec} . . . \ldots \ldots \ldots \ldots \ldots \ldots \ldots . . . . . . . . . . . .90$

FIGURE 49.

FIGURE 50. Computational grid and material geometry along bubble centerline showing bubble-cylinder interaction. Taken at $23.2 \mathrm{msec}$. .90

FIGURE 51. Computational grid and material geometry along bubble centerline showing bubble-cylinder interaction. Taken at $65.0 \mathrm{msec}$.

FIGURE 52. Computational grid and material geometry along bubble centerline showing bubble-cylinder interaction. Taken at $115.0 \mathrm{msec}$.

FIGURE 53. Computational grid and material geometry along bubble centerline showing bubble-cylinder interaction. Taken at $141.0 \mathrm{msec}$.

FIGURE 54. Computational grid and material geometry along bubble centerline showing bubble-cylinder interaction. Taken at $144.1 \mathrm{msec}$.

FIGURE 55. Description of concrete benchmark experiment. ..................................94

FIGURE 56. Comparison between experimental results and ALE3D simulation..........95

FIGURE 57. Comparison between experimental results and ALE3D simulation.........96

FIGURE 58. ALE3D finite element model of precision wall panel using homogenized rebar.

FIGURE 59. Results comparison between the ALE3D model using brick elements for rebar and the ALE3D model using homogenized rebar.

FIGURE 60. Results from homogenized rebar model using new damage visualization....

FIGURE 61. Experimental set-up and results for explosively formed projectile impacting a reinforced concrete block.

FIGURE 62. CALE finite element model of explosively formed projectile.

FIGURE 63. Damage resulting from EFP (Copper) impact into unreinforced concrete block

FIGURE 64. Comparison of overpressures from an idealized spherical charge as obtained from the military services TM5-1300 manual and ALE3D simulations.

FIGURE 65. Peak overpressures for a submerged explosive. a) Data from reference * and ALE3D simulations; b) ALE3D model of a submerged spherical explosive. 
FIGURE 66. Shock wave propagation from an underwater explosion (ALE3D simulation).

FIGURE 68. Steps in the alternate gravity initialization scheme

FIGURE 67. Shock wave propagation from an underwater explosion (ALE3D simulation).

FIGURE 69. Three analysis models considered for alternate gravity initialization scheme.

FIGURE 70. Water pressure and concrete vertical stress as a function of depth .........110

FIGURE 71. Pressure and velocity time history plots for water and concrete 110 


\section{List of Tables}

TABLE 1. Typical Engineering Properties of Structural Concrete ………….................

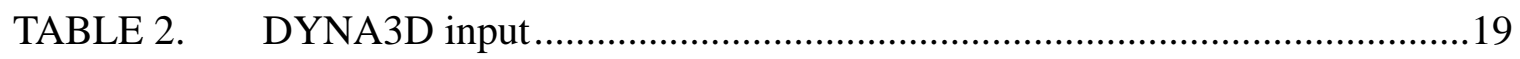

TABLE 3. Input for equation-of-state form 12: WSMR-5 3/4 concrete ......................22

TABLE 4. Input for equation-of-state form 12: SAC5 concrete ………………........23

TABLE 5. DYNA3D input for WSMR-5 3/4 concrete: mesh size ( 6 × 6 × 6 in. cube)..

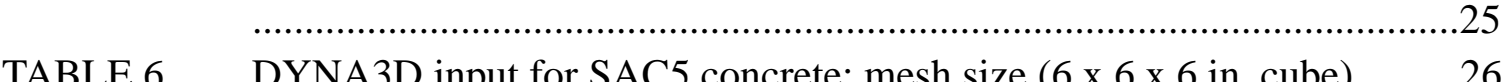

TABLE 6. DYNA3D input for SAC5 concrete: mesh size (6 x 6 × 6 in. cube)..........26

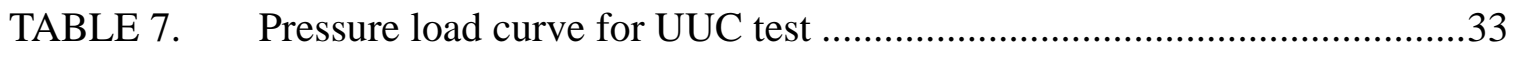

TABLE 8. ALE3D material parameters (gm, cm, msec, Mbar)..................................34

TABLE 9. ALE3D engineering parameters (gm, cm, msec, Mbar) ............................34

TABLE 10. Concrete failure surfaces (Mbar) ..............................................................35

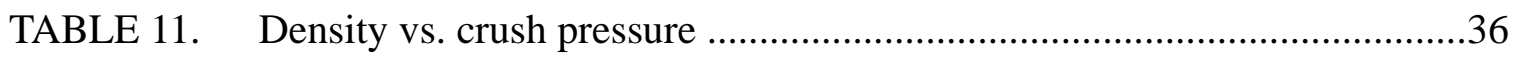

TABLE 12. Coefficients for 7-term polynomial EOS ..................................................

TABLE 13. ALE3D material parameters (gm, cm, msec, Mbar) .................................40

TABLE 14. ALE3D engineering parameters (gm, cm, msec, Mbar) ............................40

TABLE 15. Concrete failure surfaces (Mbar) ………...............................................

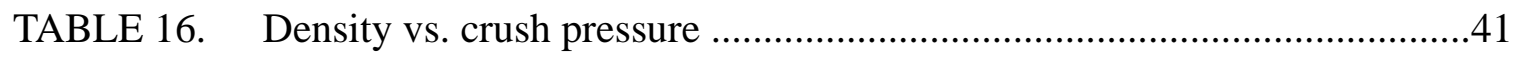

TABLE 17. Coefficients for 7-term polynomial EOS ….............................................43 
K\&C Concrete Material Model

ENGINEERING@LLNL 


\subsection{Background}

Concrete is perhaps one of the most widely used construction materials in the world. Engineers use it to build massive concrete dams, concrete waterways, highways, bridges, and even nuclear reactors. The advantages of using concrete is that it can be cast into any desired shape, it is durable, and very economical compared to structural steel. The disadvantages are its low tensile strength, low ductility, and low strength-to-weight ratio. Concrete is a composite material that consists of a coarse granular material, or aggregate, embedded in a hard matrix of material, or cement, which fills the gaps between the aggregates and binds them together. Concrete properties, however, vary widely. The properties depend on the choice of materials used and the proportions for a particular application, as well as differences in fabrication techniques. Table 1 provides a listing of typical engineering properties for structural concrete.

TABLE 1. Typical Engineering Properties of Structural Concrete

\begin{tabular}{|l|l|}
\hline Compressive strength & $\mathbf{5 0 0 0 ~ l b / i n .}{ }^{\mathbf{2}}$ \\
\hline Tensile strength & $\mathbf{4 0 0 ~} \mathbf{l b} / \mathbf{i n}^{.}$ \\
\hline Modulus of Elasticity & $4 \times 10^{6} \mathrm{lb} / \mathrm{in} .^{2}$ \\
\hline Poisson's Ratio & 0.18 \\
\hline $\begin{array}{l}\text { Failure Strain for Unconfined Uniaxial Compression } \\
\text { Test }\end{array}$ & 0.002 \\
\hline Failure Strain for Unconfined Uniaxial Tensile Test & 0.00012 \\
\hline Coefficient of Thermal Expansion & $5.6 \times 10^{-6} /{ }^{\circ} \mathrm{F}$ \\
\hline Normal Weight Density & $145 \mathrm{lb} / \mathrm{ft}^{3}$ \\
\hline Lightweight Density & $110 \mathrm{lb} / \mathrm{ft}^{3}{ }^{3}$ \\
\hline
\end{tabular}

Properties also depend on the level of concrete confinement, or hydrostatic pressure, the material is being subjected to. In general, concrete is rarely subjected to a single axial stress. The material may experience a combination of stresses all acting simultaneously. The behavior of concrete under these combined stresses are, however, extremely difficult to characterize. In addition to the type of loading, one must also consider the stress history of the material. Failure is determined not only by the ultimate stresses, but also by the rate of loading and the order in which these stresses were applied.

The concrete model described herein accounts for this complex behavior of concrete. It was developed by Javier Malvar, Jim Wesevich, and John Crawford of Karagozian and Case, and Don Simon of Logicon RDA in support of the Defense Threat Reduction 
Agency's programs. The model is an enhanced version of the Concrete/Geological Material Model 16 in the Lagrangian finite element code DYNA3D. The modifications that were made to the original model ensured that the material response followed experimental observations for standard uniaxial, biaxial, and triaxial tests for both tension and compression type loading. A disadvantage of using this material model, however, is the overwhelming amount of input that is required from the user. Therefore, the goal of this report is to provide future users with the tools necessary for successfully using this model.

\subsection{Terminology}

Before discussing the details of this model, it is instructive to provide an overview of some of the key terminology and nomenclature that will be used extensively later on in this description.

\subsubsection{Volumetric and Deviatoric Stresses and Strains}

As you may recall, stress can be broken up into its volumetric and deviatoric parts as follows,

$$
\sigma=\sigma_{M}+s
$$

In indicial form,

$$
\sigma_{M_{i j}}=\frac{1}{3} \sigma_{k k} \delta_{i j} \quad \text { or } \quad \sigma_{M_{i j}}=p \delta_{i j}
$$

where

$$
p=\frac{1}{3} \sigma_{k k} \quad \text { or } \quad p=\frac{1}{3}\left(\sigma_{11}+\sigma_{22}+\sigma_{33}\right)
$$

and

$$
s_{i j}=\sigma_{i j}-\frac{1}{3} \sigma_{k k} \delta_{i j}
$$

However, in DYNA3D, pressure is defined as the negative of the one defined above,

$$
p=-\frac{1}{3}\left(\sigma_{11}+\sigma_{22}+\sigma_{33}\right)
$$

so that pressure is positive in compression.

In addition, for a principal coordinate system that coincides with the directions of the principal stresses, all the $\sigma_{i j}$, with $i \neq j$, terms vanish so that

$$
p=\frac{1}{3}\left(\sigma_{1}+\sigma_{2}+\sigma_{3}\right)
$$


and

$$
s_{1}=\max \left\{\sigma_{1}-p, \sigma_{2}-p, \sigma_{3}-p\right\}
$$

Finally, volumetric and deviatoric strains are commonly written as,

$$
\begin{gathered}
\varepsilon_{v}=\varepsilon_{1}+\varepsilon_{2}+\varepsilon_{3} \\
\varepsilon_{q}=\frac{2}{3}\left(\varepsilon_{1}-\varepsilon_{3}\right)
\end{gathered}
$$

\subsubsection{Stress Invariants}

Scalar quantities may also be constructed out of the tensor $\sigma_{i j}$, that is,

$$
\begin{gathered}
P_{1}=\sigma_{i i} \\
P_{2}=\sigma_{i j} \sigma_{i j} \\
P_{3}=\sigma_{i j} \sigma_{j k} \sigma_{k i}
\end{gathered}
$$

These scalar quantities constructed from a tensor are independent of any particular coordinate system and are therefore known as invariants. In the principal coordinate frame, these quantities are usually written as,

$$
\begin{aligned}
& P_{1}=\sigma_{1}+\sigma_{2}+\sigma_{3} \\
& P_{2}=\sigma_{1}^{2}+\sigma_{2}^{2}+\sigma_{3}^{2} \\
& P_{3}=\sigma_{1}^{3}+\sigma_{2}^{3}+\sigma_{3}^{3}
\end{aligned}
$$

In this particular model description, however, the stress invariants are defined as follows,

$$
\begin{gathered}
I_{1}=3 p=\left(\sigma_{1}+\sigma_{2}+\sigma_{3}\right) \\
J_{2}=\frac{1}{2}\left(s_{1}^{2}+s_{2}^{2}+s_{3}^{2}\right) \quad \text { or } \\
\sqrt{J_{2}}=\frac{\sqrt{\left(\sigma_{1}-\sigma_{2}\right)^{2}+\left(\sigma_{1}-\sigma_{3}\right)^{2}+\left(\sigma_{2}-\sigma_{3}\right)^{2}}}{\sqrt{6}} \\
J_{3}=s_{1} s_{2} s_{3}
\end{gathered}
$$

\subsubsection{Triaxial Compression and Extension}

The triaxial compression test provides the means for defining the effect of confinement on the strength of the concrete. When a lateral confining pressure is applied, the increase in compressive strength can be very large. In addition, the application of a lateral confining pressure leads to a large increase in the compressive strain at failure. The effect of a con- 
fining pressure on strength is, however, more beneficial for weak than for strong concretes. In the case of tension plus biaxial compression, the tensile strength is reduced by the application of lateral compressive stresses.

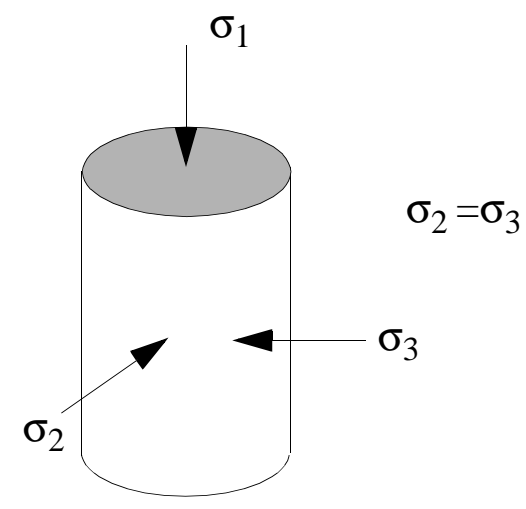

FIGURE 1. Description of triaxial test

A typical triaxial compression test is defined as follows:

1. at the beginning of the test, $\sigma_{1}=\sigma_{2}=p$.

2. during test, $\sigma_{1}$ increased until failure.

3. At failure, the concrete strength is defined as $\Delta \sigma_{c}=\left|\sigma_{1}-\sigma_{2}\right|$.

A typical triaxial extension test is defined as follows:

1. at the beginning of the test, $\sigma_{1}=\sigma_{2}=p$.

2. during test, $\sigma_{1}$ increased until failure.

3. At failure, the concrete strength is defined as $\Delta \sigma_{t}=\left|\sigma_{1}-\sigma_{2}\right|$.

A comparison of the concrete strengths may be computed as

$$
\psi=\frac{\Delta \sigma_{t}}{\Delta \sigma_{c}}
$$

The value, $\psi$, usually varies from $0.5 \leq \psi \leq 1.0$, depending on the amount of confining pressure the material is subjected to.

The $\Delta \sigma$ value defined above will be used throughout the material description as a way of referring to the shear strength of concrete. The $\Delta \sigma$ can also be related to the second invariant of the deviatoric stress by

$$
\Delta \sigma=\sqrt{3 J_{2}}
$$




\subsection{Nonlinear Concrete Model Description}

The Karagozian \& Case concrete model decouples the volumetric and deviatoric responses. The model also uses an Equation of State (EOS). The Equation of State prescribes a user-defined set of pressures, unloading bulk moduli, and volumetric strains. Once the pressure has been determined from the EOS, a movable surface, or failure surface, limits the second invariant of the deviatoric stress tensor (i.e. $\Delta \sigma$ ). In addition, the model is strain rate dependent, which is extremely important for accurately simulating blast effects.

\subsection{Failure Surfaces}

The model uses three independent fixed surfaces to define the plastic behavior of concrete. The surfaces, which define three important regions of concrete behavior, can be seen easily if one plots the stress-strain response from an unconfined uniaxial compression test (see Figure 2). The material response is considered linear up until point 1, or first yield. After yielding, a hardening plasticity response occurs until point 2, or maximum strength, is reached. After reaching a maximum strength, softening occurs until a residual strength, which is based on the amount of confinement, is obtained. The three surfaces are defined by the following equations:

$$
\begin{gathered}
\Delta \sigma_{y}=a_{o y}+\frac{p}{a_{1 y}+a_{2 y} p} \quad \text { (yield failure surface) } \\
\Delta \sigma_{m}=a_{o}+\frac{p}{a_{1}+a_{2} p} \quad \text { (maximum failure surface) } \\
\Delta \sigma_{r}=\frac{p}{a_{1 f}+a_{2 f} p} \quad \text { (residual failure surface) }
\end{gathered}
$$

where $a_{o y}, a_{1 y}, a_{2 y}, a_{o}, a_{1}, a_{2}, a_{1 f}$, and $a_{2 f}$ are all user-defined parameters which change the shape of the failure surface.

The current failure surface is calculated from the three fixed surfaces using a simple linear interpolation technique:

1. if the current state lies between the yield surface and the maximum surface, the failure surface is calculated using

$$
\Delta \sigma_{f}=\eta\left(\Delta \sigma_{m}-\Delta \sigma_{y}\right)+\Delta \sigma_{y}
$$

2. if, on the other hand, the current state is located between the maximum surface and the residual surface, the failure surface is defined by

$$
\Delta \sigma_{f}=\eta\left(\Delta \sigma_{m}-\Delta \sigma_{r}\right)+\Delta \sigma_{r}
$$


where $\eta$ varies between 0 and 1 , and depends on the accumulated effective plastic strain parameter $\lambda$. The current value of $\lambda$ - calculated using an equation that will be discussed later - is compared to a set of 13 user-defined $(\eta, \lambda)$ pairs, which are usually determined from experimental data.The $\eta$ value is 0 when $\lambda=0,1$ at some value $\lambda=\lambda_{m}$, and again 0 at some larger value of $\lambda$. Therefore, if $\lambda \leq \lambda_{m}$, the current failure surface is calculated using EQ. 17, and if $\lambda \geq \lambda_{m}$, the current failure surface is calculated using EQ. 18. In essence, the $(\eta, \lambda)$ values define where the current failure surface is in relation to the three fixed surfaces for different values of plastic strain. 

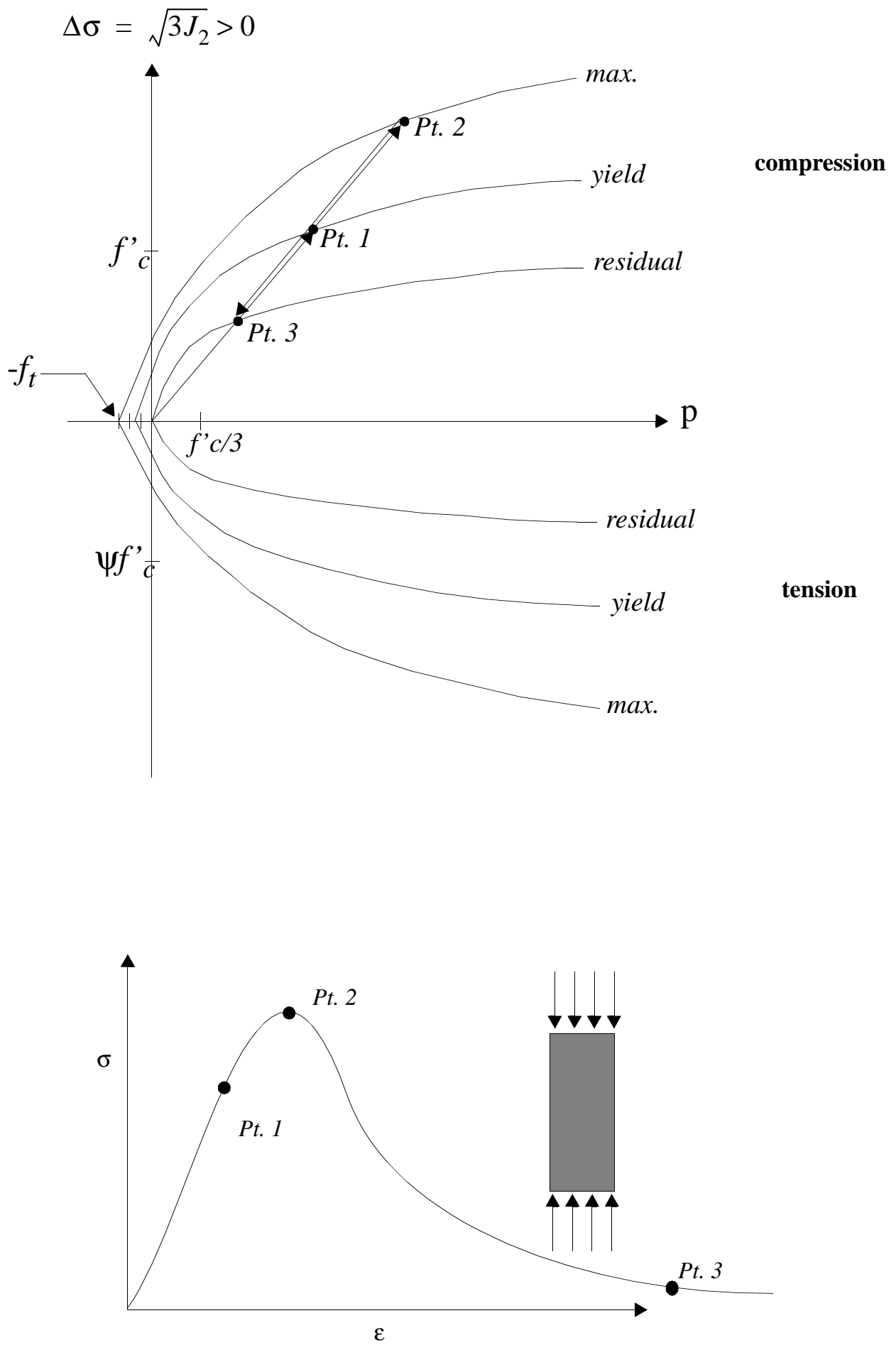

FIGURE 2. Model failure surfaces and uniaxial stress-strain response 


\subsection{Pressure Cutoff}

The pressure cutoff was modified from the original DYNA3D material model 16 to prevent the pressure from being lower than the maximum tensile strength $f_{t}$, instead of $f_{t} / 3$. This allows for correct values of $\Delta \sigma$ for both the biaxial and triaxial tensile tests (see Figure 3). For example, the uniaxial, biaxial, and triaxial $\Delta \sigma$ values are calculated as follows:

1. Uniaxial: $\left(\sigma_{1}=f_{t}, \sigma_{2}=0, \sigma_{3}=0\right)$

$$
\begin{aligned}
& \sqrt{J_{2}}=\frac{\sqrt{\left(\sigma_{1}-\sigma_{2}\right)^{2}+\left(\sigma_{1}-\sigma_{3}\right)^{2}+\left(\sigma_{2}-\sigma_{3}\right)^{2}}}{\sqrt{6}}=\frac{f_{t}}{\sqrt{3}} \\
& \Delta \sigma=f_{t} \\
& p=-\frac{f_{t}}{3}
\end{aligned}
$$

2. Biaxial: $\left(\sigma_{1}=f_{t}, \sigma_{2}=f_{t}, \sigma_{3}=0\right)$

$$
\begin{gathered}
\sqrt{J_{2}}=\frac{\sqrt{\left(\sigma_{1}-\sigma_{2}\right)^{2}+\left(\sigma_{1}-\sigma_{3}\right)^{2}+\left(\sigma_{2}-\sigma_{3}\right)^{2}}}{\sqrt{6}}=\frac{f_{t}}{\sqrt{3}} \\
\Delta \sigma=f_{t} \\
p=-\frac{2 f_{t}}{3}
\end{gathered}
$$

3. Triaxial: $\left(\sigma_{1}=f_{t}, \sigma_{2}=f_{t}, \sigma_{3}=f_{t}\right)$

$$
\begin{aligned}
& \sqrt{J_{2}}=\frac{\sqrt{\left(\sigma_{1}-\sigma_{2}\right)^{2}+\left(\sigma_{1}-\sigma_{3}\right)^{2}+\left(\sigma_{2}-\sigma_{3}\right)^{2}}}{\sqrt{6}}=0 \\
& \Delta \sigma=0 \\
& p=-f_{t}
\end{aligned}
$$


When the material has failed in the negative pressure range, the previously defined parameter $\eta$ is used to increase the pressure cutoff from $-f_{t}$ to zero. The pressure cutoff, $p_{c}$, is calculated from the following rule (see Figure 3):

1. $p_{c}$ is equal to $-f_{t}$ if the maximum failure surface has not yet been reached.

2. $p_{c}$ is equal to $-\eta f_{t}$ if the maximum failure surface has already been reached.

This pressure cutoff is needed because the EOS may calculate very large negative pressures for large volumetric extensions beyond cracking, which is, of course, physically unrealistic.

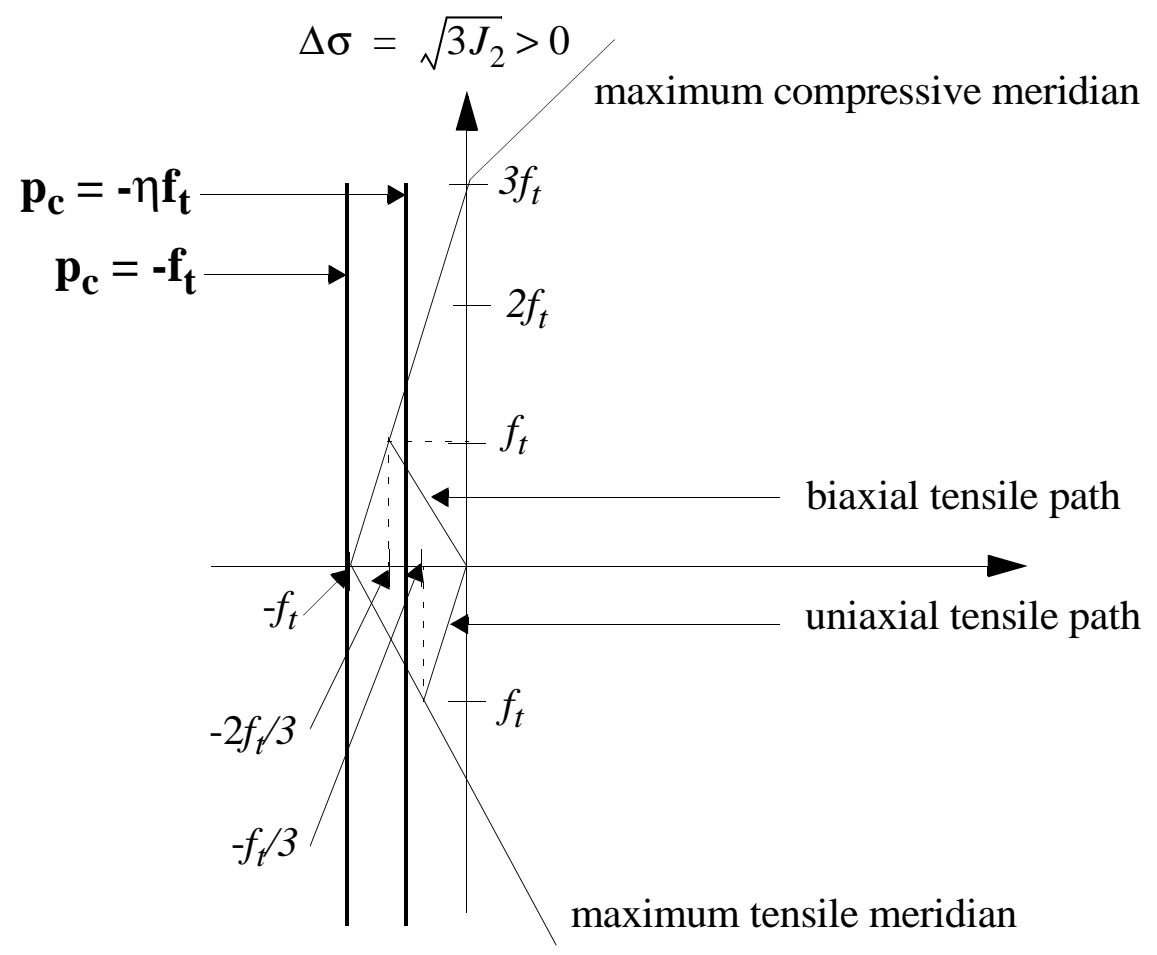

FIGURE 3. Description of pressure cutoff and tensile paths

\subsection{Damage Evolution}

As you may recall, the current failure surface is interpolated between either the yield and maximum surface or the maximum and residual surface using a set of user-defined $(\eta, \lambda)$ pairs. The current value of the damage parameter $\lambda$ is defined using the following relationships: 


$$
\begin{array}{rlll}
\lambda & =\int_{0}^{\overline{\varepsilon^{p}}} \frac{\overline{d \varepsilon^{p}}}{r_{f}\left(1+\frac{p}{r_{f} f_{f}}\right)^{b_{1}}} \quad \text { when } & p \geq 0 \\
\lambda & =\int_{0}^{\overline{\varepsilon^{p}}} \frac{\overline{d \varepsilon^{p}}}{r_{f}\left(1+\frac{p}{r_{f} f_{f}}\right)^{b_{2}}} \quad \text { when } & p<0
\end{array}
$$

where the effective plastic strain increment is given by:

$$
\overline{d \varepsilon^{p}}=\sqrt{\left(\frac{2}{3}\right) d \varepsilon_{i j}^{p} d \varepsilon_{i j}^{p}}
$$

It is instructive to mention that this effective plastic strain increment is the one commonly used for a von Mises isotropic hardening model for metals. In a more general case, the effective plastic strain increment is defined as:

$$
\begin{gathered}
\overline{d \varepsilon^{p}}=\sqrt{\left(\frac{2}{3}\right) d e_{i j}^{p} d e_{i j}^{p}} \quad \text { or in the longer format } \\
\left(\overline{d \varepsilon^{p}}=\left\{\frac{2}{9}\left[\left(d \varepsilon_{11}^{p}-d \varepsilon_{22}^{p}\right)^{2}+\left(d \varepsilon_{22}^{p}-d \varepsilon_{33}^{p}\right)^{2}+\left(d \varepsilon_{33}^{p}-d \varepsilon_{11}^{p}\right)^{2}\right]+\frac{4}{3}\left[\left(d \varepsilon_{23}^{p}\right)^{2}+\left(d \varepsilon_{31}^{p}\right)^{2}+\left(d \varepsilon_{12}^{p}\right)^{2}\right]\right\}^{\frac{1}{2}}\right)
\end{gathered}
$$

where $e_{i j}$ is the deviatoric part of strain and can be written,

$$
e_{i j}^{p}=\varepsilon_{i j}^{p}-\frac{1}{3} \delta_{i j} \varepsilon_{k k}^{p}
$$

The reasoning behind writing the effective plastic strain increment as in EQ. 21, is that when modeling metals, it is postulated that the plastic deformation occurs under constant volume (i.e. $\varepsilon_{k k}^{p}=0$ ). This assumption forces $e_{i j}^{p}=\varepsilon_{i j}^{p}$. The drawback of using a deviatoric damage criterion for concrete, is that the material cannot accumulate damage under a pure volumetric extension, or triaxial tensile test, because the second deviatoric stress invariant remains zero. Therefore, a volumetric damage increment was added to the deviatoric damage whenever the stress path was "close" to the triaxial tensile test path. The closeness to this path is calculated from the ratio $\left|\left(\sqrt{3 J_{2}}\right) / p\right|$, which is 1.5 for the biaxial tensile test, as you may recall from the pressure cutoff examples. The volumetric damage increment is limited by a closeness parameter $f_{d}$ given by 


$$
f_{d}=\left\{\begin{array}{cc}
1-\frac{\left|\left(\sqrt{3 J_{2}}\right) / p\right|}{0.1} & , 0 \leq\left|\left(\sqrt{3 J_{2}}\right) / p\right|<0.1 \\
0 & ,\left|\left(\sqrt{3 J_{2}}\right) / p\right| \geq 0.1
\end{array}\right.
$$

Then the modified effective plastic strain damage parameter is incremented by

$$
\Delta \lambda=b_{3} f_{d} k_{d}\left(\varepsilon_{v}-\varepsilon_{v, \text { yield }}\right)
$$

where $b_{3}$ is a user-defined parameter that prescribes the rate of damage primarily in the triaxial tensile regime, $k_{d}$ is an internal scalar multiplier, and $\varepsilon_{v}$ and $\varepsilon_{v, \text { yield }}$ are the volumetric strain and volumetric strain at yield.

The user-defined parameters $b_{1}$ and $b_{2}$, located in EQ. 19 and EQ. 20, also change the rate at which damage occurs, and the $r_{f}$ value is a dynamic increase factor that accounts for strain rate effects. It is important to note that the DYNA3D manual states EQ. 19 and EQ. 20 as follows:

$$
\begin{aligned}
& d \lambda=\frac{\overline{d \varepsilon^{p}}}{\left[1+\left(\frac{s}{100}\right)\left(r_{f}-1\right)\right]\left(1+\frac{p}{r_{f} f}\right)^{b_{1}}} \quad \text { when } \quad p \geq 0 \\
& d \lambda=\frac{\overline{d \varepsilon^{p}}}{\left[1+\left(\frac{s}{100}\right)\left(r_{f}-1\right)\right]\left(1+\frac{p}{r_{f} f}\right)^{b_{2}}} \quad \text { when } \quad p<0
\end{aligned}
$$

If the user defines $s=0$, the strain-rate effects have been toggled off, and if $s=100$, the strain-rate effects are included.

In addition, the values $b_{2}$ and $b_{3}$, which govern the softening part of a tensile stress-strain response, are mesh-size dependent. For example, this means that the softening response for a $6 \times 6 \times 6$ in. cube element will likely be different for a $1 \times 1 \times 1$ in. cube element, if the same values of $b_{2}$ and $b_{3}$ are used to define both element sizes. Therefore, different material definitions should be used for different regions of the finite element model. It is highly recommended that the user perform a series of single element tensile tests to view whether the material model is indeed yielding the desired softening response. If the analysis does not give a realistic stress-strain curve, the $b_{2}$ and $b_{3}$ parameters should be modified and the tensile test restarted. This iterative procedure should be continued until the 
desired result is achieved. Figure 4 shows the variation that can occur for WSMR-5 3/4 concrete.
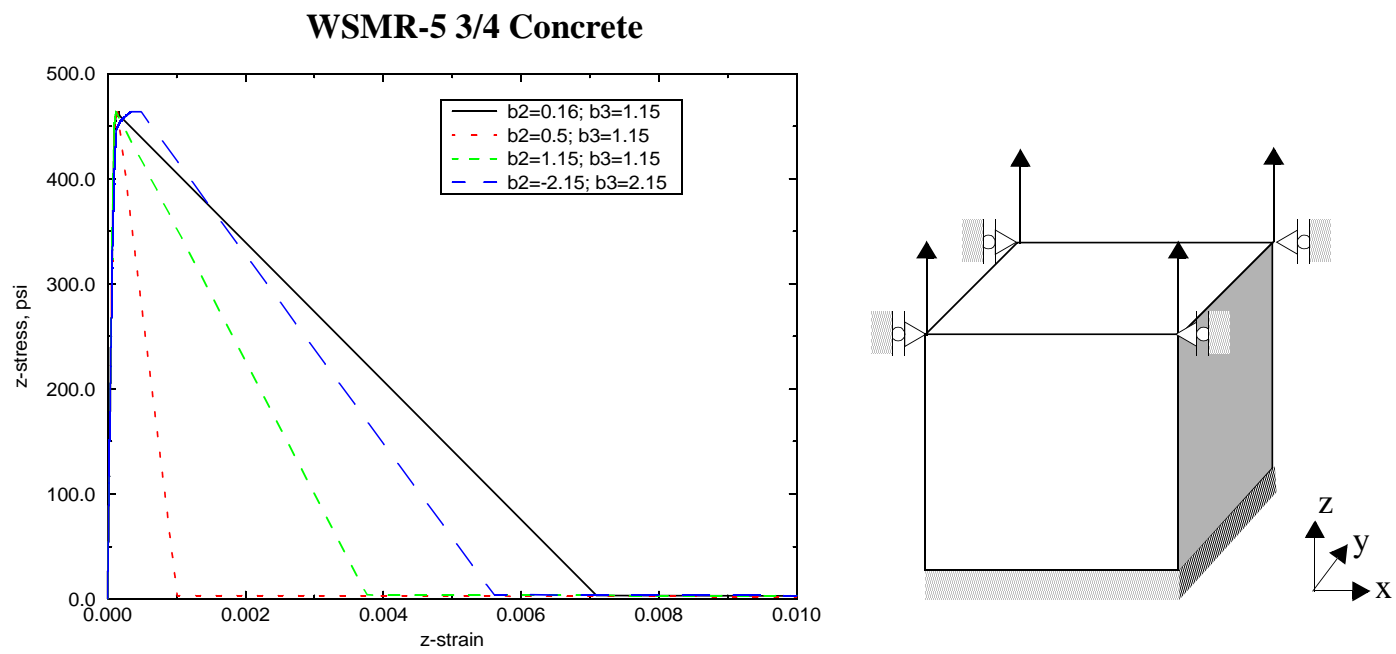

FIGURE 4. Effects of parameters $b_{2}$ and $b_{3}$ on softening for a single element tensile test.

The user may also track the failure surface evolution by specifying a value of 2 for the emr output on card 4 of the DYNA3D material deck. This parameter tells the subroutine to calculate a "damage" parameter $\delta$, which is calculated in the following manner:

$$
\delta=\frac{2 \lambda}{\lambda+\lambda_{m}}
$$

This parameter will be a value of 0 until the initial yield surface has been reached, a value of 1 when the failure surface reaches the maximum surface, and a value of 2 at the residual surface.

In addition, an element deletion criteria was added recently. During extreme loading conditions, some elements, after failing in tension, would stretch or deform continuously without any limits. As a result, the time step would decrease until it was no longer feasible to run the simulation. This can be a problem when the user wants to run the simulation out to a far enough time to see the global response of the structure being analyzed. Therefore, the element deletion criterion that seemed to give the best results for this type of situation, was one that was based on a tensile volumetric strain. To use this feature, the user places a volumetric strain value in row 4 of card 4 in the DYNA3D material deck. Once this volumetric strain has been reached, the element is deleted from the simulation. It is recommended that a relatively high value be used, however, otherwise the element may be deleted too soon. Furthermore, if the element being deleted is subjected to a pressure loading at the time of deletion, that pressure loading will not transfer to the surrounding elements. 


\subsection{Description of Third Invariant}

As you may recall, in a three-dimensional principal stress space, the yield surface may be visualized as a prism with the axis along the space diagonal $\sigma_{1}=\sigma_{2}=\sigma_{3}$, which is the ray $O C$ shown in Figure 5.

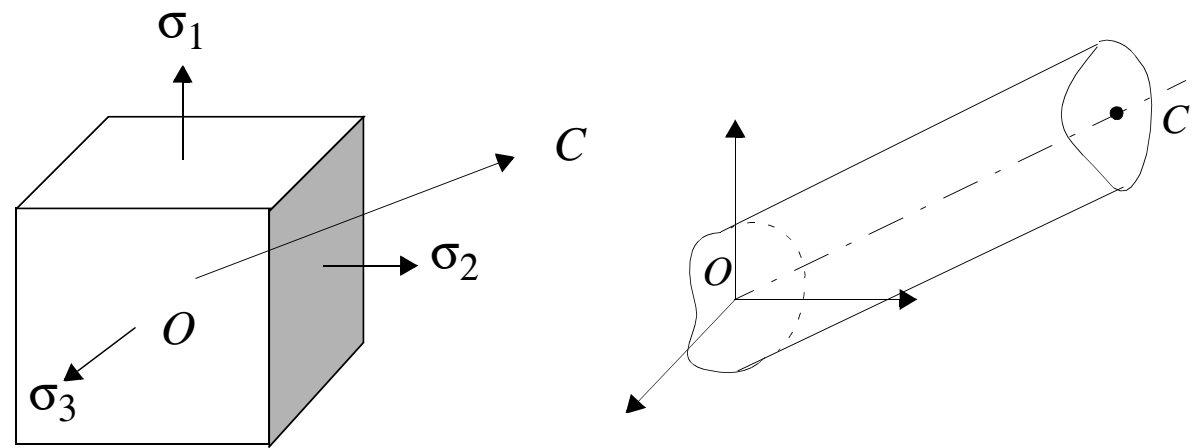

FIGURE 5. Three-dimensional state of stress and space diagonal

Since the stress state may be resolved into a volumetric component and a stress deviator component, the cross section of the prism represents the deviatoric plane. The cross section of the prism may be plotted on any plane perpendicular to the space diagonal. The deviatoric planes have the following equation:

$$
\sigma_{1}+\sigma_{2}+\sigma_{3}=\text { constant }
$$

where the $\pi$-plane is the deviatoric plane that passes through the origin.

As you know, the yield condition attributed to R. von Mises is represented by a circle on the $\pi$-plane (see Figure 6). The circle is the intersection of a sphere of radius $r$

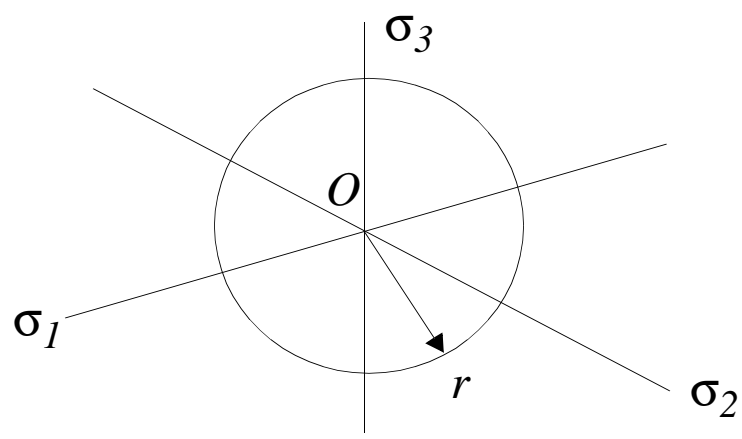

FIGURE 6. Von Mises yield surface (plan view of $\pi$-plane). 


$$
\sigma_{1}^{2}+\sigma_{2}^{2}+\sigma_{3}^{2}=r^{2}
$$

in the stress space and the plane

$$
\sigma_{1}+\sigma_{2}+\sigma_{3}=0
$$

where $r$ is defined by

$$
r=\sigma_{y} \sqrt{\frac{2}{3}}
$$

Since EQ. 31 is satisfied by strain deviator components, the equation for a von Mises yield surface becomes

$$
s_{1}^{2}+s_{2}^{2}+s_{3}^{2}=\frac{2}{3} \sigma_{y}^{2}
$$

which may also be written as

$$
\left[\sigma_{1}-\sigma_{2}\right]^{2}+\left[\sigma_{2}-\sigma_{3}\right]^{2}+\left[\sigma_{3}-\sigma_{1}\right]^{2}=2 \sigma_{y}^{2}
$$

Furthermore, written in terms of the stress deviator invariant, the yield surface becomes

$$
\sigma_{y}=\sqrt{3 J_{2}}
$$

Therefore, the von Mises yield condition is based on the stress deviator and thus are essentially independent of the hydrostatic pressure. This is appropriate for ductile materials, but is not adequate enough to describe all isotropic materials, specifically materials which are dependent on the hydrostatic pressure and the third stress invariant, such as plain concrete and sand.

If a third invariant is included, the circles used to describe the yield condition on the deviatoric plane for the von Mises surface, can become triangular curves with smooth corners. Based on experimental results of concrete, the intersection with the deviatoric plane is triangular at low pressures and circular at higher pressures (see Figure 7).

A model was proposed by William and Warnke, which yields a smooth, convex triangular surface (see Figure 7). If $r_{c}$ is the coordinate of the surface at the compressive meridian, and $r_{t}$ the one at the tensile meridian, any intermediate position $r$ may be calculated as follows:

$$
r=\frac{2 r_{c}\left(r_{c}^{2}-r_{t}^{2}\right) \cos \theta+r_{c}\left(2 r_{t}-r_{c}\right) \sqrt{4\left(r_{c}^{2}-r_{t}^{2}\right)(\cos \theta)^{2}+5 r_{t}^{2}-4 r_{t} r_{c}}}{4\left(r_{c}^{2}-r_{t}^{2}\right)(\cos \theta)^{2}+\left(r_{c}-2 r_{t}\right)^{2}}
$$


By dividing both sides by $r_{c}$ and dividing the numerator and denominator of the right hand side by $r_{c}^{2}$, the equation now becomes

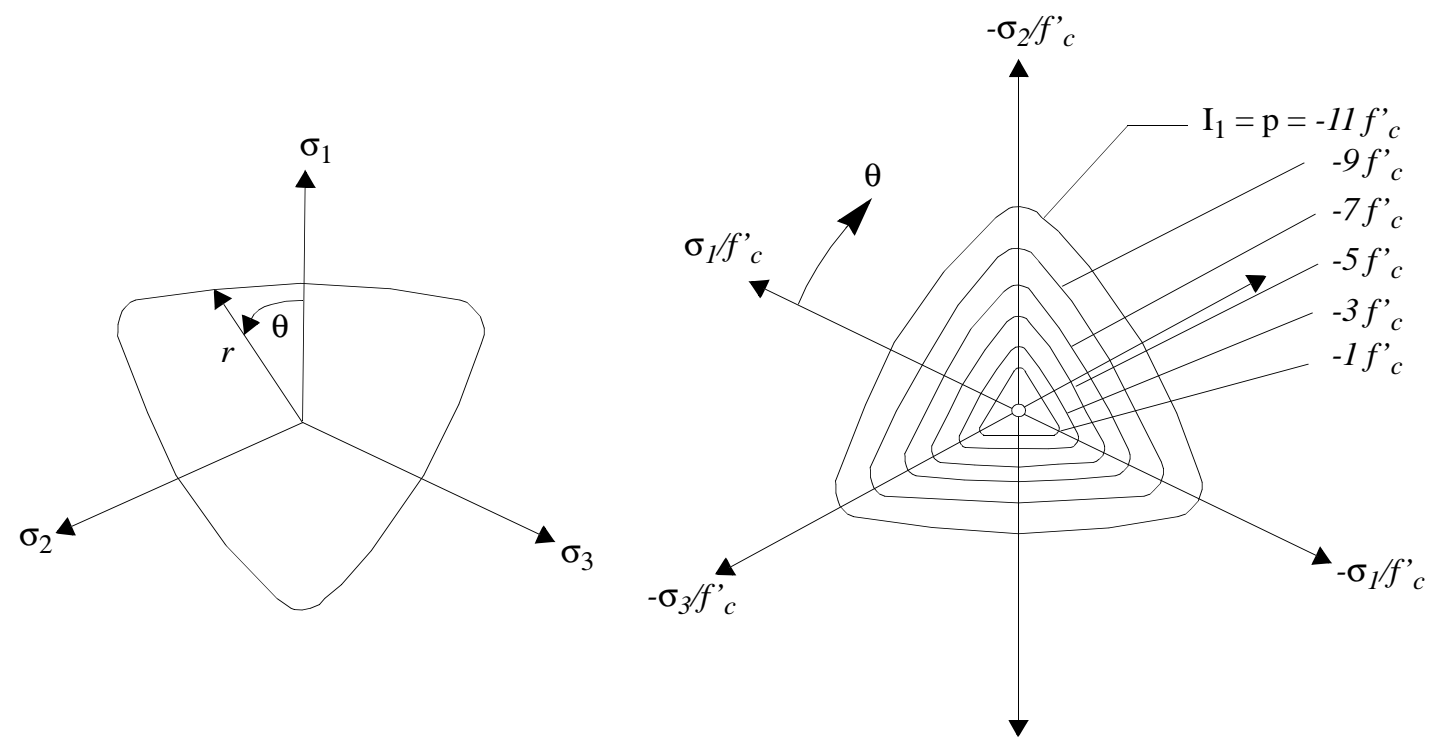

a)

(NOTE: negative stress represents compression; positive stress represents tension)

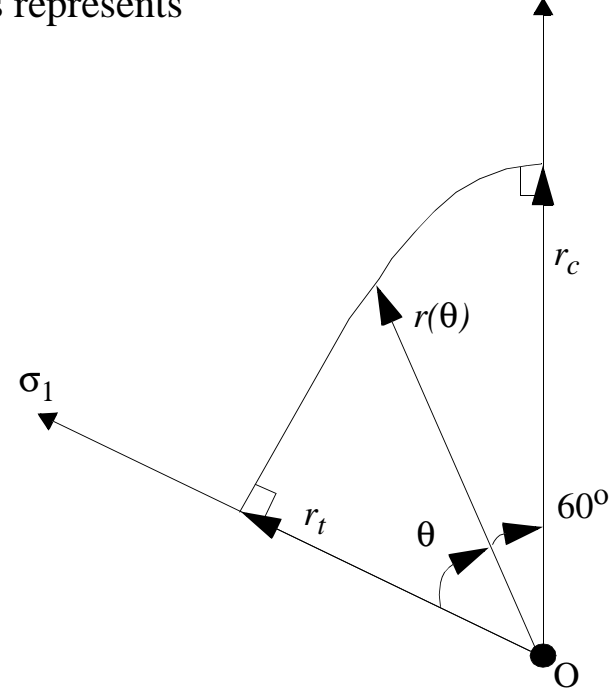

b)

FIGURE 7. a) Concrete deviatoric sections for increasing pressure; b) William and Warnke model.

$$
r^{\prime}=\frac{2\left(1-\psi^{2}\right) \cos \theta+(2 \psi-1) \sqrt{4\left(1-\psi^{2}\right)(\cos \theta)^{2}+5 \psi^{2}-4 \psi}}{4\left(1-\psi^{2}\right)(\cos \theta)^{2}+(1-2 \psi)^{2}}
$$


where $\psi=r_{t} / r_{c}$ and $r^{\prime}=r / r_{c}$. Note the similarity between our definition $\psi$ here and the one defined by EQ. 12. For $\theta=0^{\circ}$, the formula yields $r^{\prime}=\psi$, and for $\theta=60^{\circ}$ it yields $r^{\prime}=1$, where the value of $\theta$ can be obtained from the following relationships,

$$
\cos \theta=\frac{\sqrt{3}}{2} \frac{s_{1}}{\sqrt{J_{2}}} \quad \text { or } \quad \cos 3 \theta=\frac{3 \sqrt{3}}{2} \frac{J_{3}}{J_{2}^{3 / 2}}
$$

Once the value of $r^{\prime}$ is known, the original compressive meridians are multiplied by $r^{\prime}$ at that location. By doing this, we obtain separate tensile meridians and compressive meridians as was shown in Figure 2.

Up to this point, it has been said that the compressive meridian is known and the tensile meridian is found by multiplying the compressive meridian by $\psi$. However, the actual material model, in certain regions, uses the tensile meridian to determine the compressive one. For pressures greater than $f_{c}{ }_{c} / 3$, the input compressive meridians are based on the input parameters $a_{o}, a_{1}$, and $a_{2}$, as already stated. For pressures below $f_{c}^{\prime} / 3$ and above $-f_{t}$, the tensile meridian is given by

$$
\Delta \sigma=\frac{3}{2}\left(p+f_{t}\right)
$$

which passes through both the triaxial tensile test failure point and the uniaxial tensile test point (See "Pressure Cutoff" on page 10.) At $p=f_{c}{ }_{c} / 3$, the two meridians are forced to coincide by determining an appropriate value of $\psi$. The compressive meridian for pressures below $f_{c}^{\prime} / 3$ then follows as the image of the tensile meridian, which can be calculated by dividing the tensile meridian by $\psi(p)$ at every pressure $p$. The determination of $\psi(p)$ is fully discussed in [Ref 2], and will not be discussed in this report. However, it will suffice it to say that the function $\psi(p)$ is determined from experimental data, and are used internally by the code. Therefore, no input is required from the user.

\subsection{Strain Rate Effects}

In the analysis of concrete structures subjected to blast loading, the concrete may be subjected to strain rates on the order of $10 s^{-1}$ to $1000 s^{-1}$. At these high strain rates, the apparent strength of concrete and the corresponding strain at peak stress both increase. The fracture energy, or the area under the tensile load-deflection curve, is also believed to increase. Since concrete strain rate effects are generally thought to be dependent on the rate of crack propagation, the elastic modulus is assumed to be rate independent, because at low stress levels no cracking is present. It has been shown by experimental tests that there are different rate enhancements for tensile and compressive loading (see Figure 8). The tensile strength increases by a larger factor than does the compressive strength. Fur- 
thermore, the tensile strength rate enhancements have a larger slope than the compressive strength rate effects.

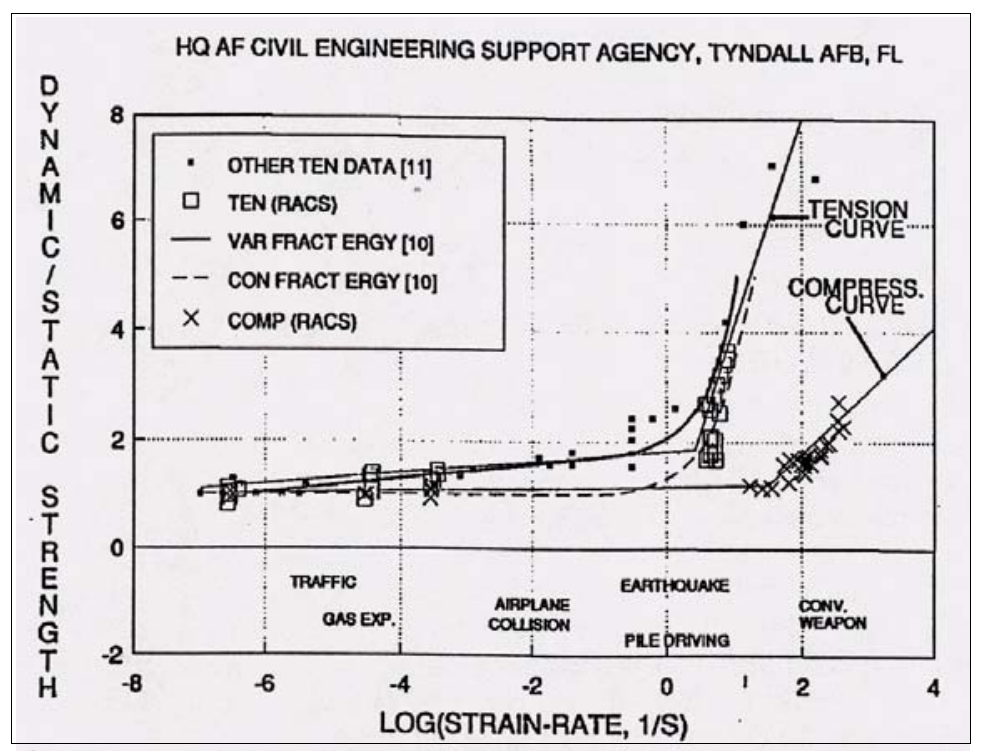

TABLE 2. DYNA3D input

\begin{tabular}{|l|l|}
\hline Strain Rate & Strength Factor \\
\hline$-1.000 \mathrm{E}+02$ & $7.960 \mathrm{E}+00$ \\
\hline$-1.000 \mathrm{E}+01$ & $4.040 \mathrm{E}+00$ \\
\hline$-1.000 \mathrm{E}+00$ & $1.890 \mathrm{E}+00$ \\
\hline$-1.000 \mathrm{E}-01$ & $1.780 \mathrm{E}+00$ \\
\hline$-1.000 \mathrm{E}-02$ & $1.670 \mathrm{E}+00$ \\
\hline$-1.000 \mathrm{E}-03$ & $1.560 \mathrm{E}+00$ \\
\hline $0.000 \mathrm{E}+00$ & $1.000 \mathrm{E}+00$ \\
\hline $1.000 \mathrm{E}-03$ & $1.119 \mathrm{E}+00$ \\
\hline $1.000 \mathrm{E}-02$ & $1.150 \mathrm{E}+00$ \\
\hline $1.000 \mathrm{E}-01$ & $1.200 \mathrm{E}+00$ \\
\hline $1.000 \mathrm{E}+00$ & $1.300 \mathrm{E}+00$ \\
\hline $1.000 \mathrm{E}+01$ & $1.375 \mathrm{E}+00$ \\
\hline $1.000 \mathrm{E}+02$ & $2.000 \mathrm{E}+00$ \\
\hline $1.000 \mathrm{E}+03$ & $3.000 \mathrm{E}+00$ \\
\hline
\end{tabular}

FIGURE 8. Strain rate effects on tensile and compressive strengths ([Ref 3] and [Ref 4]).

The DYNA3D model has the capability of using different strain rate enhancement factors for tension and compression. These factors are input into a DYNA3D via the use of a load curve (see Table 2). Please note that if strain rate effects are to be included in the calculation properly, one must specify a load curve number and also use $s=100$ on card 4 of the material deck. In addition, the negative values tell the code that those strength factors are to be used for tensile strength, while the positive ones are to be used for compressive strength.

The material model uses the negative values if $p<f_{t} / 3$ and the positive values if $p>f_{c}^{\prime} / 3$. For pressures that lie between these values, a linear interpolation is used. The rate effects are calculated by obtaining an enhanced $\Delta \sigma_{e}$ of the failure surface at some pressure $p$. This calculation is represented by the following:

$$
\begin{gathered}
\Delta \sigma_{e}=r_{f} \Delta \sigma\left(\frac{p}{r_{f}}\right) \\
r_{f}=\text { rate enhancement factor; } p=\text { pressure calculated by EOS }
\end{gathered}
$$

First, an unenhanced pressure, $p / r_{f}$, is calculated. This allows the code to obtain an unenhanced strength at $\Delta \sigma\left(p / r_{f}\right)$ from the compressive meridians. Then the unenhanced 
strength is multiplied by the strength factor to give the enhanced failure surface. This is graphically represented by Figure 9.

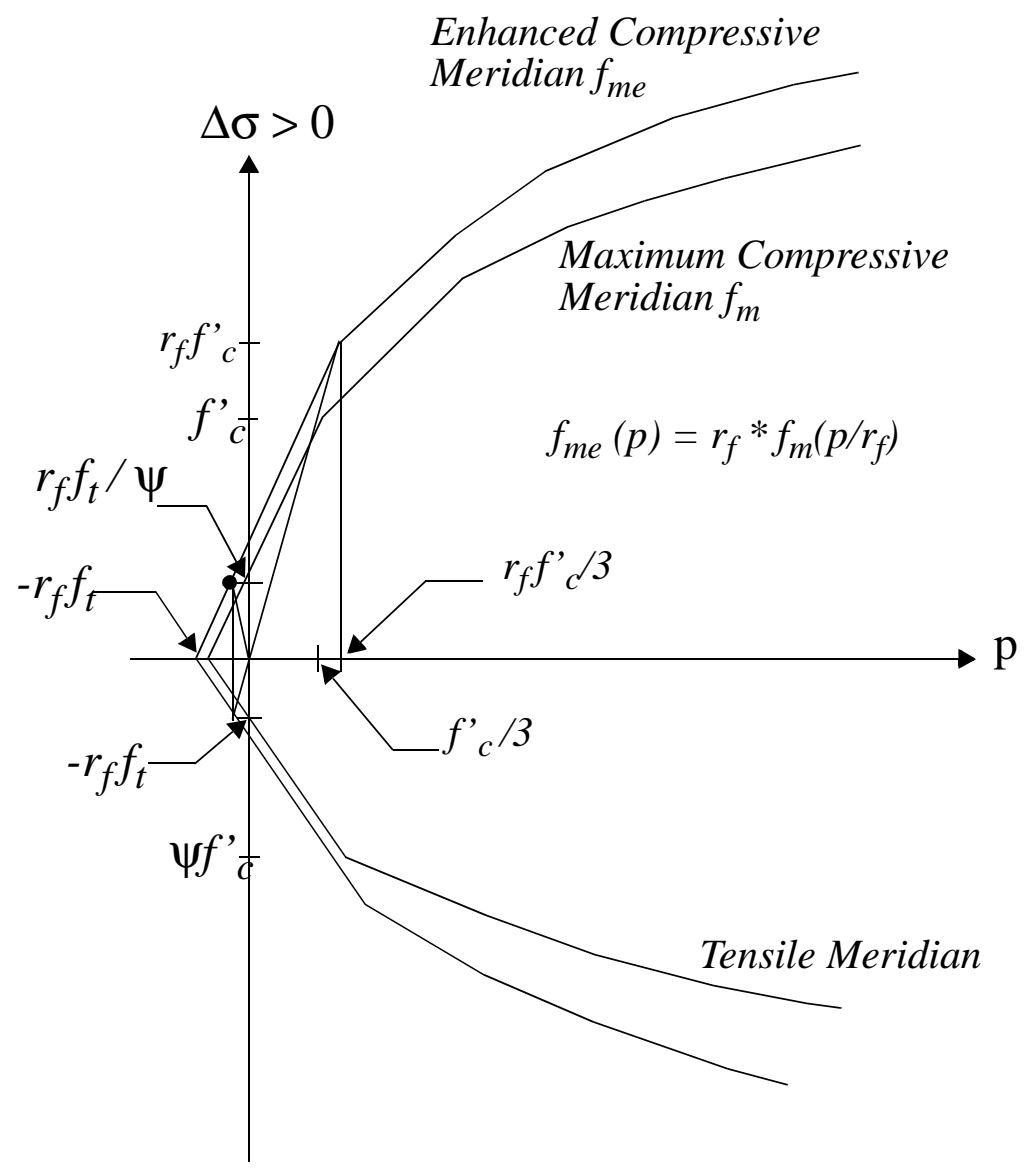

FIGURE 9. Description of strength enhancement calculation.

\subsection{Shear Dilation}

Dilatancy is a term used to describe the volume increase which may result from the formation and growth of cracks parallel to the direction of the greatest compressive stress. Shear dilation is the volume increase which may occur when concrete is subjected to shear stresses (see Figure 10). When the material is cracking, the dilation continues until the crack opening is large enough to clear the aggregates. At this point, dilatancy does not continue.

To include the effects of shear dilatancy and to make sure that too much shear dilation does not occur, a proper flow rule must be used. As you may recall, in a simple von Mises isotropic hardening law for metals, the plastic flow develops along the normal to the yield surface. This is known as an associative flow rule. If an associative flow rule is used for the concrete model, too much shear dilation tends to occur. In DYNA3D material model 16, the original version of this model, instead used a constant volume Prandtl- Reuss model, which is a non-associative flow rule. This rule, however, has the drawback of not 
being able to represent any shear dilation. Therefore, a partial associative flow rule is used, where the amount of associativity is prescribed by the user input value $\omega$, where a value of 0 indicates no change in volume during plastic flow and a value of 1 indicates shear dilation occurs according to an associative flow rule (see Figure 10). Typical concrete experiments show that the value of $\omega$ should range from 0.5 to 0.7 .

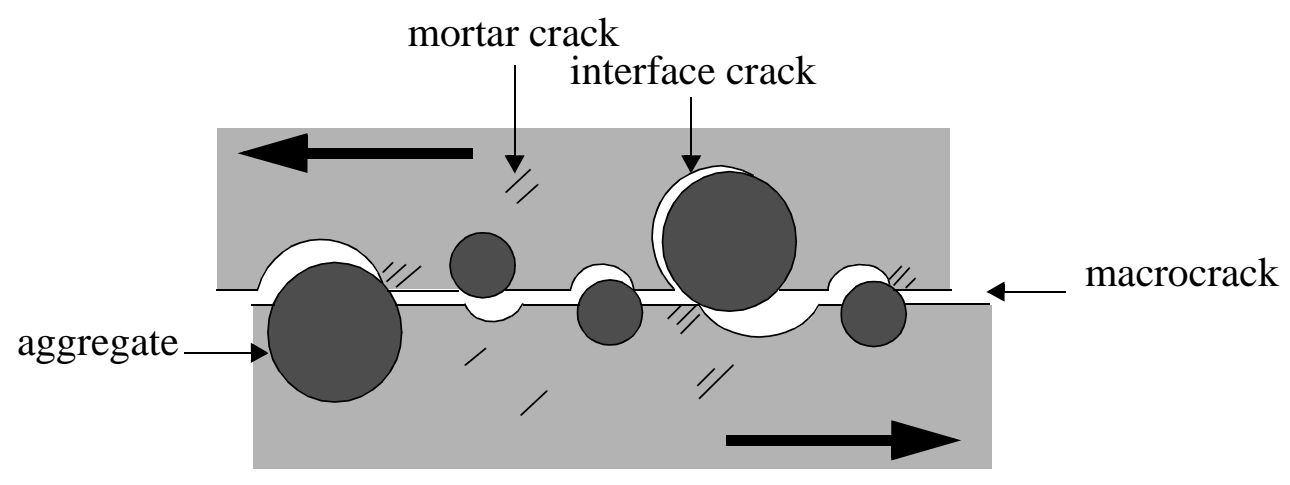

a)

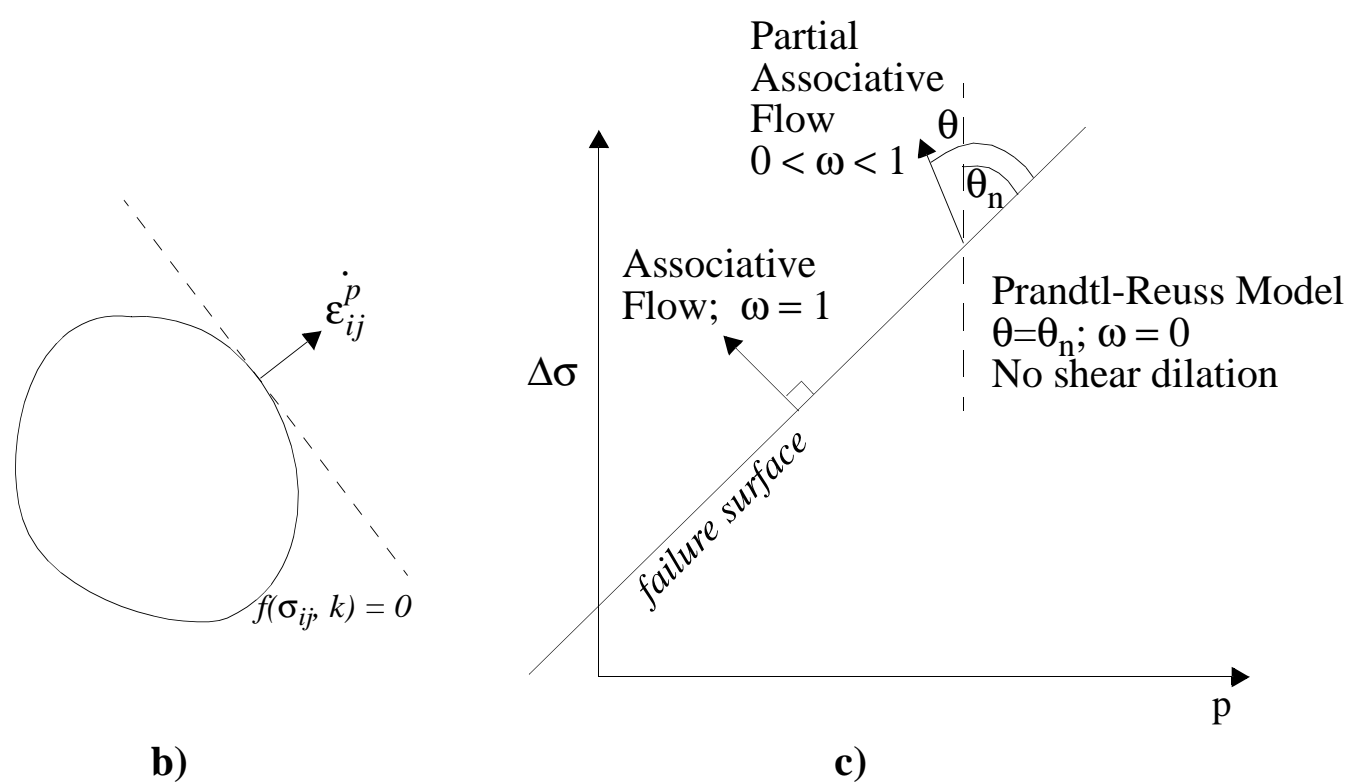

FIGURE 10. graphical representation of shear dilation; b) yield surface with associated flow rule; c) description of associative, non-associative, and partial associative flow rules.

\subsection{Equation of State}

The DYNA3D equation of state form 8 (similarly form 12), prescribes the relationship between pressure and volumetric strain. In addition, it also includes a tabulation of the unloading bulk modulus at peak volumetric strains. Please note that volumetric strain is positive in tension, and pressure is positive in compression. In general, the pressure vs. 
volumetric strain may have a cubic spline representation; however, the concrete data that will be supplied in this report consist of a linear pressure vs. volumetric strain relationship see Figure 11, Table 3, and Table 4).

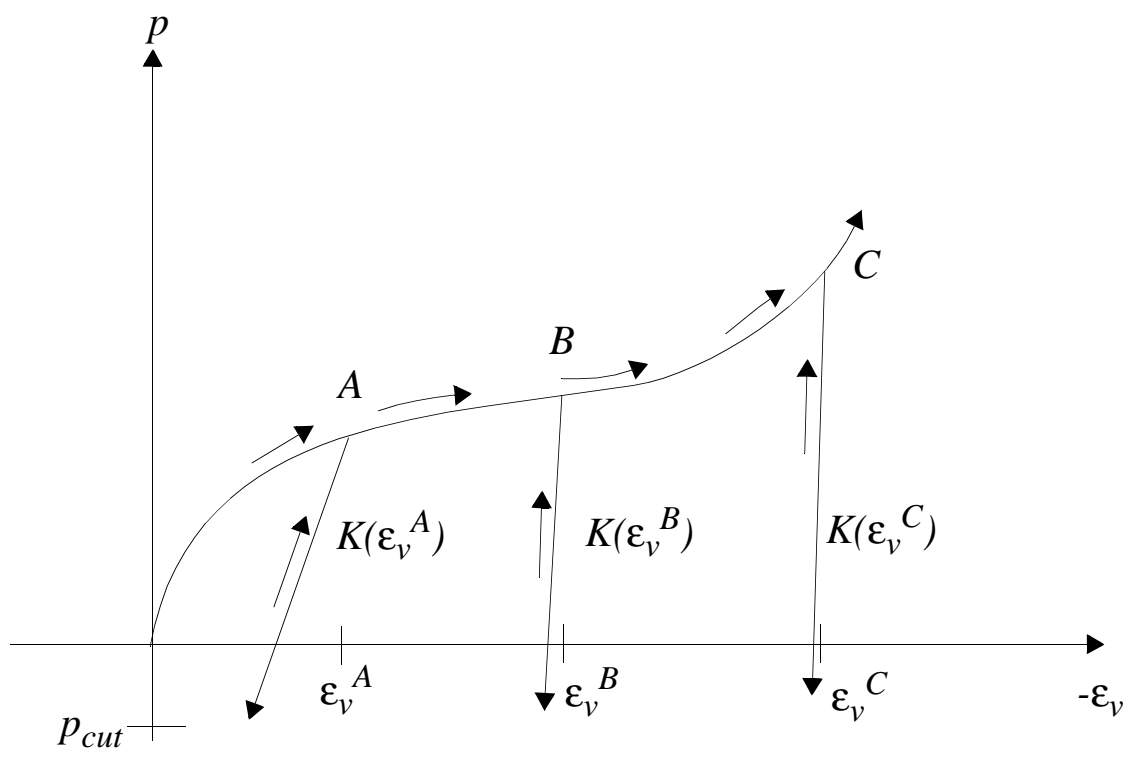

FIGURE 11. Pressure vs. volumetric strain curve for equation-of-state Form 8 with compaction (similarly Form 12).

TABLE 3. Input for equation-of-state form 12: WSMR-5 3/4 concrete

\begin{tabular}{|l|l|l|l|l|}
\hline COLUMN 1 & COLUMN 2 & COLUMN 3 & COLUMN 4 & COLUMN 5 \\
\hline $\mathbf{0 . 0 0 0 0 0 0 0 0 0 E + 0 0}$ & $\mathbf{- 1 . 4 6 6 0 0 0 0 0 0 E - 0 3}$ & $\mathbf{- 1 . 0 0 0 0 0 0 0 0 0 E - 0 2}$ & $\mathbf{- 4 . 0 0 0 0 0 0 0 0 0 E - 0 2}$ & $\mathbf{- 7 . 0 0 0 0 0 0 0 0 0 E - 0 2}$ \\
\hline$-1.000000000 \mathrm{E}+00$ & $0.000000000 \mathrm{E}+00$ & $0.000000000 \mathrm{E}+00$ & $0.000000000 \mathrm{E}+00$ & $0.000000000 \mathrm{E}+00$ \\
\hline $0.000000000 \mathrm{E}+00$ & $3.625000000 \mathrm{E}+03$ & $1.513800000 \mathrm{E}+04$ & $4.437000000 \mathrm{E}+04$ & $8.076500000 \mathrm{E}+04$ \\
\hline $1.032110000 \mathrm{E}+06$ & $0.000000000 \mathrm{E}+00$ & $0.000000000 \mathrm{E}+00$ & $0.000000000 \mathrm{E}+00$ & $0.000000000 \mathrm{E}+00$ \\
\hline $0.000000000 \mathrm{E}+00$ & $0.000000000 \mathrm{E}+00$ & $0.000000000 \mathrm{E}+00$ & $0.000000000 \mathrm{E}+00$ & $0.000000000 \mathrm{E}+00$ \\
\hline $0.000000000 \mathrm{E}+00$ & $0.000000000 \mathrm{E}+00$ & $0.000000000 \mathrm{E}+00$ & $0.000000000 \mathrm{E}+00$ & $0.000000000 \mathrm{E}+00$ \\
\hline $2.472250000 \mathrm{E}+06$ & $2.472250000 \mathrm{E}+06$ & $4.437000000 \mathrm{E}+06$ & $4.437000000 \mathrm{E}+06$ & $4.437000000 \mathrm{E}+06$ \\
\hline $4.437000000 \mathrm{E}+06$ & $0.000000000 \mathrm{E}+00$ & $0.000000000 \mathrm{E}+00$ & $0.000000000 \mathrm{E}+00$ & $0.000000000 \mathrm{E}+00$ \\
\hline $0.000000000 \mathrm{E}+00$ & $0.000000000 \mathrm{E}+00$ & $0.000000000 \mathrm{E}+00$ & $0.000000000 \mathrm{E}+00$ & $0.000000000 \mathrm{E}+00$ \\
\hline
\end{tabular}


TABLE 4. Input for equation-of-state form 12: SAC5 concrete

\begin{tabular}{|l|l|l|l|l|}
\hline COLUMN 1 & COLUMN 2 & COLUMN 3 & COLUMN 4 & COLUMN 5 \\
\hline $\mathbf{0 . 0 0 0 0 0 0 0 0 0 E + 0 0}$ & $\mathbf{- 4 . 7 6 0 0 0 0 0 0 0 e - 0 3}$ & $\mathbf{- 1 . 0 0 4 7 6 0 0 0 0 e + 0 0}$ & $\mathbf{0 . 0 0 0 0 0 0 0 0 0 e + 0 0}$ & $\mathbf{0 . 0 0 0 0 0 0 0 0 0 e + 0 0}$ \\
\hline $0.000000000 \mathrm{e}+00$ & $0.000000000 \mathrm{E}+00$ & $0.000000000 \mathrm{E}+00$ & $0.000000000 \mathrm{E}+00$ & $0.000000000 \mathrm{E}+00$ \\
\hline $0.000000000 \mathrm{E}+00$ & $1.015000000 \mathrm{e}+04$ & $7.351500000 \mathrm{e}+05$ & $0.000000000 \mathrm{E}+00$ & $0.000000000 \mathrm{E}+00$ \\
\hline $0.000000000 \mathrm{E}+00$ & $0.000000000 \mathrm{E}+00$ & $0.000000000 \mathrm{E}+00$ & $0.000000000 \mathrm{E}+00$ & $0.000000000 \mathrm{E}+00$ \\
\hline $0.000000000 \mathrm{E}+00$ & $0.000000000 \mathrm{E}+00$ & $0.000000000 \mathrm{E}+00$ & $0.000000000 \mathrm{E}+00$ & $0.000000000 \mathrm{E}+00$ \\
\hline $0.000000000 \mathrm{E}+00$ & $0.000000000 \mathrm{E}+00$ & $0.000000000 \mathrm{E}+00$ & $0.000000000 \mathrm{E}+00$ & $0.000000000 \mathrm{E}+00$ \\
\hline $2.131500000 \mathrm{e}+06$ & $2.131500000 \mathrm{e}+06$ & $2.131500000 \mathrm{e}+06$ & $0.000000000 \mathrm{e}+00$ & $0.000000000 \mathrm{e}+00$ \\
\hline $0.000000000 \mathrm{e}+00$ & $0.000000000 \mathrm{E}+00$ & $0.000000000 \mathrm{E}+00$ & $0.000000000 \mathrm{E}+00$ & $0.000000000 \mathrm{E}+00$ \\
\hline $0.000000000 \mathrm{E}+00$ & $0.000000000 \mathrm{E}+00$ & $1.000000000 \mathrm{E}+00$ & $0.000000000 \mathrm{E}+00$ & $0.000000000 \mathrm{E}+00$ \\
\hline
\end{tabular}




\subsection{Concrete Material Properties}

There are two concrete materials which have been used extensively with the DYNA3D material model. These materials include the WSMR-5 3/4 concrete and the SAC5 concrete. Because having only two sets of material data is rather limiting to the user, a procedure for scaling known data to another material is also presented.

\subsection{WSMR-5 3/4 Concrete}

This material model was used primarily for all of the Morrow Point Dam simulations presented. The primary reason for this is that the unconfined compressive strength of WSMR$53 / 4$ concrete is approximately $6500 \mathrm{psi}$, which is similar to the compressive strength of the cylinder tests conducted on the Morrow Point concrete. The corresponding tensile strength of this material is approximately 465 psi. Figure 12 shows a plot of the compressive meridians, a single element tensile test, and a uniaxial unconfined compressive test.

\subsection{SAC5 Concrete}

The SAC5 concrete material was used for the DYNA3D/ALE3D concrete wall benchmark experiment presented earlier in the report. This material has an unconfined compressive strength of approximately $5500 \mathrm{psi}$ and a tensile strength of 365 psi. Furthermore, a comparison of the $(\eta, \lambda)$ pairs of SAC5 concrete to those of WSMR-5 3/4 concrete, reveals that the failure surface of SAC5 concrete is reached at a later damage value $\lambda$ than for the WSMR-5 3/4 concrete. Figure 13 similarly shows a plot of the failure surfaces, a single element tensile test, and a uniaxial unconfined compressive test. 
TABLE 5. DYNA3D input for WSMR-5 3/4 concrete: mesh size ( 6 x 6 x 6 in. cube)

\begin{tabular}{|c|c|c|c|c|c|c|c|c|}
\hline CARDS & $\begin{array}{l}\text { COLUMN } \\
1\end{array}$ & $\begin{array}{l}\text { COLUMN } \\
2\end{array}$ & $\begin{array}{l}\text { COLUMN } \\
3\end{array}$ & $\begin{array}{l}\text { COLUMN } \\
4\end{array}$ & $\begin{array}{l}\text { COLUMN } \\
5\end{array}$ & $\begin{array}{l}\text { COLUMN } \\
6\end{array}$ & $\begin{array}{l}\text { COLUMN } \\
7\end{array}$ & $\begin{array}{l}\text { COLUMN } \\
8\end{array}$ \\
\hline 3 & $1.900 \mathrm{E}-01$ & $4.640 \mathrm{E}+02$ & $1.946 \mathrm{E}+03$ & 4.463E-01 & $1.228 \mathrm{E}-05$ & $1.500 \mathrm{E}+00$ & $5.000 \mathrm{E}-01$ & 4.417E-01 \\
\hline 4 & $\mathrm{~s}=0$ or 100 & $2.000 \mathrm{E}+00$ & $0.000 \mathrm{E}+00$ & $\begin{array}{l}\text { volumetric } \\
\text { strain at } \\
\text { failure }\end{array}$ & $0.000 \mathrm{E}+00$ & $\begin{array}{l}\text { load curve } \\
\text { giving rate } \\
\text { sensitivity }\end{array}$ & $0.000 \mathrm{E}+00$ & $0.000 \mathrm{E}+00$ \\
\hline 5 & $0.000 \mathrm{E}+00$ & $1.000 \mathrm{E}-05$ & $3.000 \mathrm{E}-05$ & $5.000 \mathrm{E}-05$ & $7.000 \mathrm{E}-05$ & $9.000 \mathrm{E}-05$ & $1.100 \mathrm{E}-04$ & $2.700 \mathrm{E}-04$ \\
\hline 6 & $5.800 \mathrm{E}-04$ & $7.800 \mathrm{E}-04$ & $1.331 \mathrm{E}-02$ & $5.000 \mathrm{E}-01$ & $6.000 \mathrm{E}-01$ & $1.150 \mathrm{E}+00$ & $1.469 \mathrm{E}+03$ & $6.250 \mathrm{E}-01$ \\
\hline 7 & $0.000 \mathrm{E}+00$ & $8.500 \mathrm{E}-01$ & $9.600 \mathrm{E}-01$ & $9.900 \mathrm{E}-01$ & $1.000 \mathrm{E}+00$ & $9.900 \mathrm{E}-01$ & $9.600 \mathrm{E}-01$ & $5.000 \mathrm{E}-01$ \\
\hline 8 & $5.000 \mathrm{E}-02$ & $1.000 \mathrm{E}-02$ & $0.000 \mathrm{E}+00$ & $0.000 \mathrm{E}+00$ & $0.000 \mathrm{E}+00$ & $1.600 \mathrm{E}-01$ & $1.797 \mathrm{E}-05$ & $3.981 \mathrm{E}-05$ \\
\hline
\end{tabular}

NOTE: all units in lbs, sec, in.

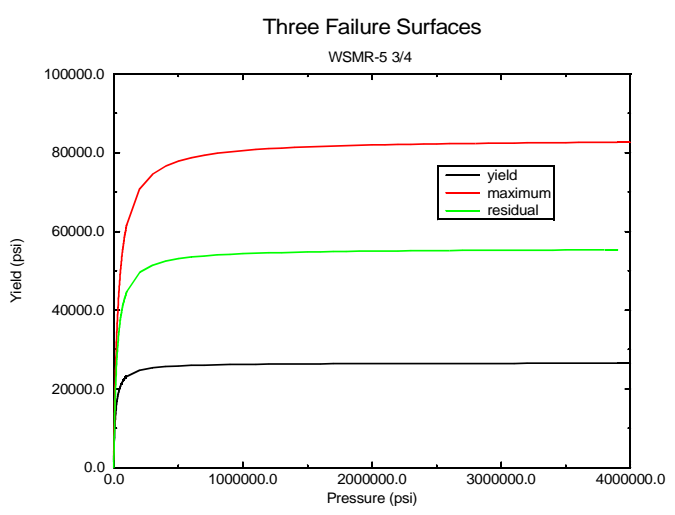

a)

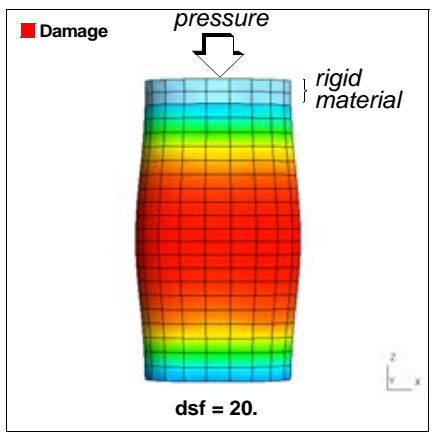

c)

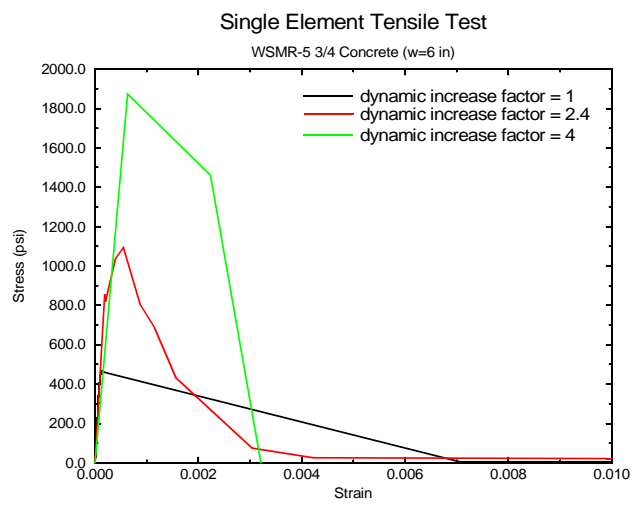

b)

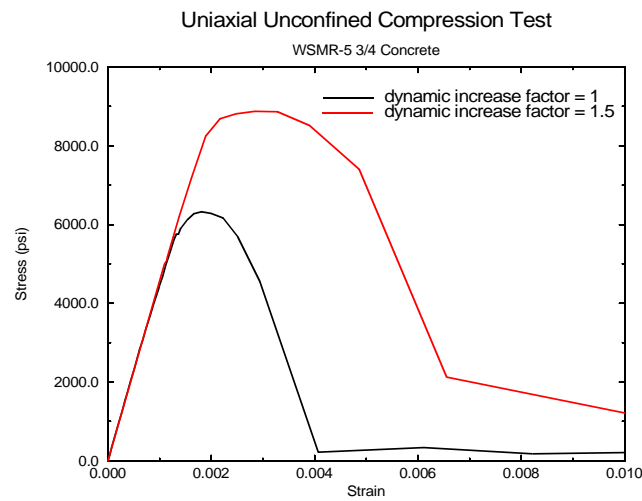

d)

FIGURE 12. WSMR-5 3/4 concrete properties: a) plot of compressive meridians; b) single element uniaxial tensile test with and without rate dependence (tensile strength $=464 \mathrm{psi}$ ); $\mathrm{c}$ ) description of unconfined uniaxial compressive test and plot of damage parameter $\delta$ after compressive failure; d) stress-strain plot of UUC test with and without rate dependence (compressive strength $=6500 \mathrm{psi}$ ). 
TABLE 6. DYNA3D input for SAC5 concrete: mesh size (6 66 x 6 in. cube)

\begin{tabular}{|c|c|c|c|c|c|c|c|c|}
\hline CARDS & $\begin{array}{l}\text { COLUMN } \\
1\end{array}$ & $\begin{array}{l}\text { COLUMN } \\
2\end{array}$ & $\begin{array}{l}\text { COLUMN } \\
3\end{array}$ & $\begin{array}{l}\text { COLUMN } \\
4\end{array}$ & $\begin{array}{l}\text { COLUMN } \\
5\end{array}$ & $\begin{array}{l}\text { COLUMN } \\
6\end{array}$ & $\begin{array}{l}\text { COLUMN } \\
7\end{array}$ & $\begin{array}{l}\text { COLUMN } \\
8\end{array}$ \\
\hline 3 & $1.900 \mathrm{E}-01$ & $3.625 \mathrm{E}+02$ & $2.192 \mathrm{E}+03$ & $4.910 \mathrm{E}-01$ & $1.246 \mathrm{E}-05$ & $1.400 \mathrm{E}+00$ & $0.000 \mathrm{E}+00$ & 4.417E-01 \\
\hline 4 & $\mathrm{~s}=0$ or 100 & $2.000 \mathrm{E}+00$ & $0.000 \mathrm{E}+00$ & $\begin{array}{l}\text { volumetric } \\
\text { strain at } \\
\text { failure }\end{array}$ & $0.000 \mathrm{E}+00$ & $\begin{array}{l}\text { load curve } \\
\text { giving rate } \\
\text { sensitivity }\end{array}$ & $0.000 \mathrm{E}+00$ & $0.000 \mathrm{E}+00$ \\
\hline 5 & $0.000 \mathrm{E}+00$ & $1.500 \mathrm{E}-04$ & $2.800 \mathrm{E}-04$ & $1.200 \mathrm{E}-03$ & $0.100 \mathrm{E}+00$ & $0.200 \mathrm{E}+00$ & $0.300 \mathrm{E}+00$ & $0.400 \mathrm{E}+00$ \\
\hline 6 & $5.000 \mathrm{E}-01$ & $6.000 \mathrm{E}-01$ & $7.000 \mathrm{E}-01$ & $8.000 \mathrm{E}-01$ & $9.000 \mathrm{E}-01$ & $0.400 \mathrm{E}+00$ & $1.560 \mathrm{E}+03$ & $7.414 \mathrm{E}-01$ \\
\hline 7 & $0.000 \mathrm{E}+00$ & $1.000 \mathrm{E}+00$ & $2.400 \mathrm{E}-01$ & $0.000 \mathrm{E}+00$ & $0.000 \mathrm{E}+00$ & $0.000 \mathrm{E}+00$ & $0.000 \mathrm{E}+00$ & $0.000 \mathrm{E}+00$ \\
\hline 8 & $0.000 \mathrm{E}+00$ & $0.000 \mathrm{E}+00$ & $0.000 \mathrm{E}+00$ & $0.000 \mathrm{E}+00$ & $0.000 \mathrm{E}+00$ & $1.500 \mathrm{E}+00$ & $1.797 \mathrm{E}-05$ & $3.569 \mathrm{E}-05$ \\
\hline
\end{tabular}

NOTE: all units in lbs, sec, in.

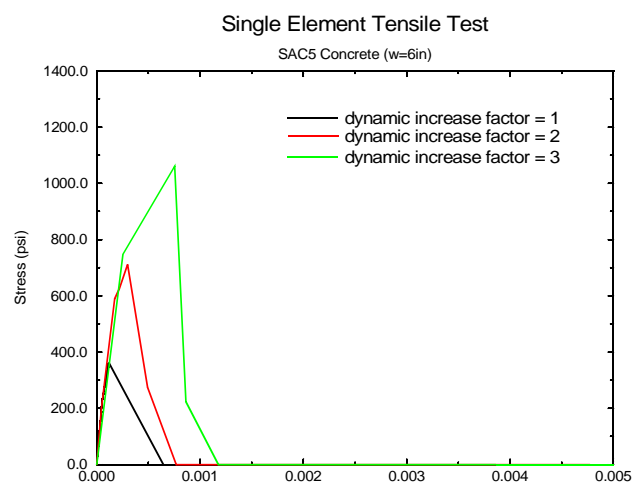

a)

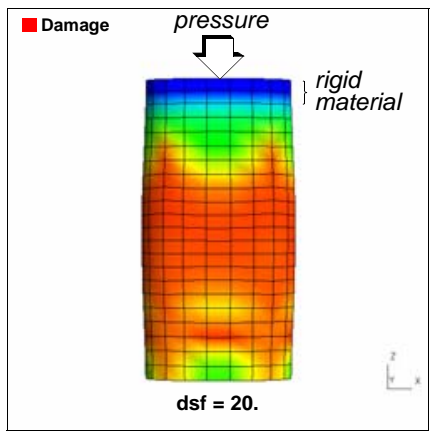

c)

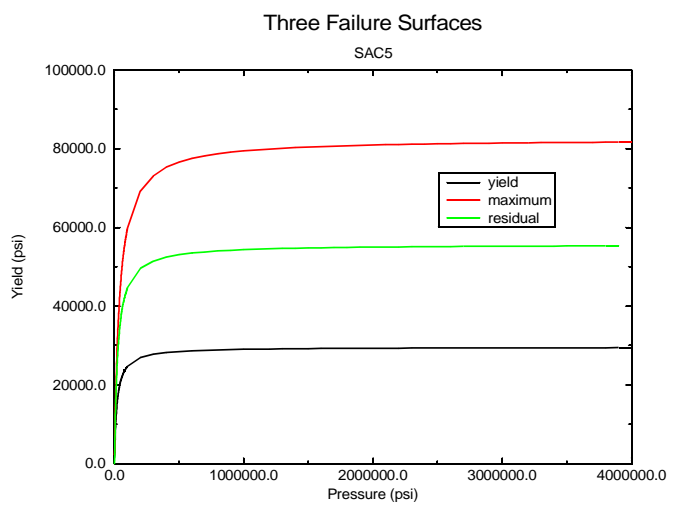

b)

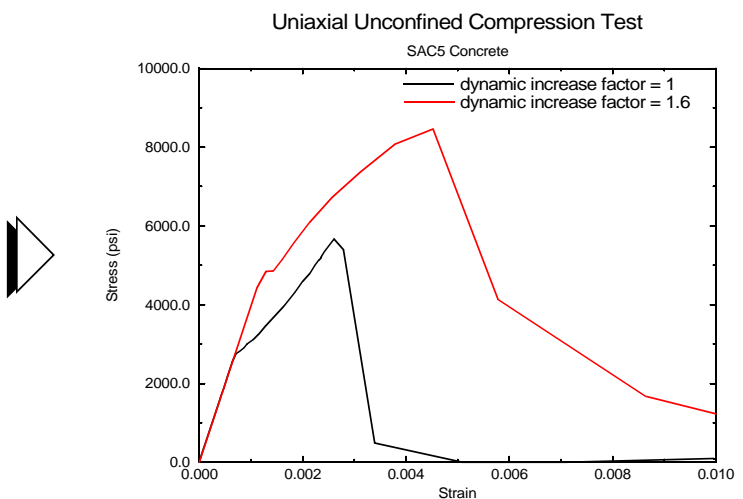

d)

FIGURE 13. SAC5 concrete properties: a) plot of compressive meridians; b) single element uniaxial tensile test with and without rate dependence (tensile strength $=363 \mathrm{psi}$ ); c) description of unconfined uniaxial compressive test and plot of damage parameter $\delta$ after compressive failure; $d$ ) stress-strain plot of UUC test with and without rate dependence (compressive strength $=\mathbf{5 5 0 0} \mathbf{p s i}$ ). 


\subsection{Scaling of Existing Data}

A disadvantage to using this particular material model is the large amount of data that is required for one type of concrete. Therefore, it is useful to discuss briefly the methods required to scale the known data, such as the data given for WSMR-5 3/4 concrete and SAC5 concrete, so that it can be used for a different material [Ref 3]. The user input that requires scaling are the failure surfaces and the equation of state.

The following steps are used to scale the failure surfaces:

1. If $f_{c_{n e w}}$ is the unconfined compression strength of the new material to be modeled, and $f_{c_{\text {old }}}^{\prime}$ is the unconfined compression strength of a previous modeled concrete material, then a ratio, $r$, may be calculated as

$$
r=\frac{f_{c_{\text {new }}}^{\prime}}{f_{c_{\text {old }}}^{\prime}}
$$

2. New coefficients for the failure surfaces may be calculated by

$$
\begin{gathered}
a_{0 n}=a_{0} r \\
a_{1 n}=a_{1} \\
a_{2 n}=a_{2} / r
\end{gathered}
$$

where the subscript $n$ represents the new material's coefficients.

The equation of state needs modification to both the input pressures and input bulk moduli. The new pressures and moduli may be calculated by the two following relationships:

$$
\begin{aligned}
& p_{\text {new }}=p_{\text {old }} \sqrt{r} \\
& K_{\text {new }}=K_{\text {old }} \sqrt{r}
\end{aligned}
$$

These relationships stem from the fact that the bulk modulus is calculated by

$$
K=\frac{E}{3(1-2 v)}
$$

where the modulus of elasticity, $E$, is related to the unconfined concrete compressive strength by

$$
E=57000 \sqrt{f_{c}^{\prime}}
$$

Please note that the empirical relationship for $E$ requires that the units be in (lbs, sec, in). 


\subsection{References}

1. Attaway, S.W., Matalucci, R.V., Morrill, K.B., Malvar, L.J., and Crawford, J.E., Enhancements to PRONTO3D to Predict Structural Response to Blast, Sandia National Laboratories Draft Copy, October 15, 1999.

2. Malvar, L.J., Crawford, J.E., Wesevich, J.W., A New Concrete Material Model For DYNA3D, Karagozian and Case, Report No. TR-94-14.1, June 1, 1994.

3. Malvar, L.J., Crawford, J.E., Wesevich, J.W., A New Concrete Material Model For DYNA3D Release II: Shear Dilation and Directional Rate Enhancements, Karagozian and Case, Report No. TR-96-2.2, February 8, 1996.

4. Ross, C.A., Kuennen, S.T., Tedesco, J.W., "Effects of Strain Rate on Concrete Strength," Session on Concrete Research in the Federal Government, ACI Spring Convention, Washington, D.C., March 1992.

5. Whirley, R.G., DYNA3D: A Nonlinear, Explicit, Three-Dimensional Finite Element Code for Solid and Structural Mechanics, Lawrence Livermore National Laboratory Report UCRL-MA-107254-REV-1. 


\section{Porous Crush Material Model}




\subsection{Background}

The ALE3D concrete model is primarily based on the CALE (C-language based Arbitrary Lagrange/Eulerian) material model 13. It is also similar to the original DYNA3D material model 16, from which material model 45 was based. The similarity lies within the description of the failure surfaces. As you may remember from Appendix A, DYNA3D material model 45 included 3 failure surfaces, which included a yield, a maximum, and a residual surface. The original version, DYNA3D material model 16, used only two surfaces. These surfaces are the maximum and the residual surfaces.

\subsection{Nonlinear Concrete Model Description}

The concrete model is described in terms of a constitutive model, a damage model, and an equation of state. The constitutive model recognizes the existence of both damaged and undamaged material through the use of the previously described failure surfaces. The damage model bases damage from four different methods of failure, which include tensile and compressive failure, tensile pressure failure, and failure based on an effective plastic strain. The equation of state is described by a seven term polynomial, instead of user input values of pressure and bulk moduli, such as the equation of state 8 in DYNA3D.

\subsection{Constitutive Model}

The constitutive model generates material properties that are based on both the initial properties of the concrete, or undamaged state, and properties that correspond to a damaged state. The shear modulus, $G$, and the yield strength, $Y$, are calculated using a linear combination of the properties of the zone's initial and damaged material as follows:

$$
\begin{gathered}
G=G_{i}(1-D)+G_{D} D \\
Y=Y_{i}(1-D)+Y_{D} D
\end{gathered}
$$

where subscripts $i$ and $D$ represent the initial and damaged state and $D$ is a damage parameter that ranges from 0 for undamaged material and 1 for a completely pulverized material. The model assumes that the yield strength is pressure dependent, similar to the DYNA3D models, and that the strength of both the initial and damaged materials are represented by tables of pressure versus yield strength (see Table 10 and Table 15). Figure 14 shows a graphical representation of the pressure vs. yield strength curves.

Instead of having user input tables of shear modulus, it is assumed that the shear modulus of the damaged material is scaled with the yield strength by

$$
G_{D}=G_{o} \frac{Y_{D}}{Y_{o}}
$$

where $G_{o}$ and $Y_{o}$ are the initial properties of the material 

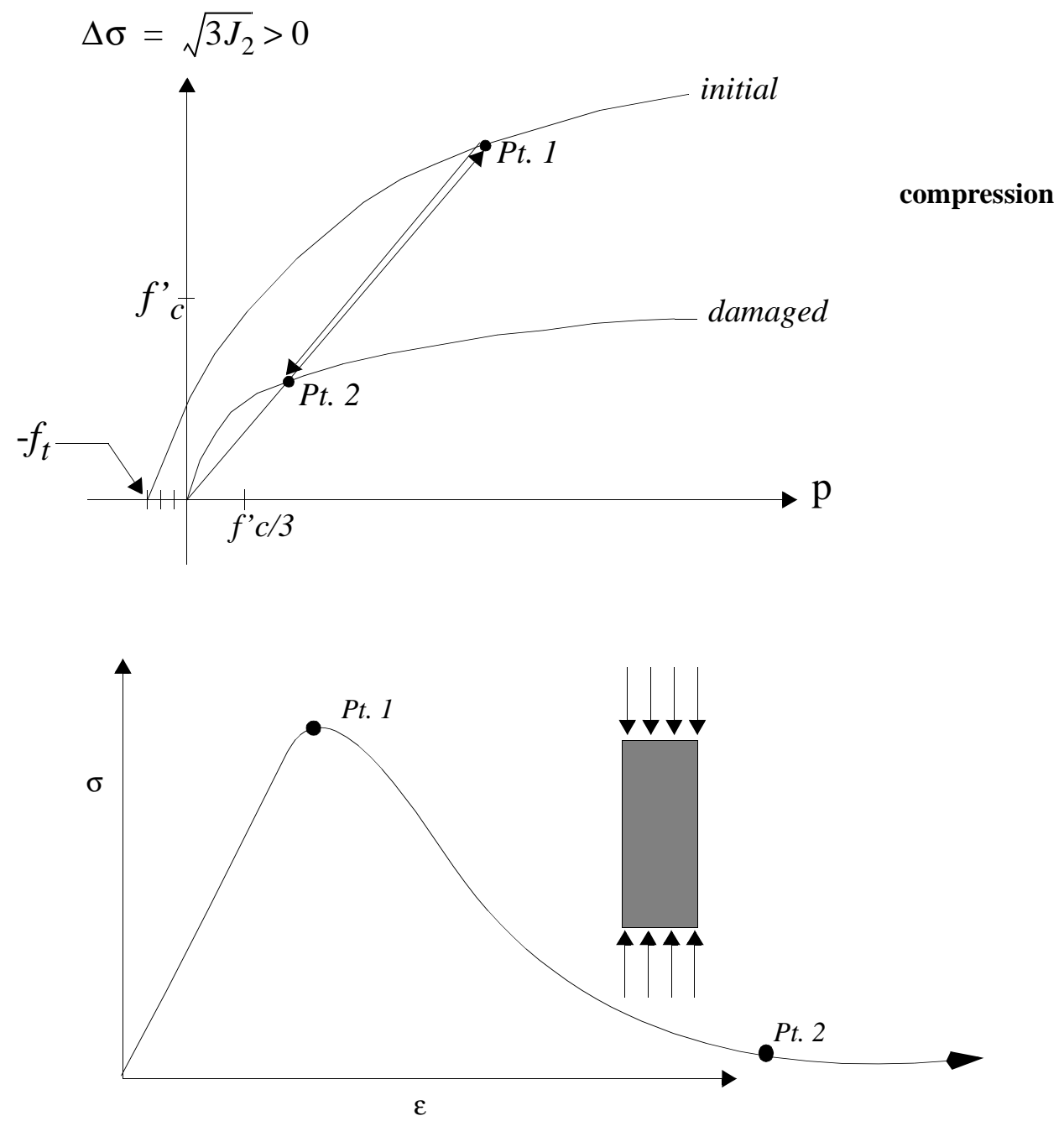

FIGURE 14. Model failure surfaces and uniaxial stress-strain response.

\subsection{Damage Model}

The material is allowed to accumulate damage from four different failure criteria input by the user: failure on tensile pressure, failure on principle tensile stress, failure on compressive principal stress, and failure on effective plastic strain. If a value of zero has been specified for a particular failure criteria, that criteria will not be used in the calculation of damage $D$.

For each criteria set to a value other than zero, the following is calculated

$$
\left(\frac{f_{i}}{F}\right)^{2}
$$


where $F$ is the failure criteria value input by the user and $f_{i}$ is the current value of that quantity in the $i$ th element. If more than one criterion is specified, these terms are summed, and if the sum exceeds unity then the $i$ th element is allowed to accumulate damage. The damage parameter $D$ is then calculated as follows

$$
D=D+\text { frate }\left(\left(\frac{4 G_{o}}{3 \rho}\right)^{\frac{1}{2}} \frac{\Delta t}{\Delta x}\right)
$$

where $\Delta x$ is a characteristic length of the $i$ th element and frate is user specified multiplier on the damage accumulation rate. In addition, it is worthwhile to note that the remaining terms are related to the sound speed of the material. As you may recall, the bulk or plate speed of longitudinal waves in an isotropic material is calculated by

$$
c=\sqrt{\frac{B+\frac{4}{3} G}{\rho}}
$$

where $B$ and $G$ are the bulk and shear moduli of the solid and $\rho$ is the density.

\subsection{Equation of State}

The equation of state, or pressure versus volumetric strain relationship, is based on a seven term polynomial given by

$$
P=A_{0}+A_{1} \mu+A_{2} \mu^{2}+A_{3} \mu^{3}+\left(B_{o}+B_{1} \mu+B_{2} \mu^{2}\right) E
$$

with $\mu$ given by

$$
\mu=\frac{v_{o}}{v}-1
$$

In other words, $\mu$ is the reciprocal of the compression minus one, $E$ is the elastic modulus of the material, and the seven coefficients, $A$ and $B$, are specified by the user. If the material is in expansion, the terms containing $A_{2}$ and $B_{2}$ are set to zero.

The complete equation of state, however, is determined by the degree of porosity, $\phi, a$ pressure density relationship of the solid phase of the material, $p_{s}\left(\rho_{s}\right)$, and the crush curve of the material, $p_{c}(\phi)$. The density of the solid phase of the material is calculated from the following 


$$
\rho_{s}=\frac{\rho}{1-\phi}
$$

where $\rho$ is the total density of the material. Then the total pressure of the material is given by

$$
p=(1-\phi) p_{s}\left(\rho_{s}\right)
$$

The crush characteristics of the material is specified by the user in terms of density versus crush pressure, $p_{c}$ (see Table 11). The code converts this table into a table of crush pressure versus porosity.

The equation of state model assumes that porosity does not reach a value of zero until the pressure exceeds the crush pressure. Furthermore, when the material is undergoing tension, the porosity will not increase until the pressure drops below the negative of the crush pressure. The pressure is obtained from EQ. 56 only if it falls between these two extremes. However, if $p>p_{c}, p$ is forced to be equal to $p_{c}$ by solving for the porosity that produces $p=p_{c}$, while keeping $\rho_{s}$ constant. If $p<-p_{c}$, then $p$ is forced to be equal to $-p_{c}$ by holding $p_{c}$ constant and adjusting the porosity.

In addition, the equation of state does not change if the material has been damaged. The only constraint is that the damaged material is not allowed to support a negative pressure. Therefore, the pressure relationship for negative pressures is similar in nature to EQ. 47 and EQ. 48. If $p<0$,

$$
p=p_{i}(1-D)
$$

\subsection{Concrete Material Properties}

The ALE3D material properties used for WSMR-5 3/4 and SAC5 concrete are given in the following sections. For the sake of consistency between ALE3D and DYNA3D, the failure surfaces used to define the DYNA3D materials were used to define the ALE3D failure surfaces. In addition, the tensile and compressive strengths given by the DYNA3D materials were also used to help define the ALE3D properties. An example of the evolution of the damage parameter for an unconfined uniaxial compression test is given for each material (see Figure 17 and Figure 20). It should be noted that the load curve specifying the amount of pressure load the cylinder is being subjected to is given by

TABLE 7. Pressure load curve for UUC test

\begin{tabular}{|l|l|}
\hline Time (sec) & Pressure (psi) \\
\hline 0.0 & 0.0 \\
\hline
\end{tabular}


TABLE 7. Pressure load curve for UUC test

\begin{tabular}{|l|l|}
\hline 0.004 & $2 \times$ yield strength \\
\hline 2.0 & $2 \times$ yield strength \\
\hline
\end{tabular}

which suggests that damage should begin accumulating after $0.002 \mathrm{sec}$ or 2000 microsec. This is indeed the case, since the pseudocolor damage plots, given in Figure 17 and Figure 20, begin rapidly changing color after $\mathrm{t}=0.002 \mathrm{sec}$ is reached.

\subsection{WSMR-5 3/4 Concrete}

TABLE 8. ALE3D material parameters (gm, cm, $\mu \mathrm{sec}$, Mbar)

\begin{tabular}{|l|l|}
\hline minimum pressure & $-1.0(-14.5 \mathrm{e}+06 \mathrm{psi})$ \\
\hline reference density & $2.68\left(165 \mathrm{lbs} / \mathrm{ft}^{3}\right)$ \\
\hline initial value of relative volume & 1.1652174 \\
\hline initial value of energy & 0.0 \\
\hline $\begin{array}{l}\text { quadratic coefficient of artifi- } \\
\text { cial viscosity }\end{array}$ & 0.75 \\
\hline hourglass viscosity coefficient & 0.1 \\
\hline $\begin{array}{l}\text { linear coefficient of artificial } \\
\text { viscosity }\end{array}$ & 0.3 \\
\hline plastic strain at failure & 2.5 \\
\hline
\end{tabular}

TABLE 9. ALE3D engineering parameters (gm, cm, $\mu \mathrm{sec}$, Mbar)

\begin{tabular}{|l|l|}
\hline initial porosity & 0.142 \\
\hline $\begin{array}{l}\text { scalar shear modulus of initial } \\
\text { material }\end{array}$ & $0.13(1.885 \mathrm{e}+06 \mathrm{psi})$ \\
\hline damage rate multiplier & 0.5 \\
\hline $\begin{array}{l}\text { scalar yield strength at zero pres- } \\
\text { sure }\end{array}$ & $4.52 \mathrm{e}-04(6500 \mathrm{psi})$ \\
\hline
\end{tabular}


TABLE 9. ALE3D engineering parameters (gm, $\mathrm{cm}, \mu \mathrm{sec}, \mathrm{Mbar})$

\begin{tabular}{|l|l|}
\hline $\begin{array}{l}\text { failure on compressive principal } \\
\text { stress }\end{array}$ & $4.52 \mathrm{e}-04(6500 \mathrm{psi})$ \\
\hline failure on principal tensile stress & $-3.2 \mathrm{e}-05(-464 \mathrm{psi})$ \\
\hline
\end{tabular}

TABLE 10. Concrete failure surfaces (Mbar)

\begin{tabular}{|c|c|c|c|}
\hline pressure (Mbar) & $\begin{array}{l}\text { maximum } \\
\text { strength (Mbar) }\end{array}$ & $\begin{array}{l}\text { pressure } \\
\text { (Mbar) }\end{array}$ & $\begin{array}{l}\text { residual strength } \\
\text { (Mbar) }\end{array}$ \\
\hline-1.0 & 0.0 & -1.0 & 0.0 \\
\hline$-3.0 \mathrm{e}-05$ & 0.0 & 0.0 & 0.0 \\
\hline 0 & 0.000134207 & 0 & 0.0 \\
\hline 0.0002069 & 0.000562447 & 0.0002069 & 0.000417465 \\
\hline 0.0005 & 0.00106821 & 0.0005 & 0.000874153 \\
\hline 0.001 & 0.001735847 & 0.001 & 0.001423964 \\
\hline 0.002 & 0.002626667 & 0.002 & 0.00207721 \\
\hline 0.003 & 0.003193933 & 0.003 & 0.002452192 \\
\hline 0.004 & 0.003586828 & 0.004 & 0.00269549 \\
\hline 0.005 & 0.003875042 & 0.005 & 0.00286611 \\
\hline 0.006 & 0.004095492 & 0.006 & 0.002992384 \\
\hline 0.007 & 0.004269563 & 0.007 & 0.003089614 \\
\hline 0.008 & 0.004410498 & 0.008 & 0.003166787 \\
\hline 0.009 & 0.004526936 & 0.009 & 0.003229528 \\
\hline 0.01 & 0.004624754 & 0.01 & 0.00328154 \\
\hline 0.015 & 0.004946218 & 0.015 & 0.003448137 \\
\hline 0.02 & 0.005124849 & 0.02 & 0.003537944 \\
\hline 1.0 & 0.005124849 & 1.0 & 0.003537944 \\
\hline
\end{tabular}


TABLE 11. Density vs. crush pressure

\begin{tabular}{|c|c|}
\hline Density & crush pressure \\
\hline $2.170000 \mathrm{e}+00$ & $1.965815 \mathrm{e}-03$ \\
\hline $2.223552 \mathrm{e}+00$ & $2.040947 \mathrm{e}-03$ \\
\hline $2.277103 e+00$ & $2.128210 \mathrm{e}-03$ \\
\hline $2.330655 \mathrm{e}+00$ & $2.313926 \mathrm{e}-03$ \\
\hline $2.384207 \mathrm{e}+00$ & $3.194372 \mathrm{e}-03$ \\
\hline $2.437759 \mathrm{e}+00$ & $5.283355 \mathrm{e}-03$ \\
\hline $2.491310 \mathrm{e}+00$ & $8.637741 \mathrm{e}-03$ \\
\hline $2.544862 \mathrm{e}+00$ & $1.313209 \mathrm{e}-02$ \\
\hline $2.598414 \mathrm{e}+00$ & $1.861119 \mathrm{e}-02$ \\
\hline $2.651966 \mathrm{e}+00$ & $2.595234 \mathrm{e}-02$ \\
\hline $2.705517 \mathrm{e}+00$ & $3.405108 \mathrm{e}-02$ \\
\hline $2.759069 \mathrm{e}+00$ & $4.304677 \mathrm{e}-02$ \\
\hline $2.812621 \mathrm{e}+00$ & $5.367771 \mathrm{e}-02$ \\
\hline $2.866172 \mathrm{e}+00$ & $6.431914 \mathrm{e}-02$ \\
\hline $2.919724 \mathrm{e}+00$ & $7.490655 \mathrm{e}-02$ \\
\hline 2.977330328 & $8.542928 \mathrm{e}-02$ \\
\hline 3.039748792 & $9.590160 \mathrm{e}-02$ \\
\hline 3.107923005 & $1.063485 \mathrm{e}-01$ \\
\hline 3.182717163 & $1.167962 \mathrm{e}-01$ \\
\hline 3.264392077 & $1.272606 \mathrm{e}-01$ \\
\hline 3.351897378 & $1.377500 \mathrm{e}-01$ \\
\hline 3.442343767 & $1.482654 \mathrm{e}-01$ \\
\hline 3.53169518 & $1.588100 \mathrm{e}-01$ \\
\hline 3.616530785 & $1.694012 \mathrm{e}-01$ \\
\hline 3.695278287 & $1.800851 \mathrm{e}-01$ \\
\hline
\end{tabular}


TABLE 11. Density vs. crush pressure

\begin{tabular}{|l|l|}
\hline Density & crush pressure \\
\hline 3.768014317 & $1.909394 \mathrm{e}-01$ \\
\hline 3.835829102 & $2.020894 \mathrm{e}-01$ \\
\hline 3.900445462 & $2.137473 \mathrm{e}-01$ \\
\hline 3.960535143 & $2.256753 \mathrm{e}-01$ \\
\hline 4.017783834 & $2.380718 \mathrm{e}-01$ \\
\hline
\end{tabular}

TABLE 12. Coefficients for 7-term polynomial EOS

\begin{tabular}{|l|l|}
\hline$A_{0}$ & 0 \\
\hline$A_{1}$ & 0.85 \\
\hline$A_{2}$ & -1.71 \\
\hline$A_{3}$ & 2.08 \\
\hline$B_{0}$ & 0.0 \\
\hline$B_{1}$ & 0.0 \\
\hline$B_{2}$ & 0.0 \\
\hline
\end{tabular}




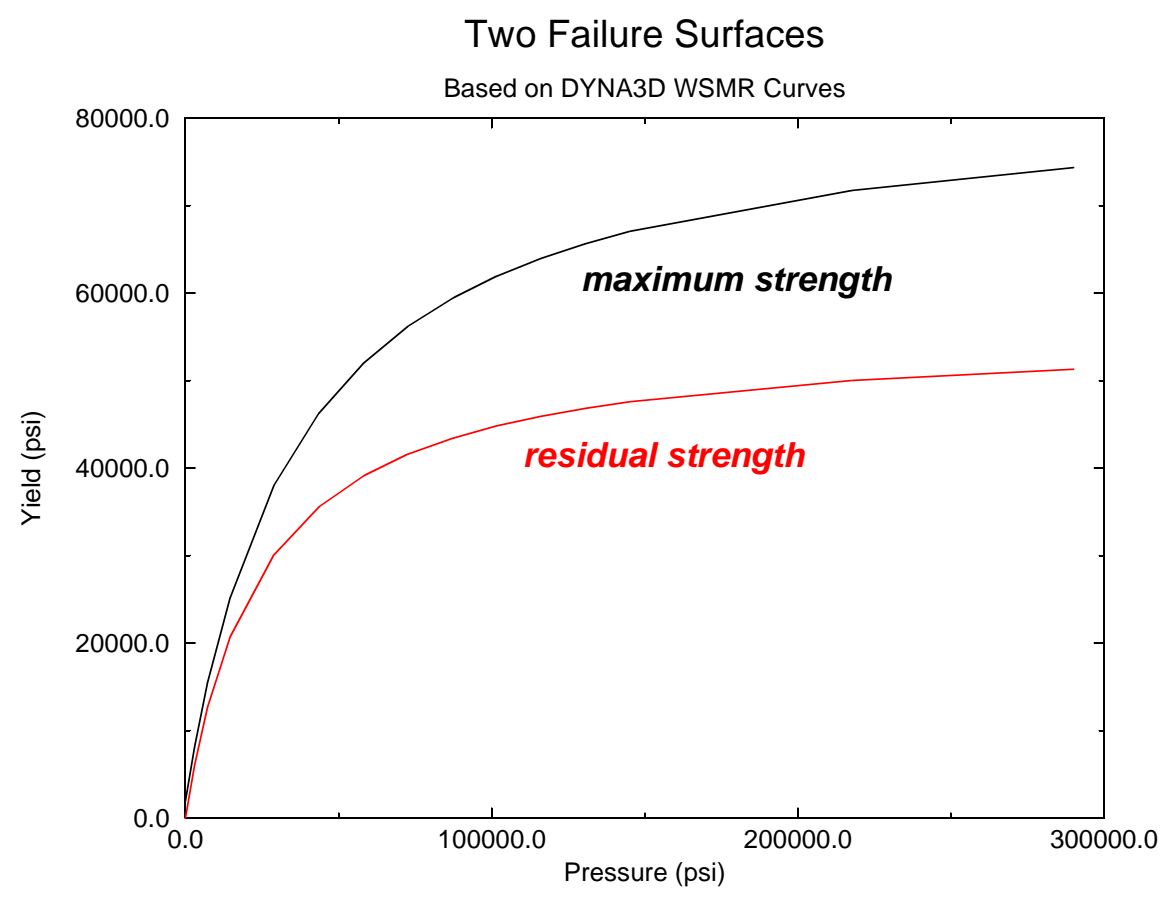

FIGURE 15. Compressive meridians for WSMR-5 3/4 concrete based on DYNA3D failure surfaces.

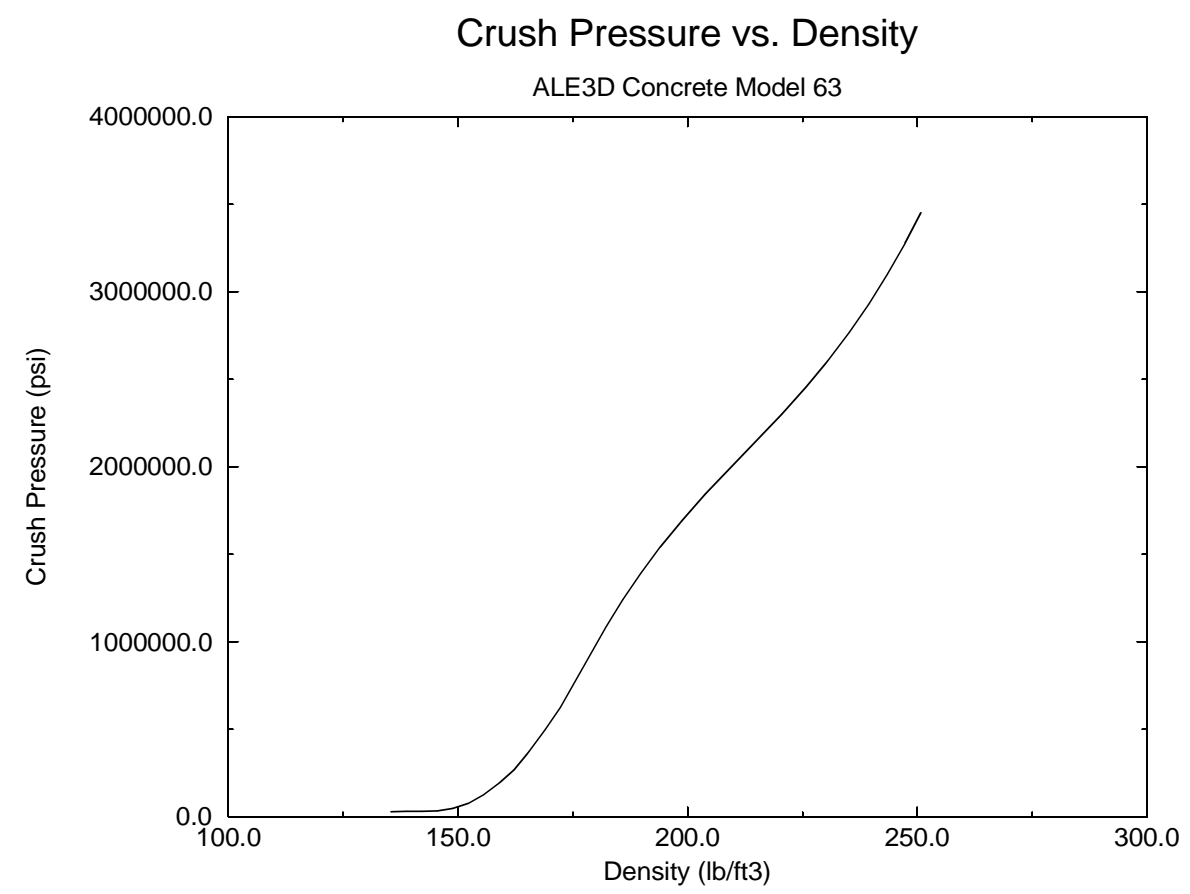

FIGURE 16. Crush pressure vs. density plot. 

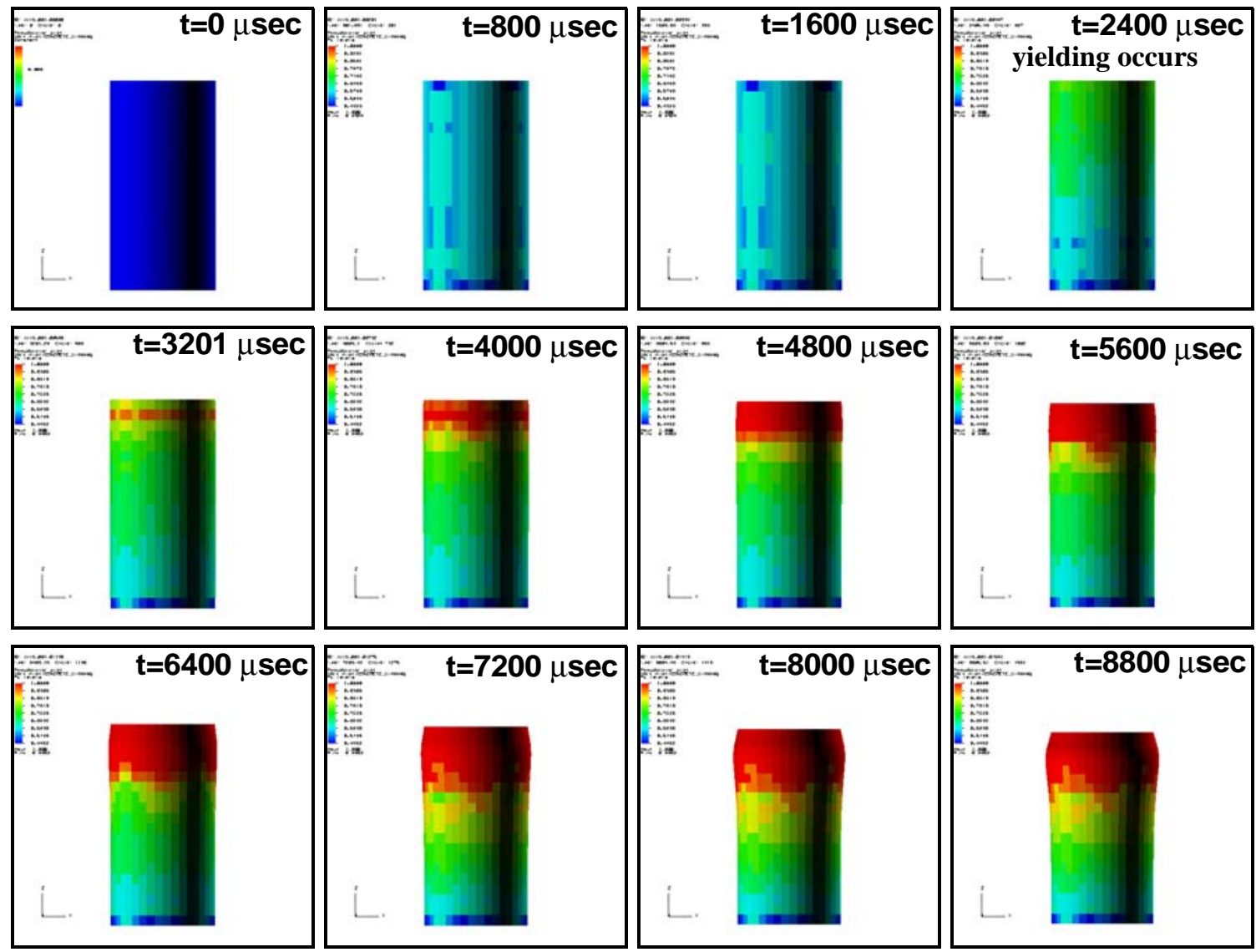

damage

FIGURE 17. Evolution of damage for unconfined uniaxial compression test in which the pressure load curve specified compressive yield should occur after $2000 \mu$ sec. 


\subsection{SAC5 Concrete}

TABLE 13. ALE3D material parameters (gm, cm, $\mu \mathrm{sec}$, Mbar)

\begin{tabular}{|l|l|}
\hline minimum pressure & $-1.0(-14.5 \mathrm{e}+06 \mathrm{psi})$ \\
\hline reference density & $2.68\left(165 \mathrm{lbs} / \mathrm{ft}^{3}\right)$ \\
\hline initial value of relative volume & 1.1652174 \\
\hline initial value of energy & 0.0 \\
\hline $\begin{array}{l}\text { quadratic coefficient of artifi- } \\
\text { cial viscosity }\end{array}$ & 0.75 \\
\hline hourglass viscosity coefficient & 0.1 \\
\hline $\begin{array}{l}\text { linear coefficient of artificial } \\
\text { viscosity }\end{array}$ & 0.3 \\
\hline plastic strain at failure & 2.5 \\
\hline
\end{tabular}

TABLE 14. ALE3D engineering parameters (gm, cm, $\mu \mathrm{sec}$, Mbar)

\begin{tabular}{|l|l|}
\hline initial porosity & 0.142 \\
\hline $\begin{array}{l}\text { scalar shear modulus of initial } \\
\text { material }\end{array}$ & $0.13(1.885 \mathrm{e}+06 \mathrm{psi})$ \\
\hline damage rate multiplier & 0.5 \\
\hline $\begin{array}{l}\text { scalar yield strength at zero pres- } \\
\text { sure }\end{array}$ & $3.79 \mathrm{e}-04(5500 \mathrm{psi})$ \\
\hline $\begin{array}{l}\text { failure on compressive principal } \\
\text { stress }\end{array}$ & $3.79-04(5500 \mathrm{psi})$ \\
\hline failure on principal tensile stress & $-2.5 \mathrm{e}-05(-363 \mathrm{psi})$ \\
\hline
\end{tabular}


TABLE 15. Concrete failure surfaces (Mbar)

\begin{tabular}{|c|c|c|c|}
\hline pressure (Mbar) & $\begin{array}{l}\text { maximum } \\
\text { strength (Mbar) }\end{array}$ & $\begin{array}{l}\text { pressure } \\
\text { (Mbar) }\end{array}$ & $\begin{array}{l}\text { residual strength } \\
\text { (Mbar) }\end{array}$ \\
\hline-1.0 & 0.0 & -1.0 & 0.0 \\
\hline$-3.0 \mathrm{e}-05$ & 0.0 & 0.0 & 0.0 \\
\hline 0 & 0.000151172 & 0 & 0.0 \\
\hline 0.0002069 & 0.000542746 & 0.0002069 & 0.000417465 \\
\hline 0.0005 & 0.001011262 & 0.0005 & 0.000874153 \\
\hline 0.001 & 0.001639999 & 0.001 & 0.001423964 \\
\hline 0.002 & 0.002497654 & 0.002 & 0.00207721 \\
\hline 0.003 & 0.003055307 & 0.003 & 0.002452192 \\
\hline 0.004 & 0.003446934 & 0.004 & 0.00269549 \\
\hline 0.005 & 0.003737073 & 0.005 & 0.00286611 \\
\hline 0.006 & 0.003960648 & 0.006 & 0.002992384 \\
\hline 0.007 & 0.004138209 & 0.007 & 0.003089614 \\
\hline 0.008 & 0.004282636 & 0.008 & 0.003166787 \\
\hline 0.009 & 0.004402411 & 0.009 & 0.003229528 \\
\hline 0.01 & 0.004503351 & 0.01 & 0.00328154 \\
\hline 0.015 & 0.004837135 & 0.015 & 0.003448137 \\
\hline 0.02 & 0.005023992 & 0.02 & 0.003537944 \\
\hline 1.0 & 0.005023992 & 1.0 & 0.003537944 \\
\hline
\end{tabular}

TABLE 16. Density vs. crush pressure

\begin{tabular}{|l|l|}
\hline Density & crush pressure \\
\hline $2.170000 \mathrm{e}+00$ & $1.965815 \mathrm{e}-03$ \\
\hline $2.223552 \mathrm{e}+00$ & $2.040947 \mathrm{e}-03$ \\
\hline
\end{tabular}


TABLE 16. Density vs. crush pressure

\begin{tabular}{|c|c|}
\hline Density & crush pressure \\
\hline $2.277103 e+00$ & $2.128210 \mathrm{e}-03$ \\
\hline $2.330655 \mathrm{e}+00$ & $2.313926 \mathrm{e}-03$ \\
\hline $2.384207 \mathrm{e}+00$ & $3.194372 \mathrm{e}-03$ \\
\hline $2.437759 \mathrm{e}+00$ & $5.283355 \mathrm{e}-03$ \\
\hline $2.491310 \mathrm{e}+00$ & $8.637741 \mathrm{e}-03$ \\
\hline $2.544862 \mathrm{e}+00$ & $1.313209 \mathrm{e}-02$ \\
\hline $2.598414 \mathrm{e}+00$ & $1.861119 \mathrm{e}-02$ \\
\hline $2.651966 \mathrm{e}+00$ & $2.595234 \mathrm{e}-02$ \\
\hline $2.705517 \mathrm{e}+00$ & $3.405108 \mathrm{e}-02$ \\
\hline $2.759069 \mathrm{e}+00$ & $4.304677 \mathrm{e}-02$ \\
\hline $2.812621 \mathrm{e}+00$ & $5.367771 \mathrm{e}-02$ \\
\hline $2.866172 \mathrm{e}+00$ & $6.431914 \mathrm{e}-02$ \\
\hline $2.919724 \mathrm{e}+00$ & $7.490655 \mathrm{e}-02$ \\
\hline 2.977330328 & $8.542928 \mathrm{e}-02$ \\
\hline 3.039748792 & $9.590160 \mathrm{e}-02$ \\
\hline 3.107923005 & $1.063485 \mathrm{e}-01$ \\
\hline 3.182717163 & $1.167962 \mathrm{e}-01$ \\
\hline 3.264392077 & $1.272606 \mathrm{e}-01$ \\
\hline 3.351897378 & $1.377500 \mathrm{e}-01$ \\
\hline 3.442343767 & $1.482654 \mathrm{e}-01$ \\
\hline 3.53169518 & $1.588100 \mathrm{e}-01$ \\
\hline 3.616530785 & $1.694012 \mathrm{e}-01$ \\
\hline 3.695278287 & $1.800851 \mathrm{e}-01$ \\
\hline 3.768014317 & $1.909394 \mathrm{e}-01$ \\
\hline 3.835829102 & $2.020894 \mathrm{e}-01$ \\
\hline 3.900445462 & $2.137473 \mathrm{e}-01$ \\
\hline
\end{tabular}


TABLE 16. Density vs. crush pressure

\begin{tabular}{|l|l|}
\hline Density & crush pressure \\
\hline 3.960535143 & $2.256753 \mathrm{e}-01$ \\
\hline 4.017783834 & $2.380718 \mathrm{e}-01$ \\
\hline
\end{tabular}

TABLE 17. Coefficients for 7-term polynomial EOS

\begin{tabular}{|l|l|}
\hline$A_{0}$ & 0 \\
\hline$A_{1}$ & 0.85 \\
\hline$A_{2}$ & -1.71 \\
\hline$A_{3}$ & 2.08 \\
\hline$B_{0}$ & 0.0 \\
\hline$B_{1}$ & 0.0 \\
\hline$B_{2}$ & 0.0 \\
\hline
\end{tabular}




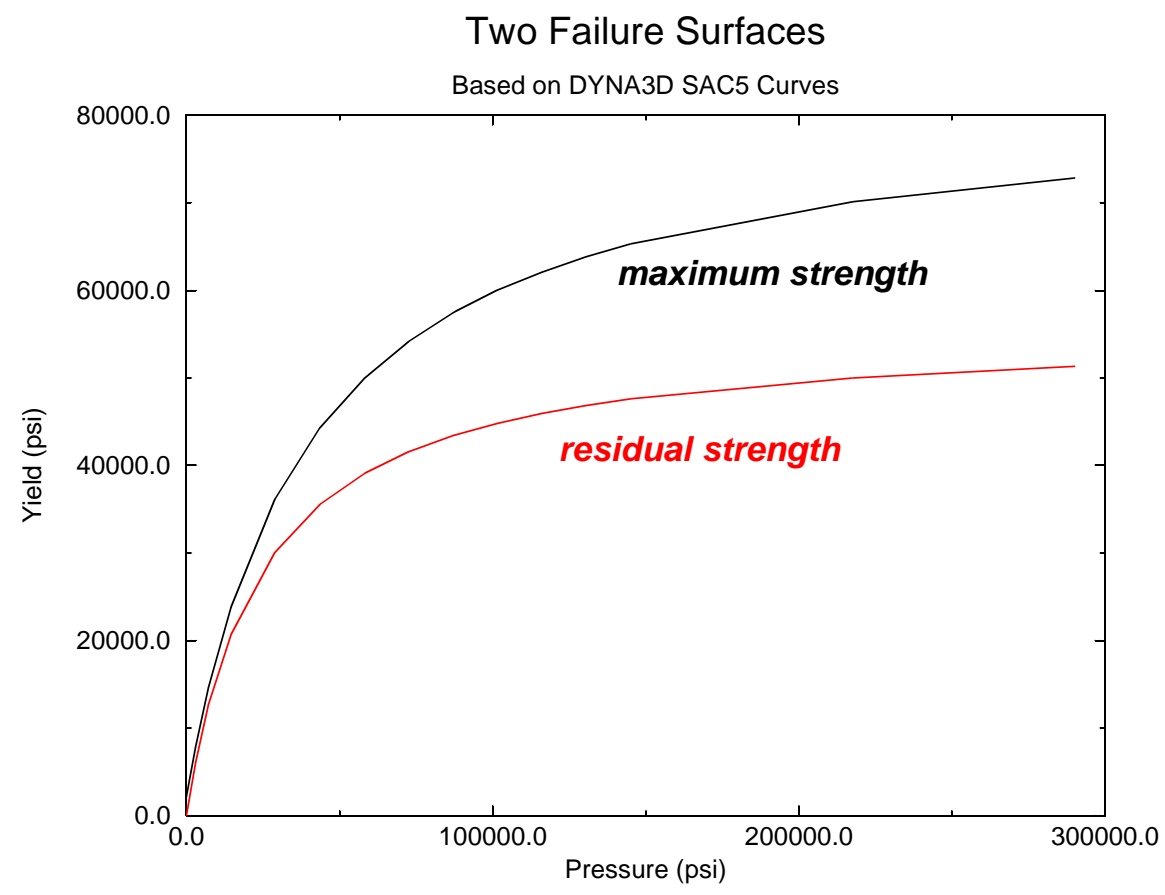

FIGURE 18. Compressive meridians for SAC5 concrete based on DYNA3D failure surfaces.

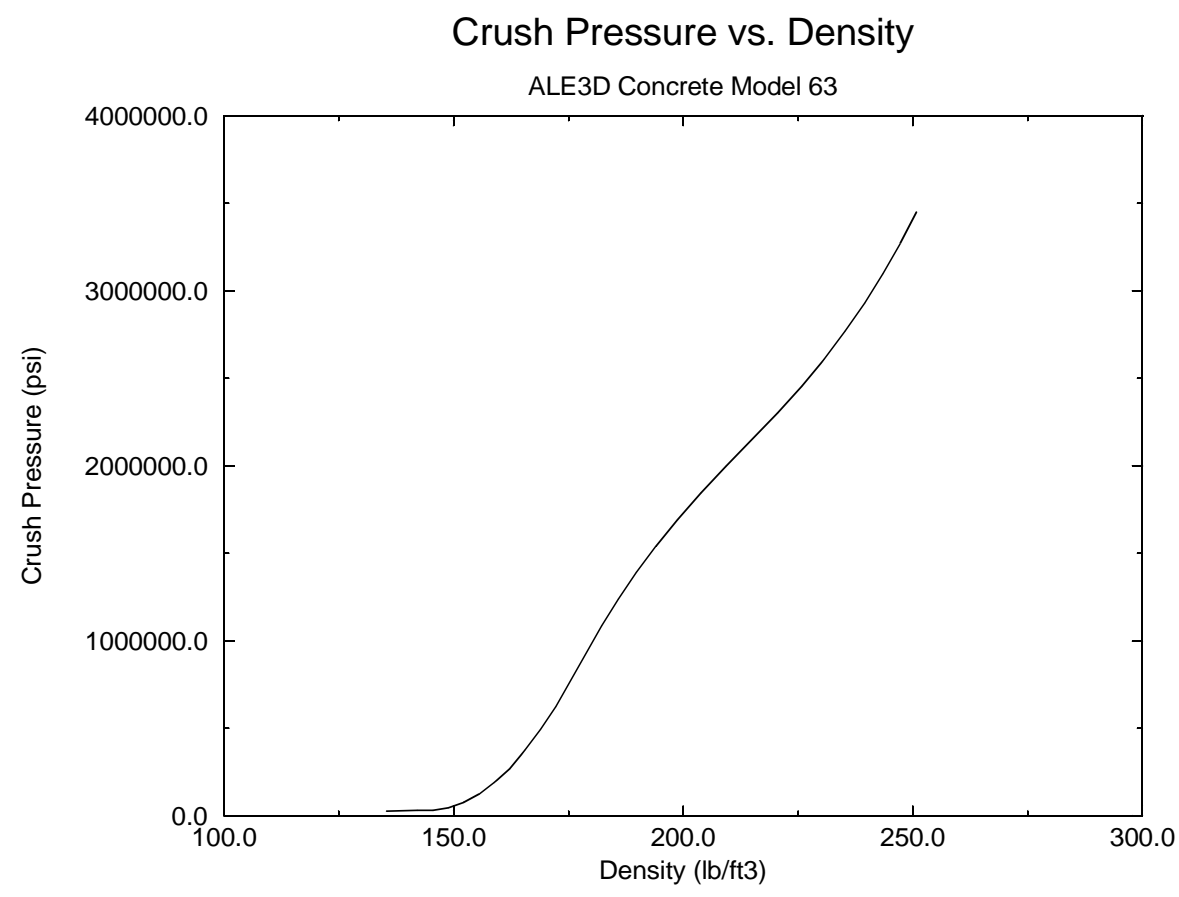

FIGURE 19. Crush pressure vs. density plot. 

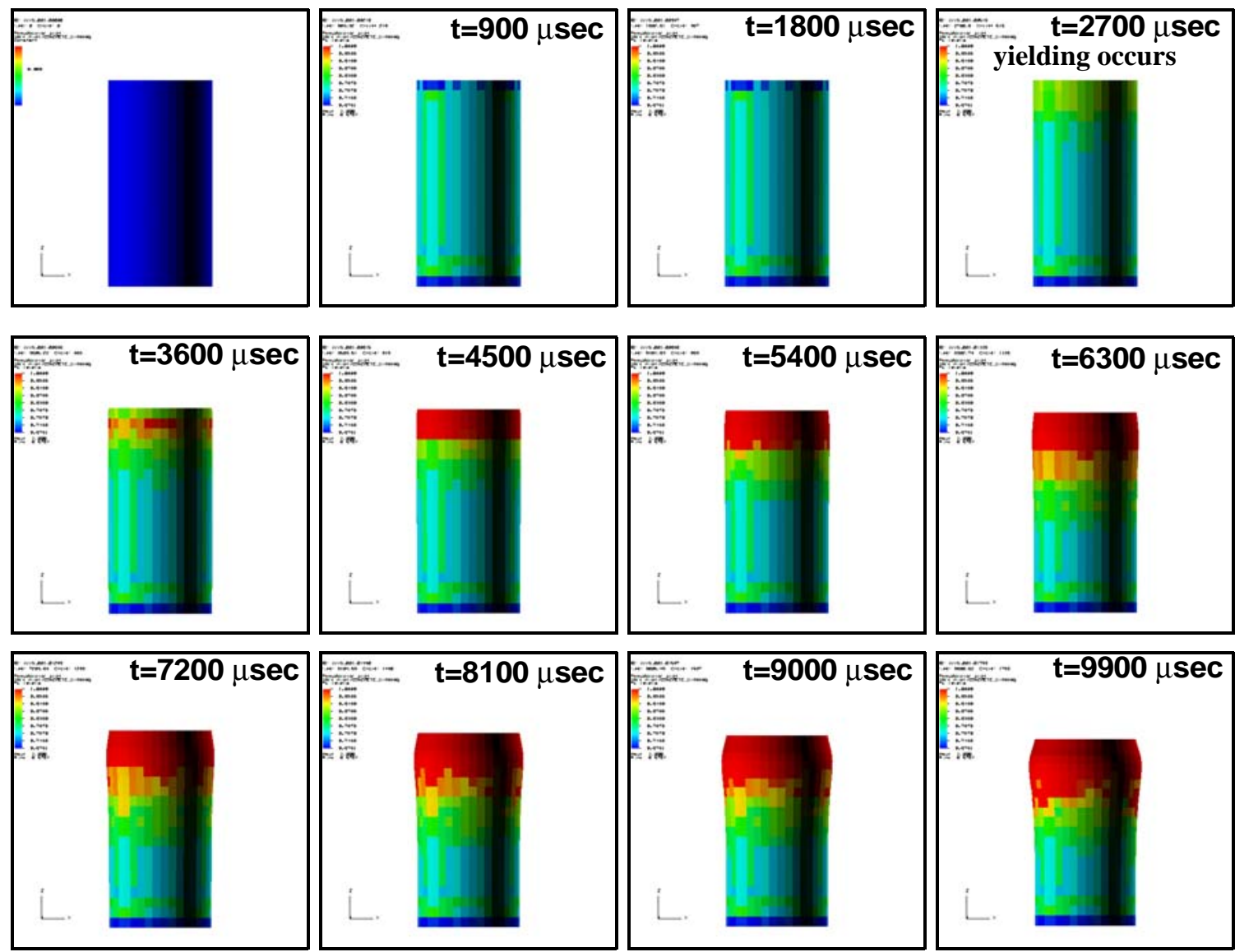

damage

FIGURE 20. Evolution of damage for unconfined uniaxial compression test in which the pressure load curve specified compressive yield should occur after $2000 \mu$ sec. 


\subsection{References}

1. Dube, E., Neely, R., Nichols, A., Sharp, R., Couch, R., Users Manual for ALE3D: An Arbitrary Lagrange/Eulerian 3D Code System, Lawrence Livermore National Laboratory, Version 2.6.3, May 19, 1999.

\subsection{CALE Concrete Material Model Verification}

A calculation to verify the CALE concrete material model input parameters was completed as part of this study. The CALE equation of state (EOS) form 13 TEPLA-F pourous material EOS with arbitrary crush curve was used to model the concrete. This equation of state features a pressure dependent yield and residual strength curve with failure criterion based on the tensile and compressive principal stress as well as the effective plastic strain in the material. The equation of state is outlined in Figure 21 and more details of the formulation can be found in the CALE users manual.

\begin{tabular}{|c|c|c|}
\hline \multirow{3}{*}{$\begin{array}{l}\text { Concrete: } \\
\text { TEPLA-F Porous Material EOS w/ Arbitrary Crush Curve } \\
\text { Equations: }\end{array}$} & \multicolumn{2}{|l|}{ Key: } \\
\hline & $\mathbf{P}_{\text {total }}$ & Total Pressure \\
\hline & & \\
\hline$\rho$ & $\theta$ & Porosity \\
\hline $1-\theta$ & $\mathbf{P}_{\mathrm{s}}$ & Solid Pressure \\
\hline$\mu=\frac{\rho_{s}}{\rho_{R E F}}-1$ & $\rho_{\mathrm{s}}$ & Solid Density \\
\hline $\begin{array}{l}P_{S}=A_{0}+A_{1} * \mu+A_{2} * \mu^{2}+A_{3} * \mu^{3}+\left(B_{0}+B_{1} * \mu+B_{2} * \mu^{2}\right) * E \\
P_{C}(\rho)=\text { Specified_by_user_in_form_of_curve }\end{array}$ & $\mathbf{P}_{\mathbf{c}}$ & Compaction Pressure \\
\hline$P_{\text {Total }}=P_{S} *(1-\theta)^{E X}$ & $\rho$ & Current Density \\
\hline$\bullet 8$ Coefficients & $\rho_{\text {ref }}$ & Reference Density \\
\hline - Two yield curves (yield vs. pressure, residual strength vs. pressure) & $\mathbf{E x}$ & User Specific Exponent \\
\hline - Failure criterion (tensile and compressive principal stress, EPS) & & \\
\hline
\end{tabular}

FIGURE 21. CALE TEPLA-F Porous Material EOS w/ Arbitrary Crush Curve

The verification simulation focused on insuring that an unconfined compression test sample of concrete would fail at a designated stress state. The plots on the left in Figure 22 illustrate the stress and strain time histories for a tracer particle on the axis of the concrete sample. A corresponding total vertical stress strain plot for the concrete section through the tracer particle is plotted in the same figure on the right. The graphic in Figure 23 illustrates the state of damage in the sample where white indicates no-damage and pink indicates failure. Note that the material at the tracer location fails and falls to it's residual strength curve prior to the entire section failing. This simulation verifies that the concrete section is behaving reasonably in compression from yield to failure. 


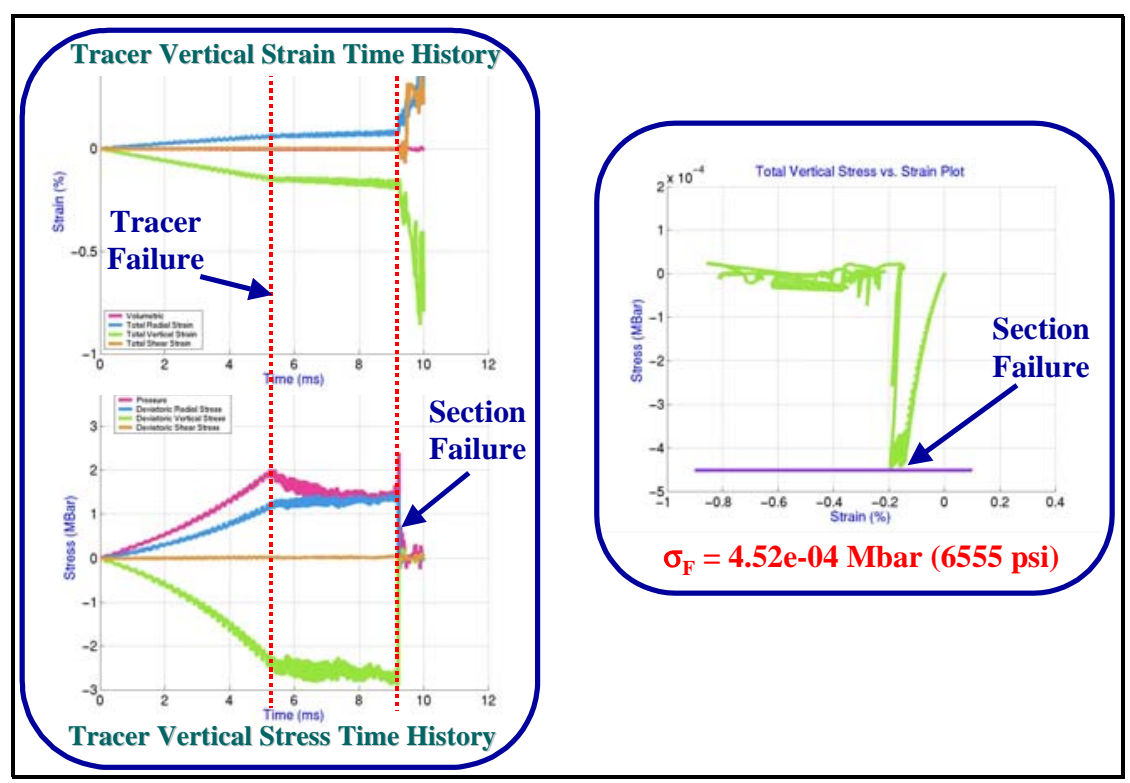

FIGURE 22. CALE stress and strain time history plots for concrete in an unconfined compression test

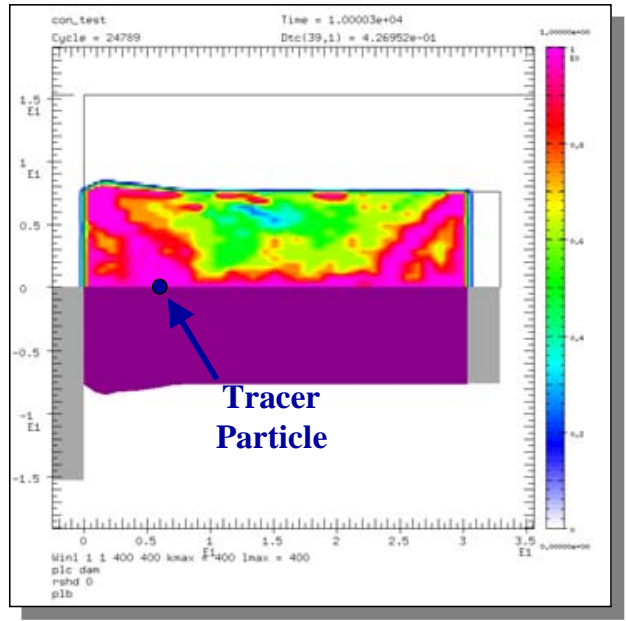

Damage Parameter Accumulation

\section{Color Scale}

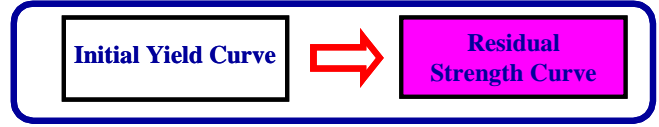

FIGURE 23. CALE damage parameter plot for concrete in an unconfined compression test 


\section{Homogenized Rebar Model}

\subsection{Background}

Accurately simulating the effects of reinforced concrete structures subjected to extreme events (e.g. blast or aircraft impact) in an efficient and timely manner continues to be extremely challenging. Currently, LLNL has the capability of simulating the complex behavior of reinforced concrete by explicitly modeling the rebar using either 2-node (beam) or 8-node (brick) elements and modeling the concrete using 8-node elements. There are inherent problems, though, with these modeling techniques. Beam elements do not account for the 3-dimensional effects of the rebar. For example, under extreme loading conditions, the concrete is able to flow around the beam element, because it lacks dimension. Brick elements include the 3-dimensional effects but require significantly more degrees of freedom than the beam elements, as fine zoning is required to capture the geometry of the rebar.

While Bricks are costly in terms of degrees of freedom, they allow the use of slide surfaces that can model the bond strength between the rebar and concrete. Sometimes it is necessary to use an ALE formulation to perform parts or all of the structural analysis and it is currently easier to run an ALE problem if the model is restricted to using only brick elements. Modeling the rebar explicitly with brick elements quickly becomes cost-prohibitive, however, for many problems of interest. For example, simulating the response of an entire building requires more computing capacity than is normally available. Even when the problem size can be accommodated, the turnaround time may be prohibitive, especially if multiple analyses are required.

In other words, we need the capability to determine the response of a reinforced concrete structure efficiently while maintaining sufficient accuracy. We would like not only to reduce computational effort, but also to simplify and speed up the mesh generation process. With greater efficiency in mesh generation and computation, the analyst would have more time to perform parameter studies and validation studies.

\subsection{Homogenized Rebar Model}

To assist the engineer in modeling reinforced concrete more efficiently, a composite $\mathrm{K} \& \mathrm{C}$ (Karagozian \& Case) Concrete model with homogenized rebar has been coded in ALE3D. This model gives the engineer the capability to simulate strain-rate dependencies, workhardening, and tensile failure for rebar embedded in concrete. This material models concrete with rebar up to three arbitrary directions at any location, each of which may have differing material properties and cross-sectional areas. The $\mathrm{K} \& \mathrm{C}$ concrete model is used to model the concrete and is augmented with a rebar model. The axial load within the rebar is calculated using the material properties of the rebar, its strain history, its strain rate, and the stress in the concrete. Only the axial response in the rebar is considered, while bending and shear are neglected. 
In order to give confidence in the rebar/concrete formulation for simulating blast effects on reinforced concrete structures, a number of validation studies have been completed to date. The first study considers an air blast against a highly reinforced concrete wall that undergoes light damage. In other words, no breaching of the concrete wall occurs for the first validation study. The second validation study considers a different regime of loading. The loading in the second study consists of extreme overpressures where physical breaching of the reinforced concrete wall occurs. In addition, the walls in the second study were lightly reinforced and the study evaluated the effects of reinforced concrete walls to air, atwater, and underwater contact bursts.

\subsection{Material Model Formulation}

The evolution of the rebar configuration is calculated based on a vector, $r$, that is aligned with the rebar and the velocity gradient, $L$, as follows,

$$
\dot{r}_{i}=L_{i j} r_{j}
$$

The current value of $r$ is found by integrating $\dot{r}$ in time,

$$
r_{i}=r_{i}^{0}+\int_{t}^{\dot{r}_{j}} d t
$$

Where $t$ is time, and $r^{0}$ is a vector initially aligned with the rebar.

The total strain, $\varepsilon$, is calculated from the current configuration of $r$ as follows,

$$
\varepsilon=\ln \left(\frac{|r|}{\mid r^{0}}\right)
$$

This strain is partitioned into an elastic component, $\varepsilon_{e}$, and a plastic component, $\varepsilon_{p}$. The elastic strain is recovered in a zero stress state.

$$
\varepsilon=\varepsilon_{e}+\varepsilon_{p}
$$

Work hardening is assumed to occur for both positive and negative plastic deformations. Therefore, an effective plastic strain, $\varepsilon_{e p}$, is defined and evolves as,

$$
\dot{\varepsilon}_{e p}=\left|\dot{\varepsilon}_{p}\right|
$$

The rebar material model uses both a power law work hardening model and a power law strain rate hardening model. The yield surface is defined as follows,

$$
\sigma^{\prime} \leq \sigma_{y}^{0}\left(1+\beta\left(\varepsilon_{e p}+\varepsilon_{e p}^{0}\right)\right)^{n}\left(1+\frac{\dot{\varepsilon}_{e p}}{\dot{\varepsilon}_{r e f}}\right)^{m}
$$


Where $\sigma^{\prime}$ is the von Mises stress, $\sigma_{y}^{0}$ is the initial yield stress, $\varepsilon_{e p}^{0}$ is the initial effective plastic strain, $\beta$ and $n$ are work hardening material parameters, and $\dot{\varepsilon}_{r e f}$ and $m$ are strain rate hardening material parameters.

The axial stress $\sigma_{a}$ in the rebar evolves as follows,

$$
\dot{\sigma}_{a}=E \dot{\varepsilon}_{e}+v\left(\dot{\sigma}_{t 1}+\dot{\sigma}_{t 2}\right)
$$

Where $\dot{\sigma}_{t 1}$ and $\dot{\sigma}_{t 2}$ are normal stresses in the concrete that are transverse to the rebar and orthogonal to each other.

The von Mises stress in the rebar is calculated in three different ways depending on the rebar-concrete coupling assumptions the user wishes to make. The von Mises stress is calculated from a stress tensor that includes,

a) Only the axial stress in the rebar or,

b) Only the axial stress in the rebar and the confining stress, $\frac{\left(\sigma_{t 1}+\sigma_{t 2}\right)}{2}$, due to the
concrete or,

c) The full stress tensor from the concrete, with the normal stress in the direction of the rebar replaced with the axial stress of the rebar. This formulation allows the shear stress in the concrete to contribute to the yielding of the rebar.

Equations 4-7 are solved iteratively and the axial stress in the rebar is found.

The homogenized rebar-concrete stress tensor is found by first calculating the normal stress in the concrete in the direction of the rebar axis. This stress and the rebar axial stress are now combined with the volume fraction rule to calculate a homogenized normal stress in the direction of the rebar. This homogenized stress is used to overwrite the corresponding stress value in the concrete stress tensor, resulting in a homogenized stress tensor. Thus, in the axial direction the stresses add as a simple volume, and in the lateral directions, the rebar has no effect.

\subsection{Validation Example No. 1}

During 2002, the US Army Engineer Research \& Development Center (ERDC) performed a series of tests on air-backed RC walls subjected to conventional cased and uncased high explosives. The tests were intended to provide data for validating the latest air-backed wall-response model implemented in the Integrated Munitions Effects Assessment tool (Applied Research Associates, 2004) [Ref. 1]. Figure 24 shows the test wall setup as well as a computational comparison of the concrete damage between a model with no rebar, a Paradyn model with rebar modeled using beam elements, and an ALE3D model with the 
rebar modeled using the homogenized rebar model described above. The concrete damage plots are taken at the mid-section of the concrete wall. As is evident in the figure, if one does not model the rebar at all, severe damage occurs to the wall. This plot shows that rebar is necessary to accurately simulate the concrete damage that occurs in the actual experiment. Comparing the Paradyn beam model and the ALE3D homogenized rebar model, it is clear that you can achieve similar results with the homogenized rebar model as with the Paradyn beam model. Slight differences do occur when using the homogenized rebar model, however. The most noticeable difference is that the homogenized rebar simulation does not predict the same amount of damage in the support as compared to the Paradyn beam simulation. This is due to the fact that shear is neglected in the homogenized rebar model.

Figure 25 shows a comparison of the back face wall damage between a Paradyn model with rebar modeled using resultant beams, a Paradyn model with rebar modeled using integrated beams, a Paradyn model with rebar modeled using brick elements, an ALE3D model with rebar modeled using brick elements, and an ALE3D model with rebar modeled using the homogenized rebar model. The ALE3D model with rebar modeled using the homogenized rebar model predicted very similar concrete damage to the damage predicted by the other computational models. In addition to predicting similar damage, the amount of time to build a computational mesh of the brick rebar models was approximately 7 days, whereas it took only a half a day to build the mesh for the homogenized rebar model. 


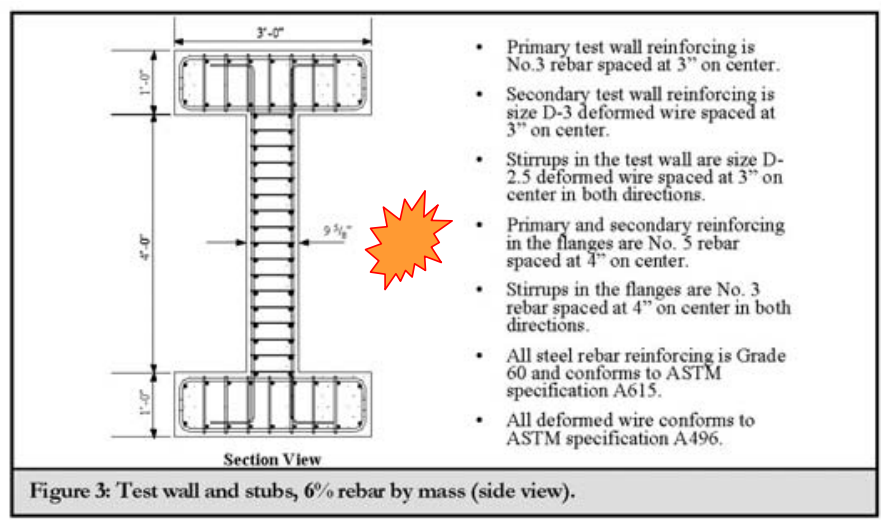

'Precision Test Wall Study: Modeling a U.S. ArmyERDC Test of a Blast Loaded RC Wall'. Arden Anderson. LLNL. August

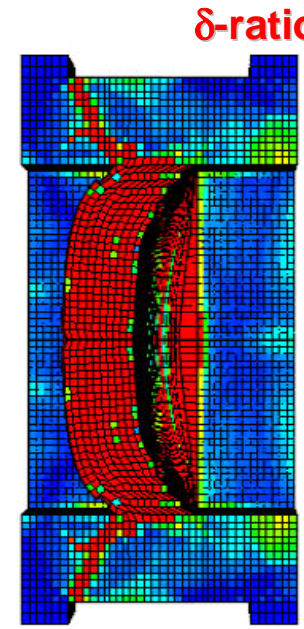

No Rebar Modeled

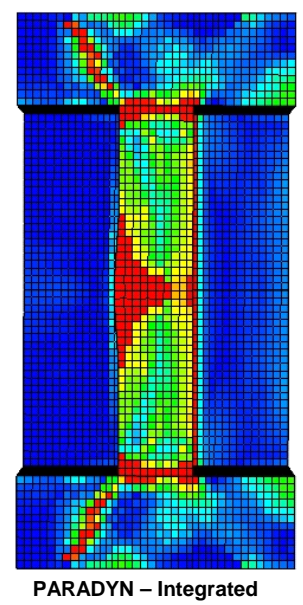

Beams
2004.

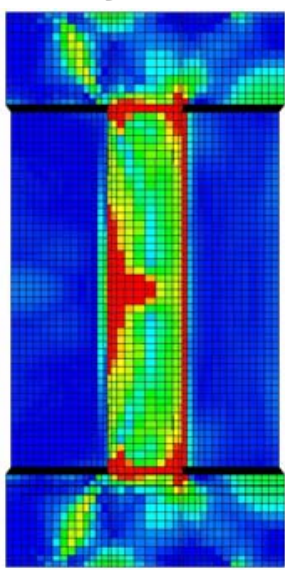
ALE3D - Homogenized
Elements

Models and simulations provided by A. Anderson, DSAG, LLNL

FIGURE 24. Precision test wall study description and computational comparison of concrete damage at mid-section of wall. 

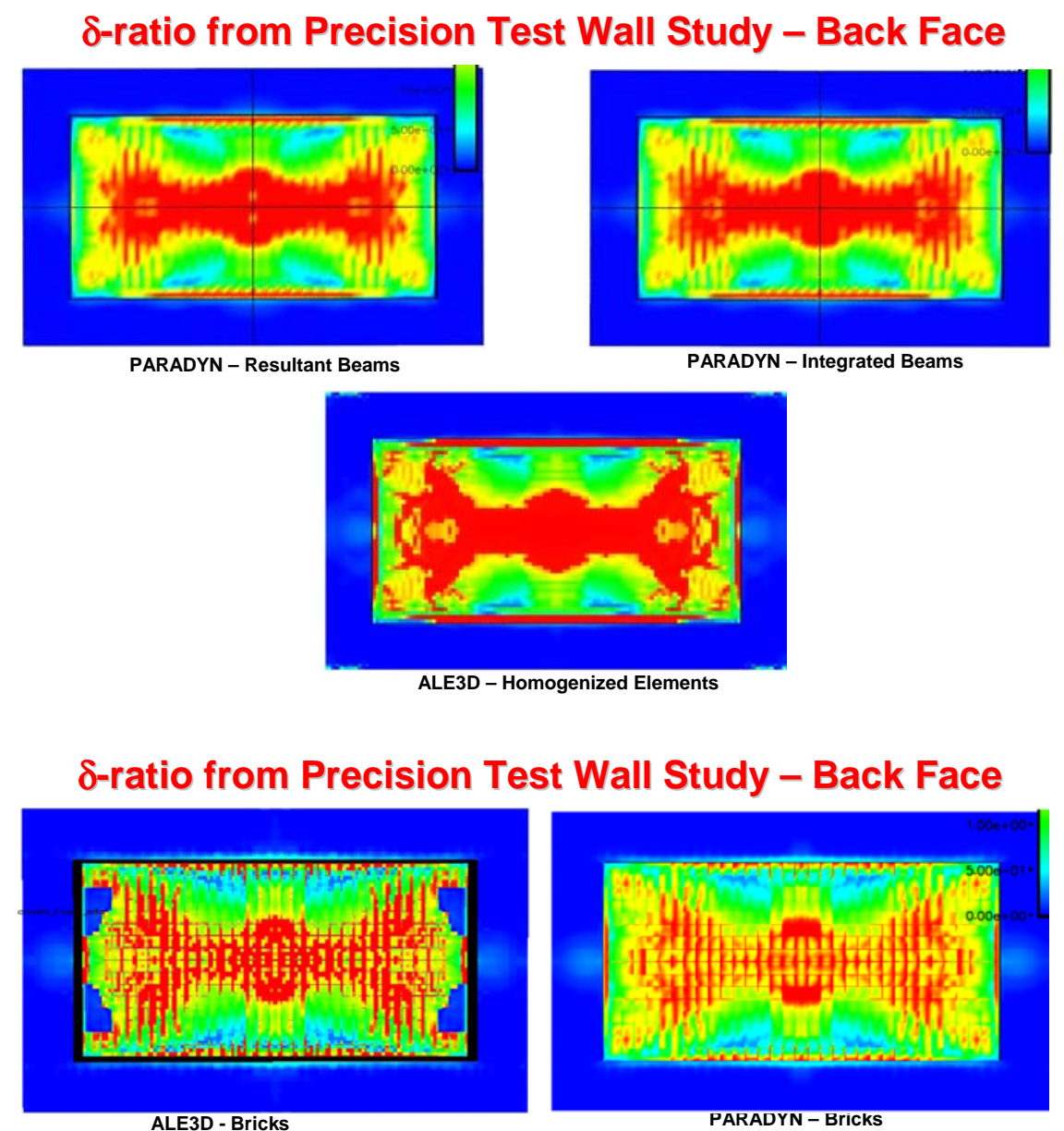

Mesh Generation for Brick Models: $\sim 7$ days

Mesh Generation for Homogenized Element Model: $\sim 1 / 2$ day

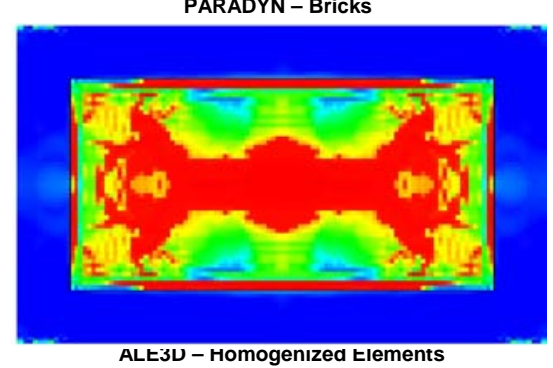

FIGURE 25. Precision test wall study computational comparison of concrete damage at backface of wall.

\subsection{Validation Example No. 2}

The objective of the experiments described below was to develop damage predictions for contact bursts on reinforced concrete bridge piers. Reinforced concrete piers of 6-, 10-, and 20-inch thicknesses were constructed and subjected to contact bursts of spherical TNT charges that ranged from $1 / 4$ to 50 pounds. Damage prediction curves were developed in order to choose the minimum charge above, at, and below the water surface for pier destruction [Ref. 2]. For this validation study, only the 6" and 10" thick piers were 
evaluated. A brief description of the test layout is given below in Figure 26. The 10" pier was evaluated for a $1 \mathrm{lb}$ contact charge placed at three locations - below water, at water surface, and above water. The 6" pier was evaluated for a $2 \mathrm{lb}$ contact charge placed at the water surface and above water. Figure 27 shows a comparison between the experimental breach diameters to that of the computationally predicted breach diameters. Figure 28 through Figure 30 shows the computationally predicted concrete damage and breach diameters for each simulation. Each plot shows the predicted concrete damage alongside a visualization of the spall criterion (which is a superposition of the concrete damage and velocity of the concrete). Two plots are shown for the spall criterion, one that uses $500 \mathrm{in} /$ $\mathrm{sec}$ for the concrete velocity, and one that uses $750 \mathrm{in} / \mathrm{sec}$ for the concrete velocity. The $500 \mathrm{in} / \mathrm{sec}$ concrete velocity matches better with experiment. By analyzing the results table and the damage plots, it is clear that there is reasonable agreement between the experimental results and the computational results.

Other analyses were completed to determine the effects of modeling no rebar or modeling the rebar explicitly with brick elements. Figure 29 shows a computational comparison of the 10" thick pier (with a $1 \mathrm{lb}$ charge located below the water surface) with rebar modeled using the homogenized rebar and a model with no rebar. Although it is less obvious than the first validation study, there are differences between the two simulations. The rebar tends to stiffen the structure slightly, causing more damage to occur higher up the mid-section of the wall. In addition, when no rebar is modeled, the wall tends to be more dimpled near the blast. Figure 30 shows a comparison between the 6" thick pier with rebar explicitly modeled and with homogenized rebar. Similar damage, breach, and deformation occurs between these two models.

Figure 31 and Figure 32 show the experimental postshot views. By comparing these pictures with the damage plots given in the earlier figures, similar trends and damage occur between experiment and simulation. For instance, the postshot views of the 10" thick pier show major breach for the underwater charge, less damage for the at water surface charge, and even lesser damage for the above water contact charge, which is what is seen the experimental results. 


\section{Contact Burst on Reinforced Concrete Bridge Piers:}

U.S. Army Waterways Experiment Station (WES): DNA PR 0026 (1976)

- Materials:

D HE:

Cast sphere of TNT

- Concrete:

3500 psi compressive strength

- Rebar:

ASTM A615-68 Grade 40 steel

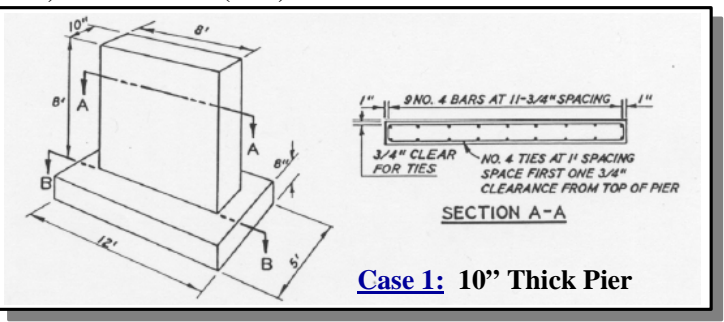

- Variations:

- Charge Position:

Below, above, and at surface

- Pier Thickness:

6" and 10" pier
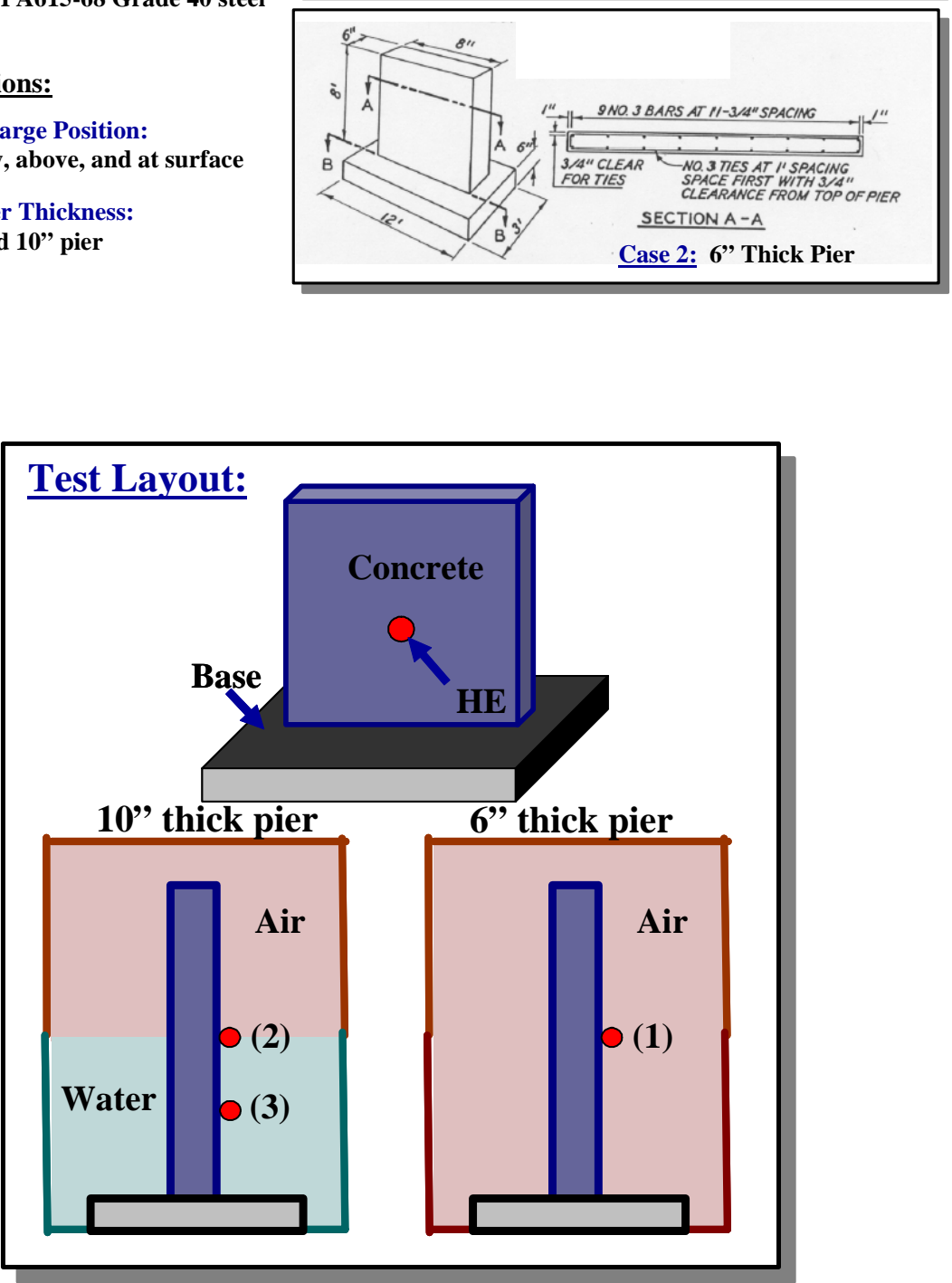

Key: $\square$ Base $\square$ Water $\square$ Air $\square$ RC Wall $\square$ HE

FIGURE 26. Test setup for contact charges placed at different locations on varying thicknesses of $\mathrm{RC}$ bridge piers. 


\section{Results Table:}

\begin{tabular}{|c|c|c|c|c|c|}
\hline & & \multicolumn{4}{|c|}{ Damage Region Diameter } \\
\hline & & \multicolumn{2}{|c|}{ Front Face } & \multicolumn{2}{|c|}{ Back Face } \\
\hline & & Calculation & Experiment & Calculation & Experiment \\
\hline \multirow{3}{*}{$\begin{array}{l}\text { 10" Thick Pier } \\
\text { (1 lb charge) }\end{array}$} & Below water & $\sim 140 \mathrm{~cm}$ & --- & $\sim 140 \mathrm{~cm}$ & $\sim 113.38 \mathrm{~cm}$ \\
\hline & At surface & $\sim 80-85 \mathrm{~cm}$ & --- & $\sim 80-85 \mathrm{~cm}$ & $\sim 82.07 \mathrm{~cm}$ \\
\hline & No water & $\sim 25 \mathrm{~cm}$ & $25.91 \mathrm{~cm}$ & $0 \mathrm{~cm}$ & $0 \mathrm{~cm}$ \\
\hline \multirow{3}{*}{$\begin{array}{l}\text { 6" Thick Pier } \\
\text { (2 lb charge) }\end{array}$} & $\begin{array}{l}\text { At Surface } \\
\text { (Explicit) }\end{array}$ & $\sim 85-90 \mathrm{~cm}$ & --- & $\sim 85-90 \mathrm{~cm}$ & $\sim 81.46 \mathrm{~cm}$ \\
\hline & $\begin{array}{c}\text { At Surface } \\
\text { (Homogenized) }\end{array}$ & $\sim 85-90 \mathrm{~cm}$ & ---- & $\sim 85-90 \mathrm{~cm}$ & $\sim 81.46 \mathrm{~cm}$ \\
\hline & No water & $\sim 40 \mathrm{~cm}$ & $18.29 \mathrm{~cm}$ & $\sim 60 \mathrm{~cm}$ & $44.20 \mathrm{~cm}$ \\
\hline
\end{tabular}

\section{Measurements:}

- The experimental results for the size of hole or crater created during each experiment was measured using a string placed across the hole or crater as a reference. A deviation out of plane from the string marked the start and end of the hole or crater

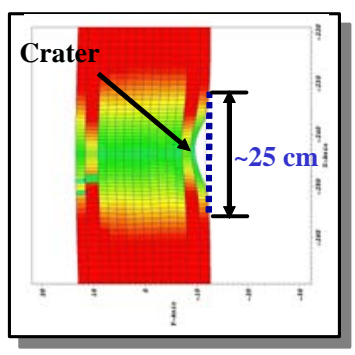

FIGURE 27. Comparison between experiment and simulation for RC bridge pier experiments. 


\section{Crater Measurements:}

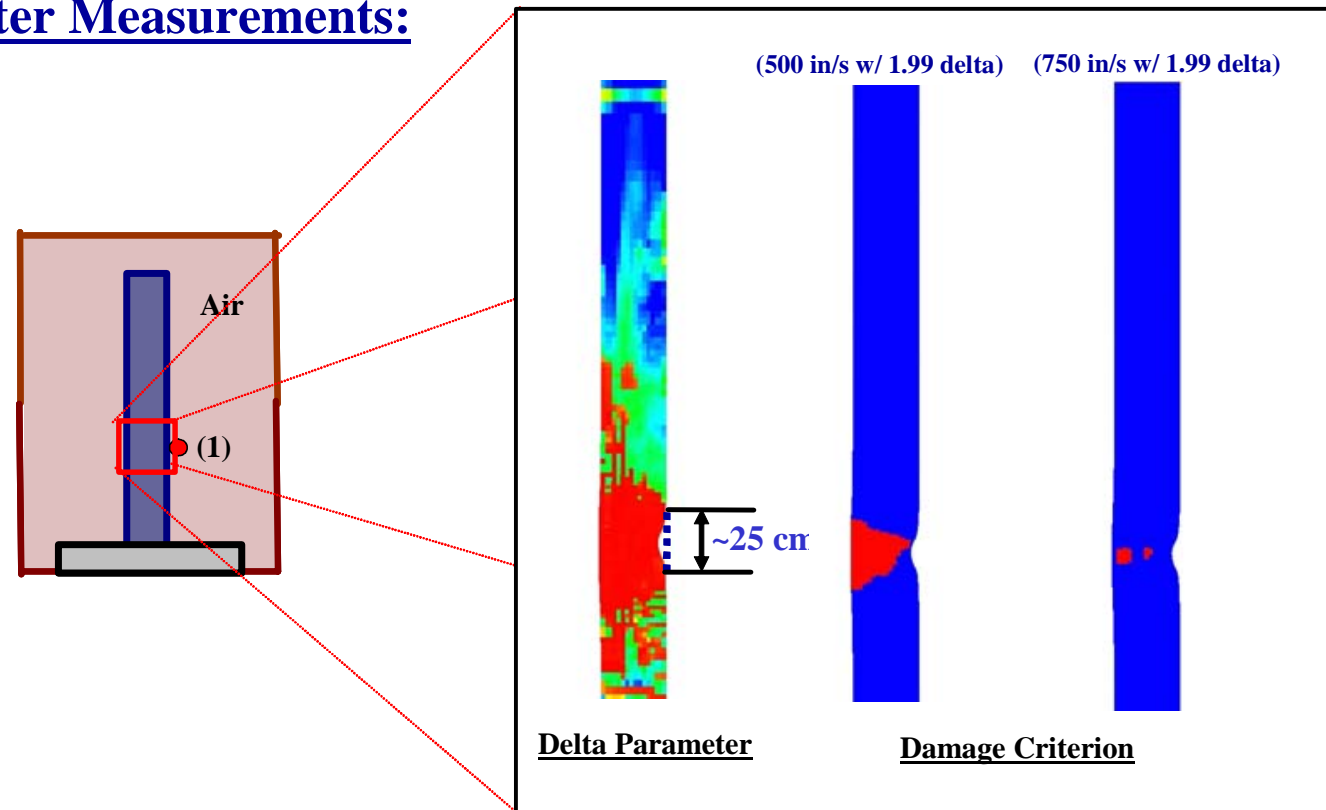

Above Water: 10" Thick Pier (1 lb charge)

\section{Crater Measurements:}

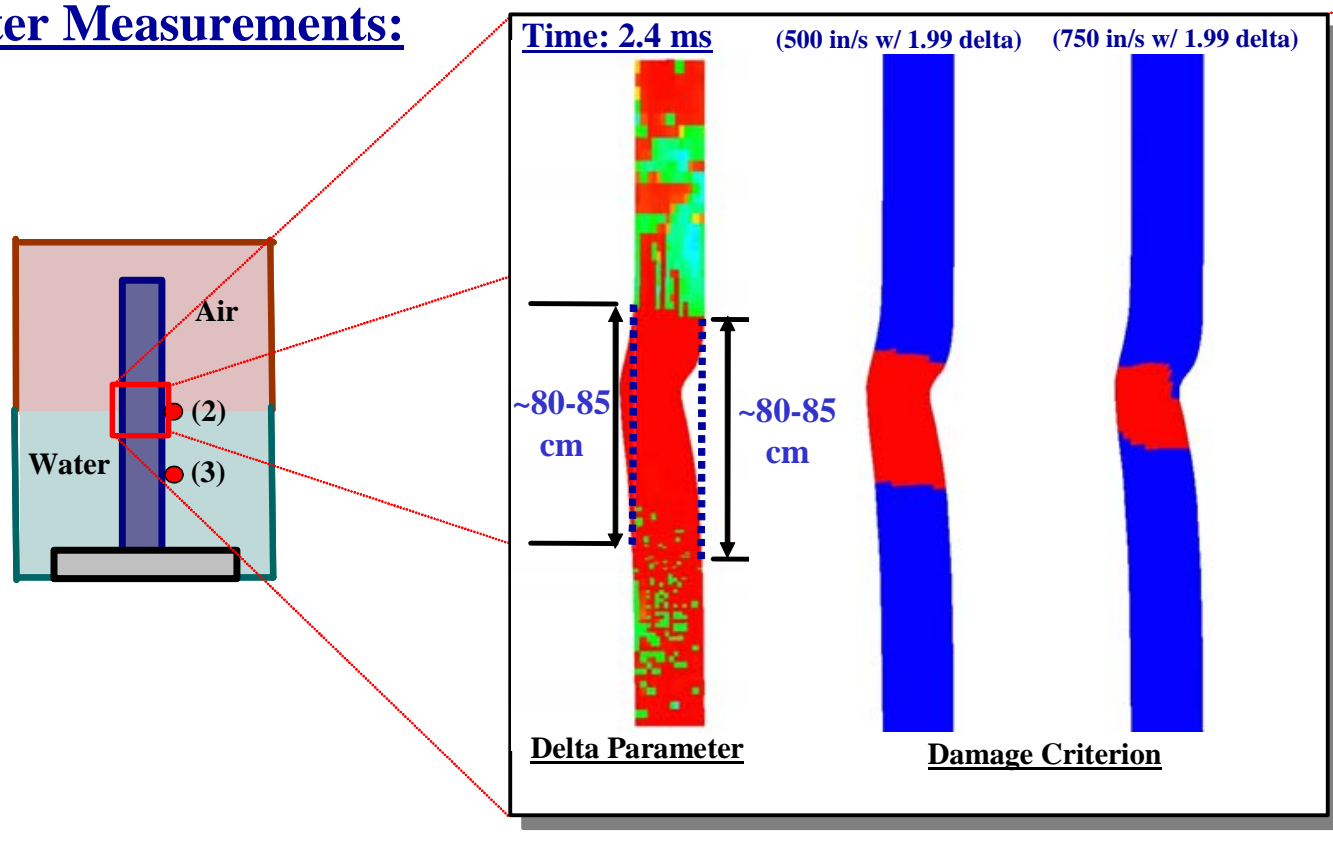

At Water Surface: 10" Thick Pier (1 lb charge)

FIGURE 28. Computational results of $1 \mathrm{lb}$ above water and at water surface charges on 10" thick bridge piers. 


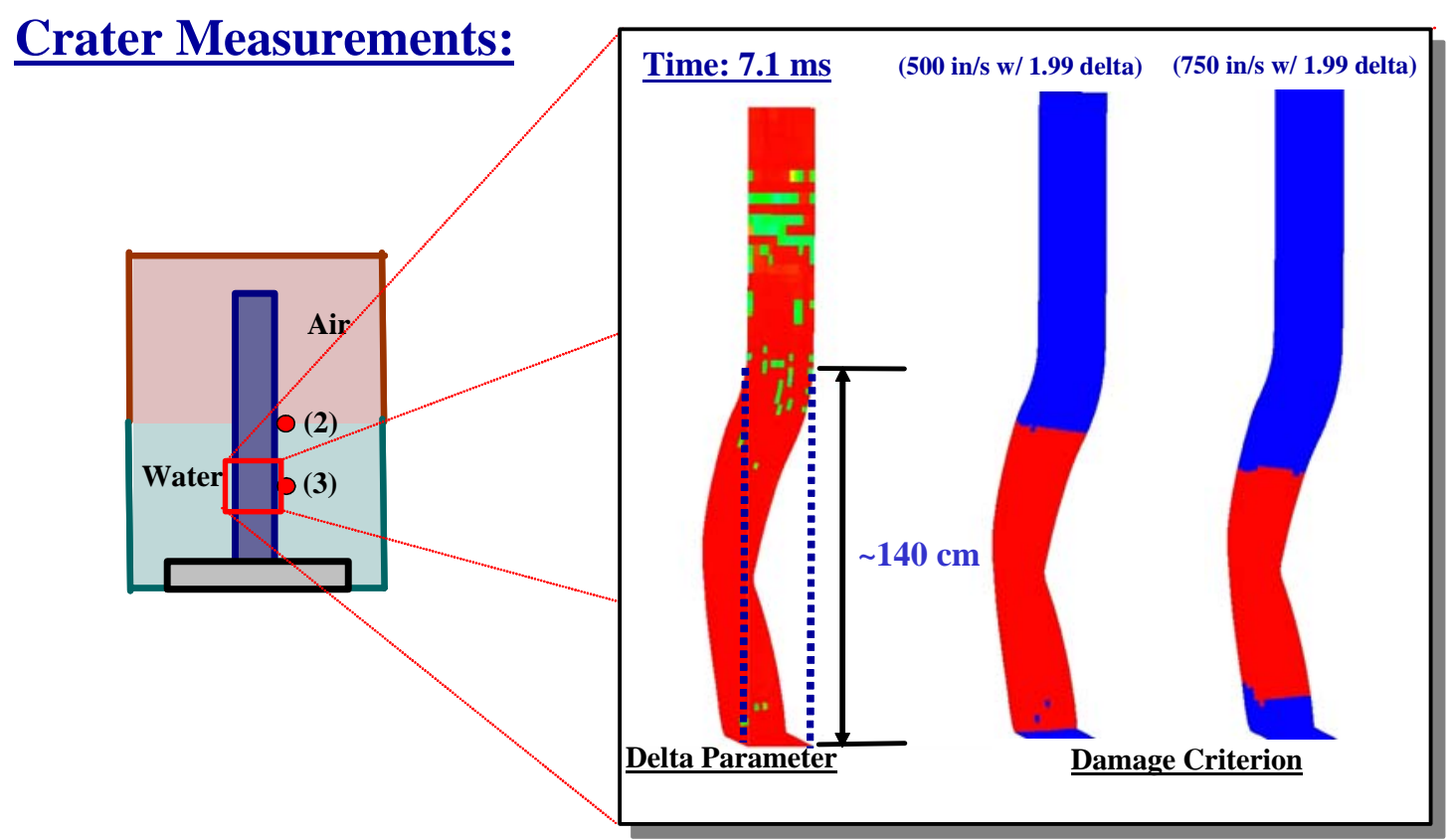

Below Water Suface: 10” Thick Pier (1 lb charge)

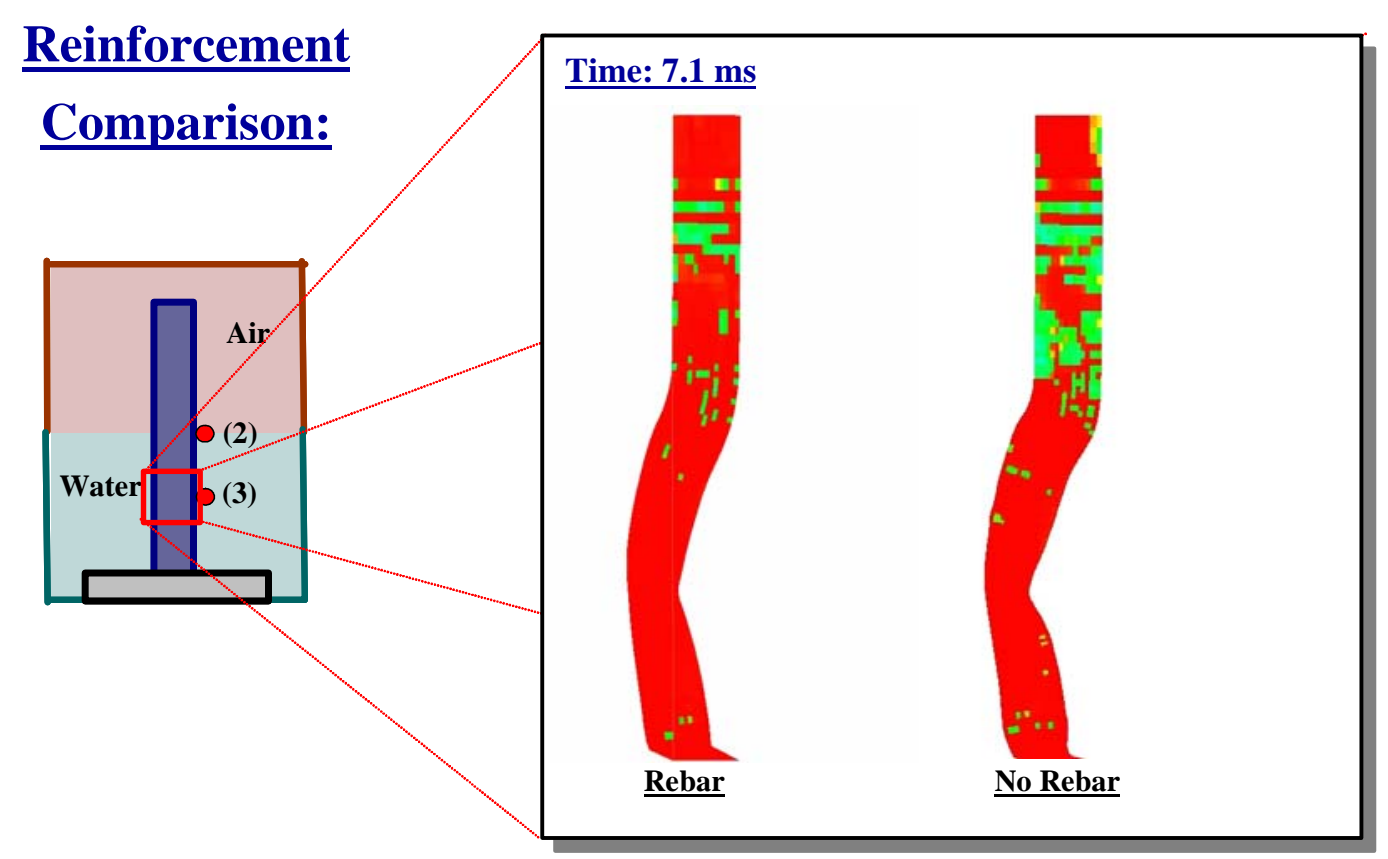

Below Water Suface: 10" Thick Pier (1 lb charge)

FIGURE 29. Computational results of $1 \mathrm{lb}$ below water surface charge on 10" thick bridge piers. 


\section{Crater Measurements:}

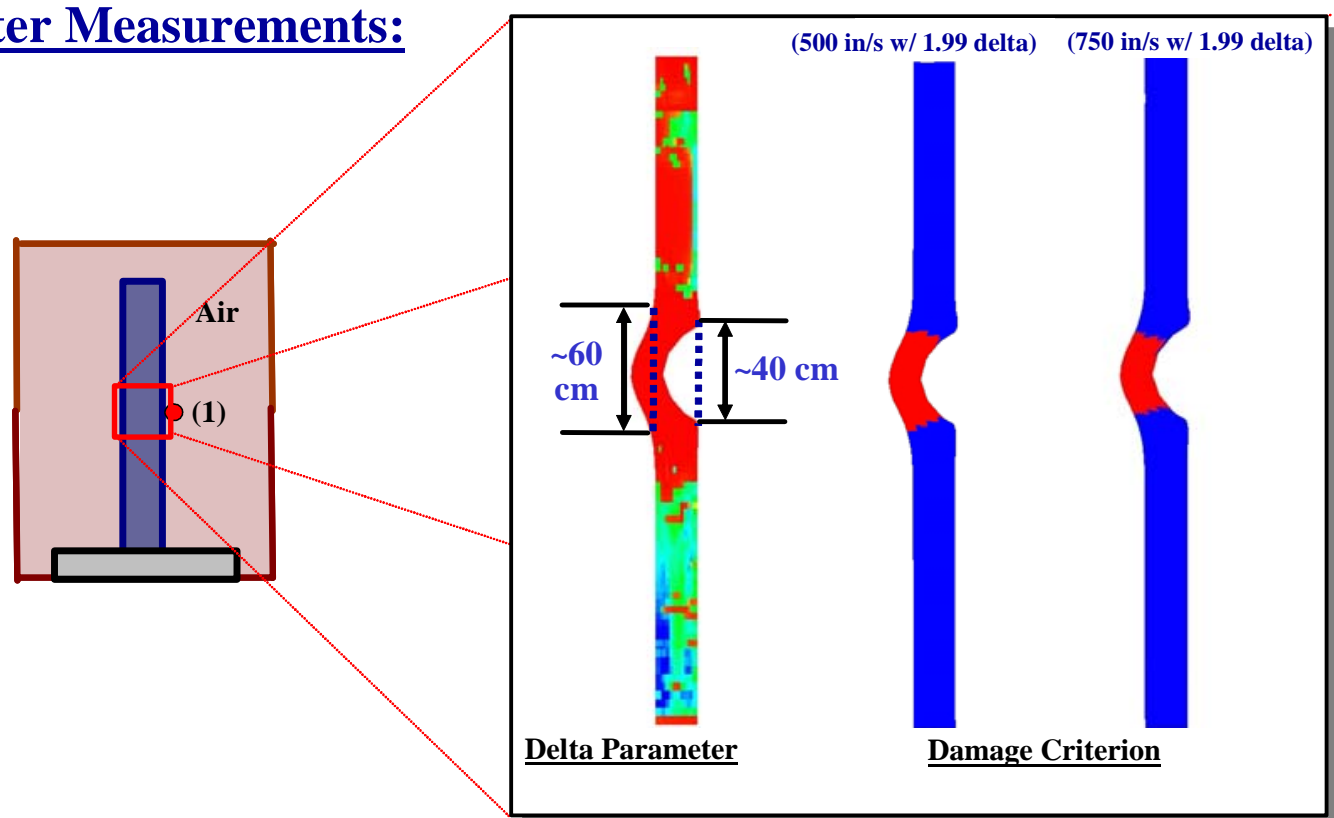

Above Water: 6" Thick Pier (2 lb charge)

\section{Crater Measurements:}

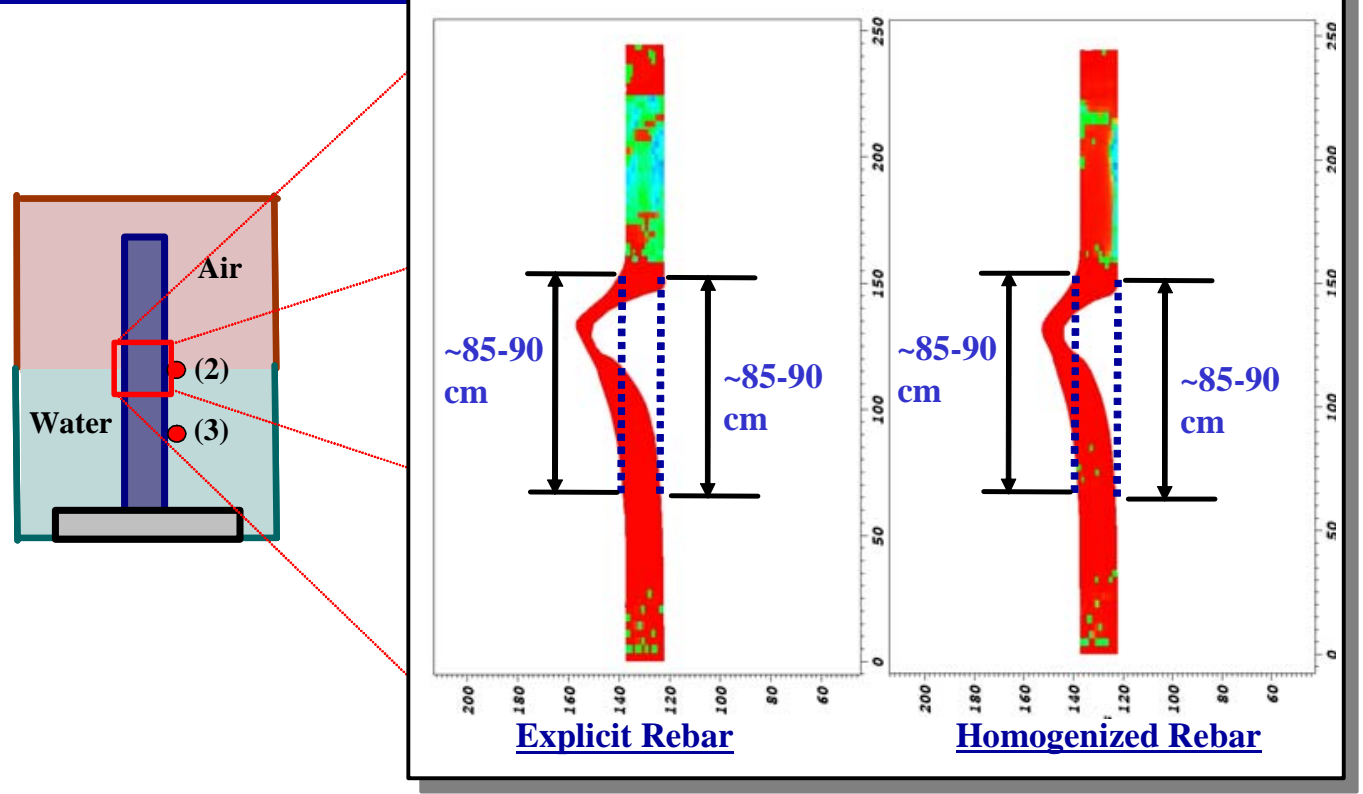

At Water Surface: 6" Thick Pier (2 lb charge)

FIGURE 30. Computational results of $2 \mathrm{lb}$ above water and at water surface charges on 6" thick bridge piers. 
Postshot views of 1- and 2-pound shots above water surface on 10-inch thick pier:

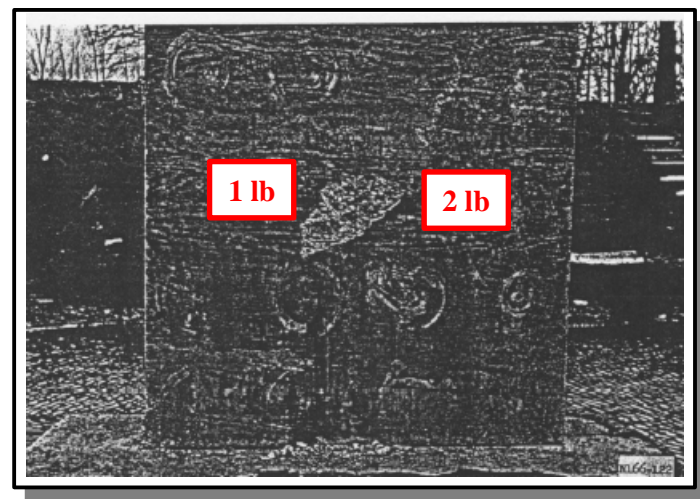

Back Side: 10” Thick Pier

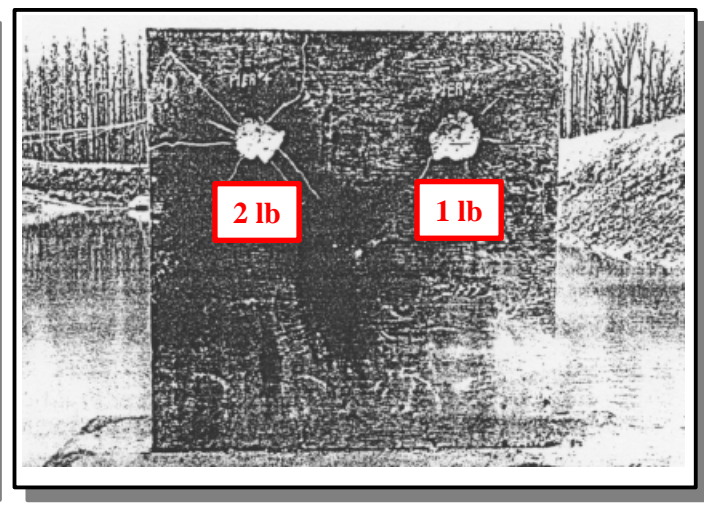

Front Side: 10" Thick Pier

\section{Above Water}

Postshot views of 1-pound shot at water surface on 10-inch thick pier:

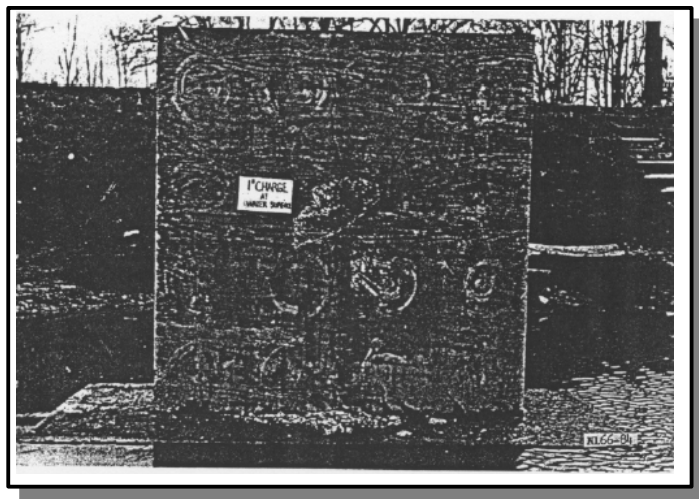

Back Side: 10" Thick Pier

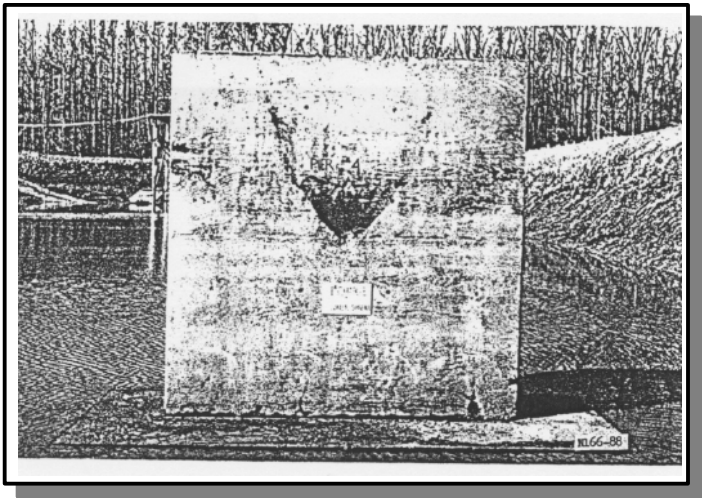

Front Side: 10" Thick Pier

\section{$\underline{\text { At Water Surface }}$}

FIGURE 31. Postshot views of above water and at water surface bursts for 10" thick bridge pier. 
- Postshot views of 1-pound shot below water surface on 10-inch-thick pier:

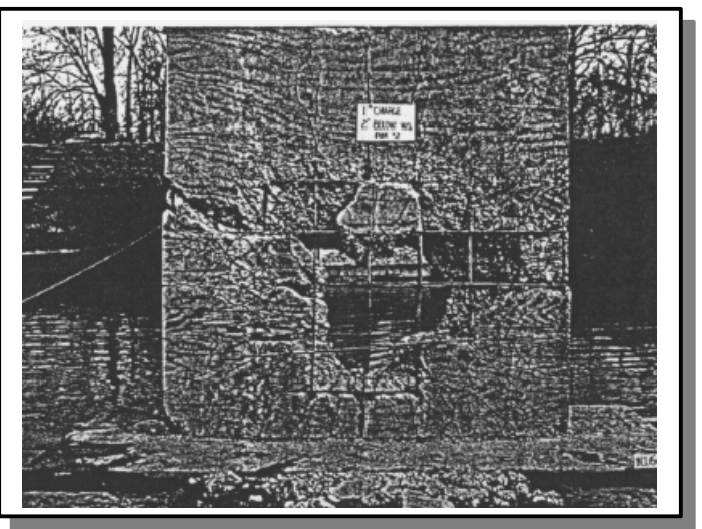

Back Side: 10” Thick Pier

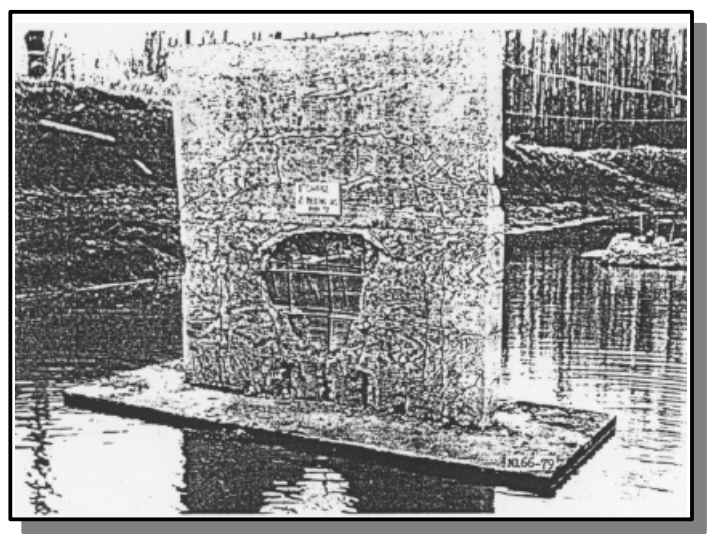

Front Side: 10" Thick Pier

\section{Below Water}

Postshot views of 1/4-, 1-, and 2-pound shots above water surface on 6-inch-thick pier:

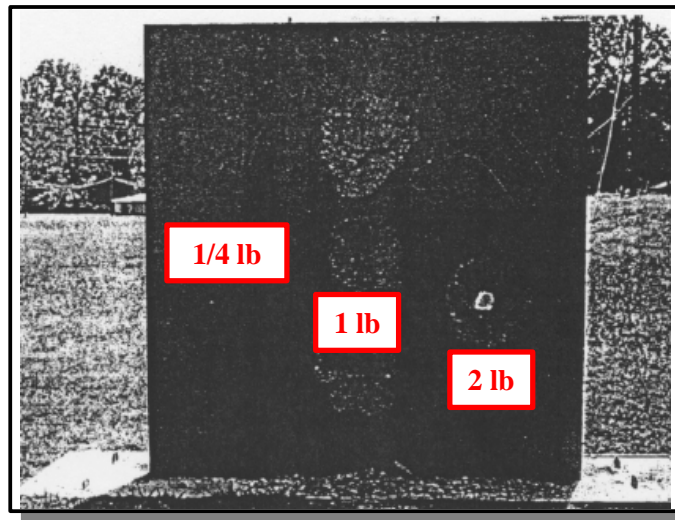

Back Side: 6" Thick Pier

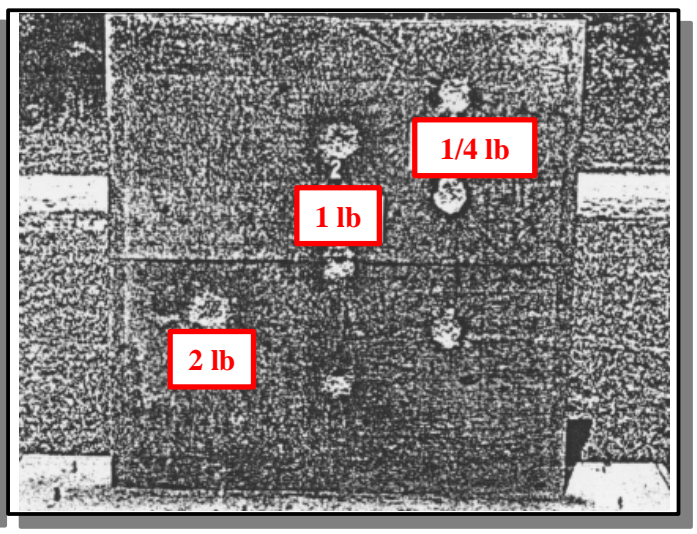

Front Side: 6" Thick Pier

\section{Above Water}

FIGURE 32. Postshot views of below water and above surface bursts for 6" and 10" thick bridge piers.

\subsection{Conclusion}

In conclusion, the homogenized rebar model has been shown to give similar results to that shown in experiment for a variety of different scenarios. These scenarios study the effects of the homogenized rebar model for air blast and underwater blast, lightly reinforced walls and heavily reinforced walls, and light concrete damage to physical breaching of walls. It 
should be noted that it is most appropriate to use this material model when modeling rebar explicitly with brick or beam elements is too time consuming and cost prohibitive or when it is not necessary to model shear or bending in the rebar.

In addition, improvements to the homogenized rebar model are still being implemented. For instance, in its original implementation, the rebar was specified as a volume fraction in the concrete model in an approximate region where rebar is located. A pre-processor has been developed, called FiberGrid, that will implement the volume fractions of rebar in the individual concrete elements (and not a whole concrete region) where rebar is located in reality. By using this preprocessor FiberGrid, the rebar will look and behave very similar to truss elements overlaid inside the concrete. A quick validation of FiberGrid was performed on the Precision Test Wall and the results are shown in Figure 33. As is seen in the results comparison below, the homogenized rebar with FiberGrid simulation begins to converge very nicely towards the rebar brick element simulation.

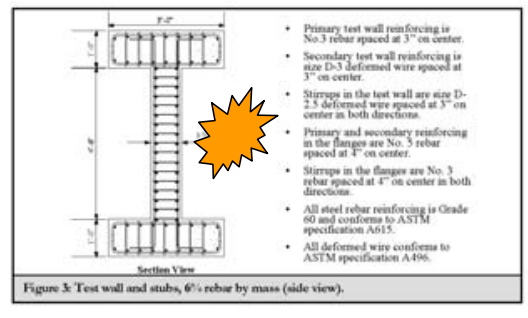

Precision Test Wall Study: Modeling a U.S. Army-ERDC Test of a Blast Loaded RC Wall
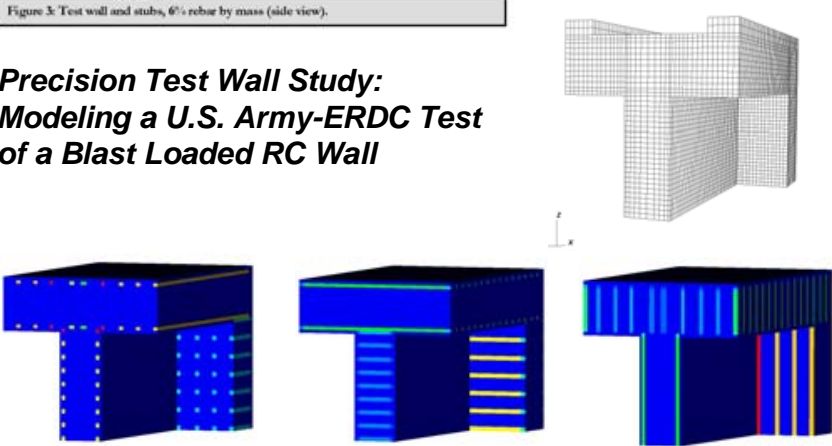

Volume fractions of rebar in $\mathrm{x}, \mathrm{y}, \mathrm{z}$ directions Time Comparison for Mesh Generation: Brick rebar models $\sim 7$ days Homogenized rebar model $\sim 1 / 2$ day
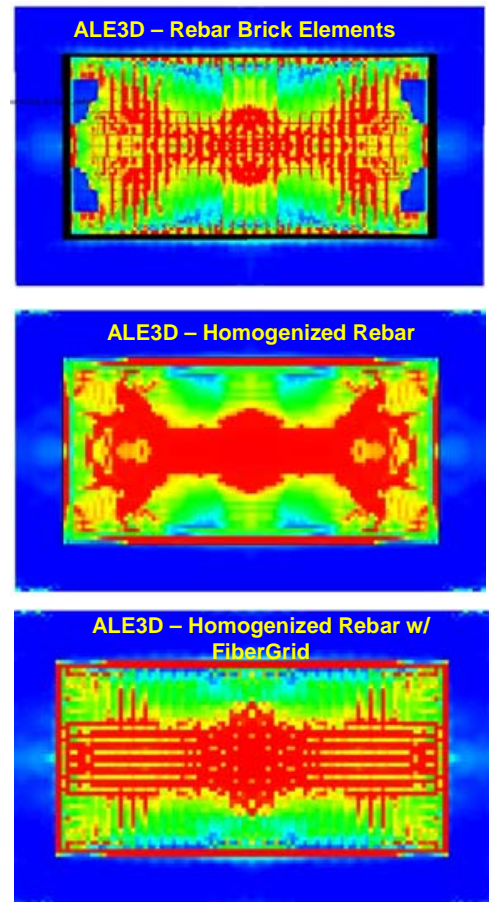

FIGURE 33. Damage comparison between model with rebar brick elements, homogenized rebar, and homogenized rebar using FiberGrid.

\subsection{References}

1. Anderson, A., Precision Test Wall Study: Modeling a US ArmyERDC Test of a Blast Loaded RC Wall, Lawrence Livermore National Laboratory: New Technologies Engineering Division, August 6, 2004. 
2. Ball, J.W., Damage Predictions for Contact Bursts on Reinforced Concrete Bridge Piers, Project ESSEX III, Weapons Effects Laboratory, U.S. Army Waterways Experiment Station, December, 1976. 


\section{Benchmark Studies}

\subsection{Background}

This section attempts to summarize some of the remaining verification and validation work that has been completed to date for related blast analysis studies.

\subsection{Shell Element Validation Studies}

Up until recently, the only structural elements supported by ALE3D were 8-node hexahedral elements. Due to the recent implementation of the DYNA3D-type shell elements into ALE3D, it was necessary to test the newly implemented elements for a wide variety of scenarios such as:

- single element tensile test

- beam bending

- underwater explosions

- deformation and rupture of thin plates subjected to underwater shock

\subsection{Single Element Tensile Tests}

A single element was pulled in tension for both an ALE3D and DYNA3D shell element. An elastic-plastic material with the properties of steel was used. The resulting effective plastic strain for both codes was 0.297. Figure 34 shows a stress-strain comparison between DYNA3D and ALE3D. The codes gave exactly the same answer for this test problem. 


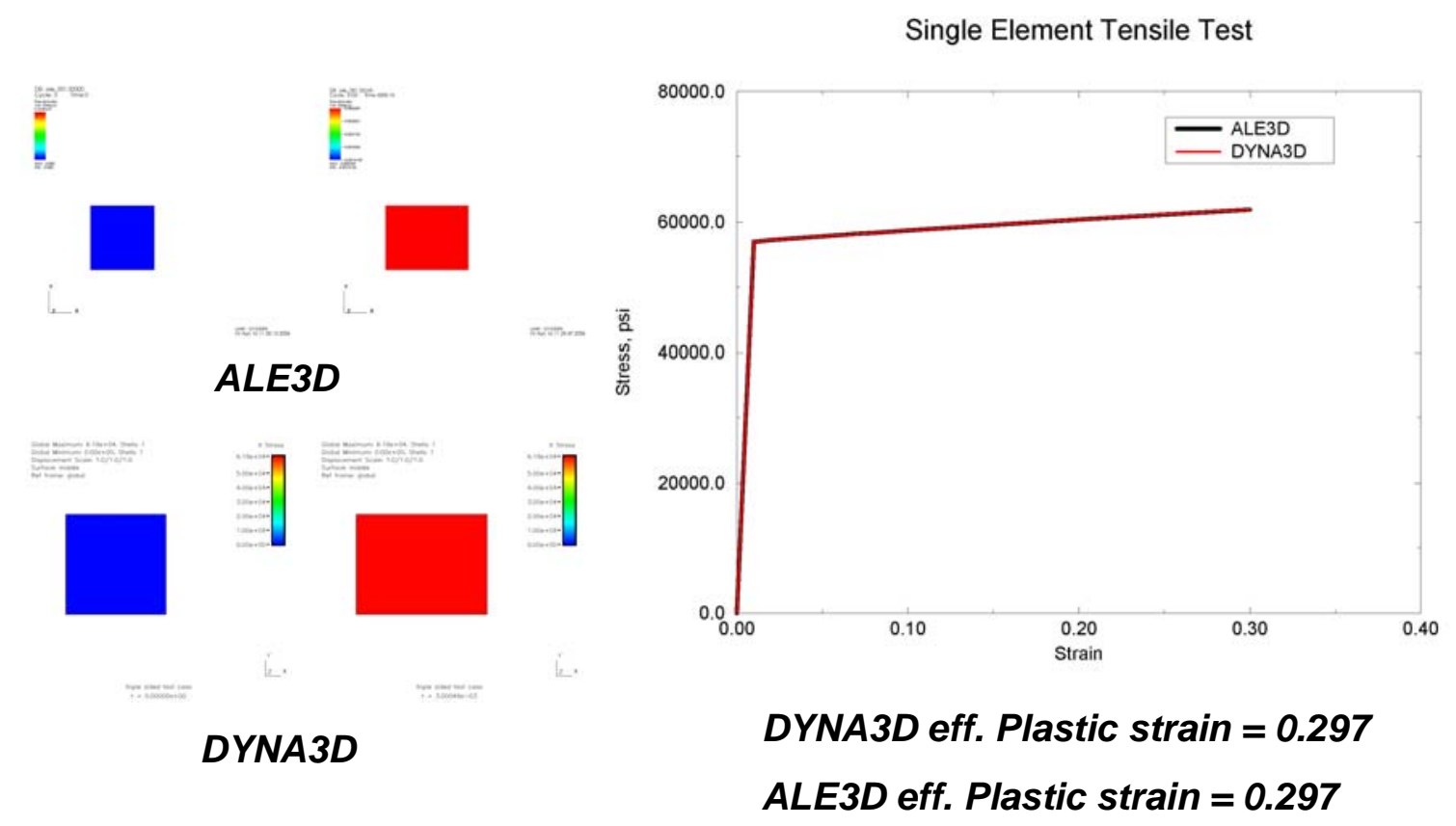

FIGURE 34. ALE3D and DYNA3D single shell element tensile test comparison.

\subsection{Shell Element Bending Tests}

This problem considers a cantilever beam consisting of 105 shell elements with a load applied to one end of the beam. The displacement or position vs. time plot given in Figure 35 shows that DYNA3D and ALE3D deformation results compare very well. The maximum effective plastic strain recorded at the fixed end of the cantilever was 0.1993 for ALE3D and 0.203 for DYNA3D. 


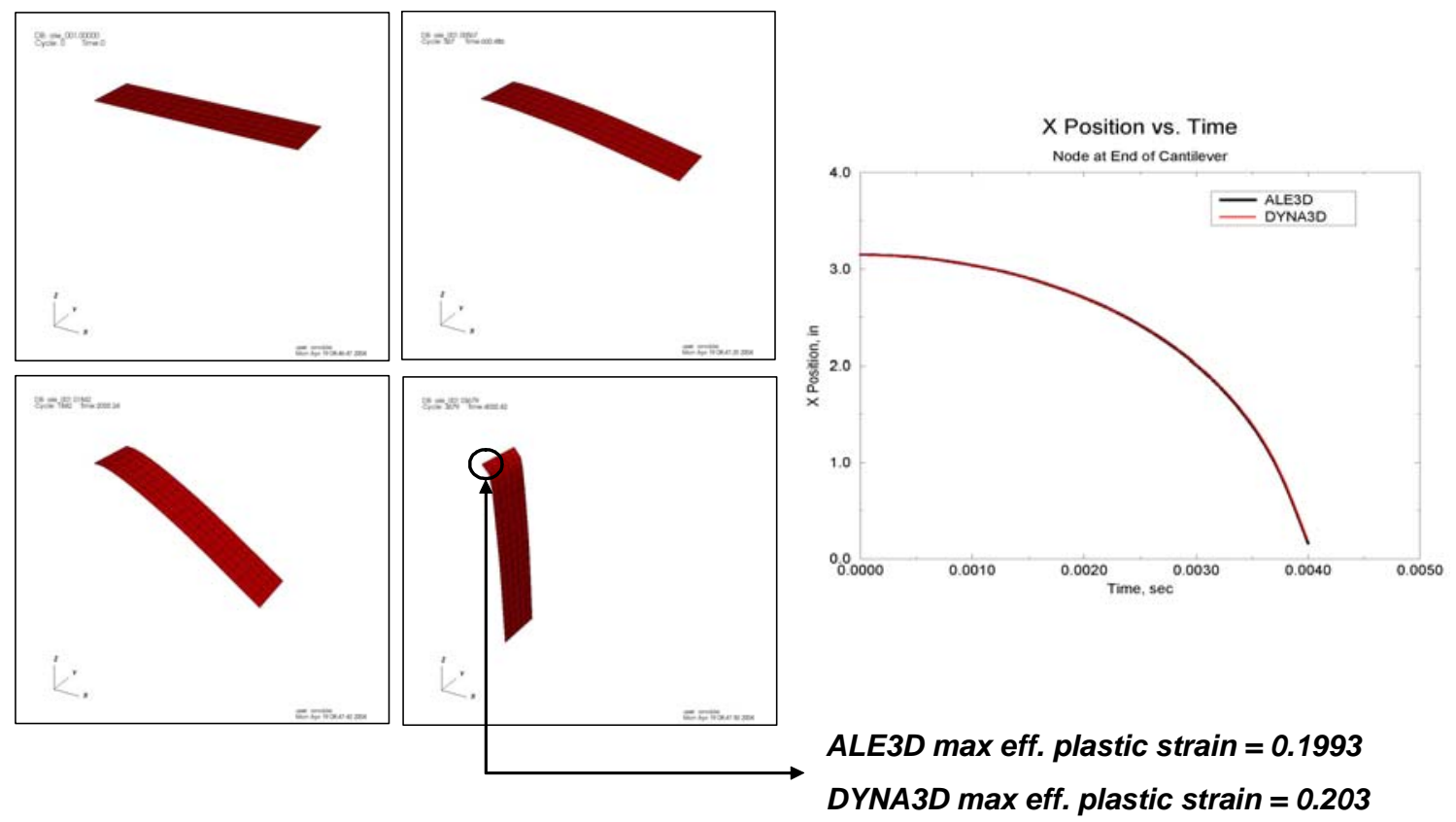

FIGURE 35. ALE3D and DYNA3D shell element bending test comparison.

\subsection{Underwater Explosions Near Thin-Walled Structures}

Two separate experiments were used to evaluate ALE3D's capability to perform fullycoupled underwater blast analyses on thin-walled structures using the newly implemented shell elements.

\subsubsection{1-T6 Aluminum Test Cylinder}

The reference for this experiment is document NSWCDD/TN-93-34 authored by McClure. This report contains descriptions of the experimental configuration and the relevant data to be matched.

The experiment was conducted in 1989 by the Naval Surface Warfare Center, Dahlgren Division, at its Pumpkin Neck Facility in Dahlgren, Va. The test target was a submerged, unstiffened, 18" diameter aluminum cylinder with end caps and a 2" diameter steel rod in the center. The explosive charge was 11 grams of pentolite centered 3.5" above the cylinder and 8.5" below the surface of the water. Figure 36 shows the test configuration, where the crane was used to hold the aluminum cylinder 12" below the surface of the water. Weights were attached to the cylinder to compensate for the buoyant effect of the air entrapped in the cylinder. The explosive charge was a 7/8" long, 3/4" diameter cylinder of pentolite (10.769 grams), which was ignited by a RP80 detonator using 0.123 grams of RDX and 0.08 grams of PETN.

A deformation comparison plot has been given in Figure 37 and it shows good agreement between the ALE3D and experimental results. 


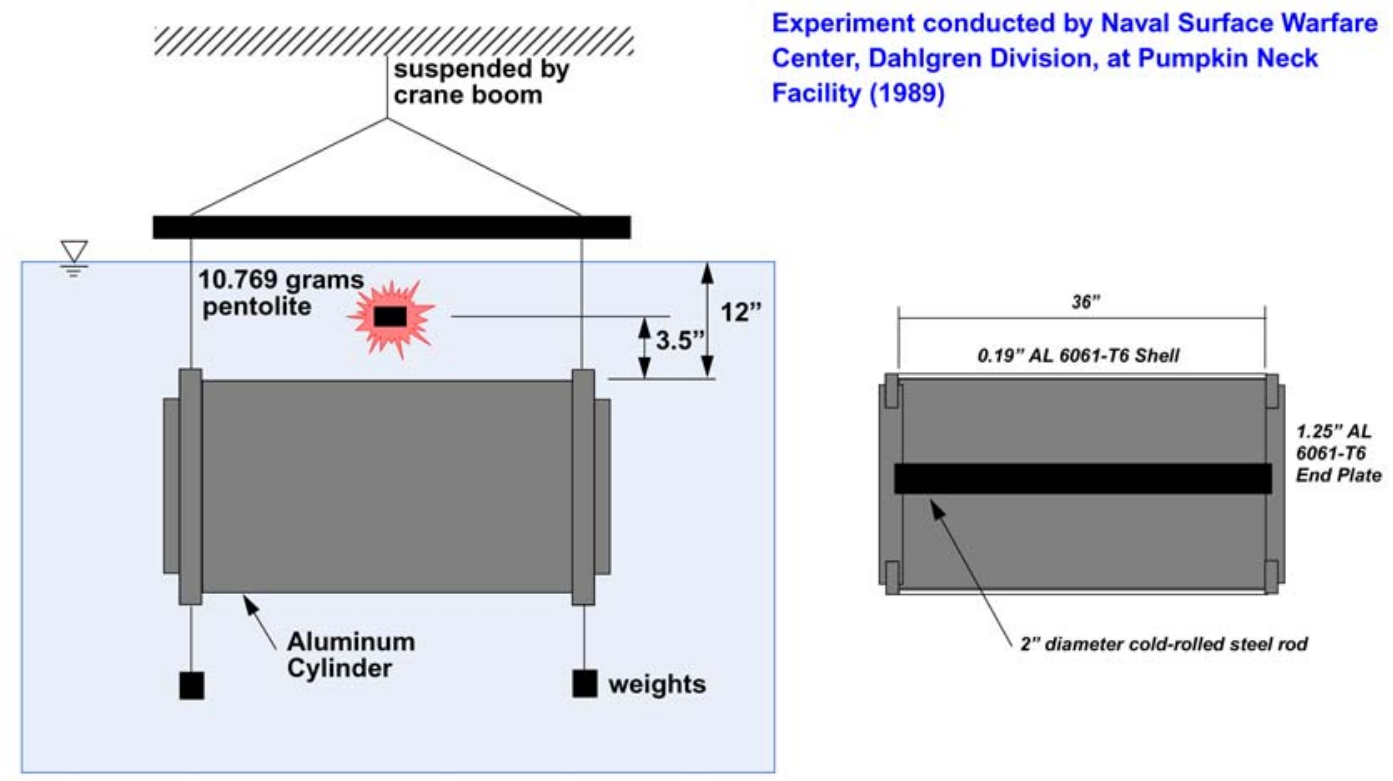

FIGURE 36. 6061-T6 aluminum test cylinder underwater blast experiment conducted by NSWC.

IED Cylinder Deformation Comparison

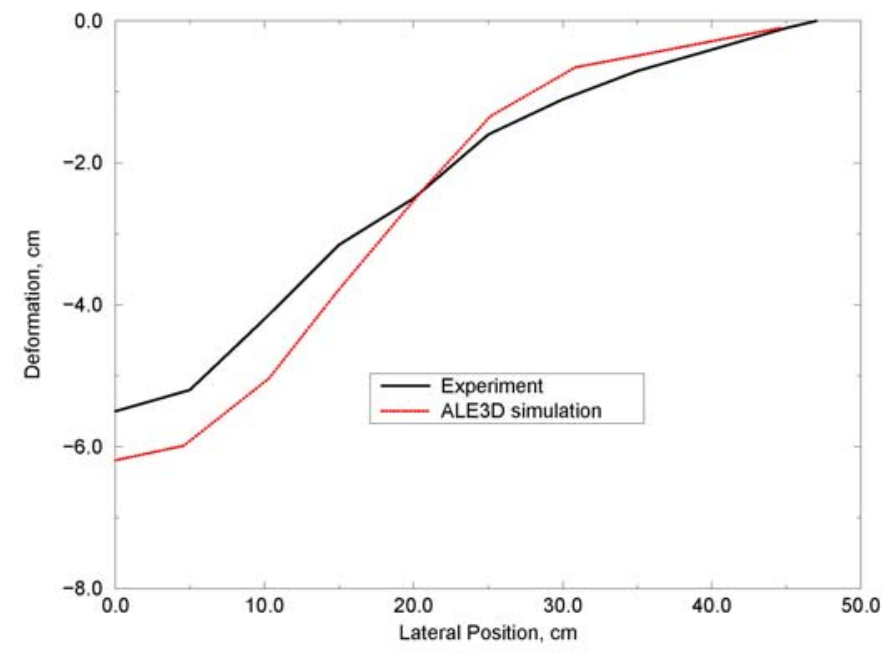

FIGURE 37. 6061-T6 aluminum test cylinder deformation comparison between experiment and ALE3D simulation.

\subsubsection{Deformation and Rupture of Thin Plates Subjected to Underwater Shock}




\title{
VALIDATION OF AIR-BACKED UNDERWATER EXPLOSION EXPERIMENTS WITH ALE3D
}

\author{
Lara D. Leininger \\ Department of Civil and Environmental Engineering \\ University of California \\ Davis, California, 95616 \\ Defense Systems Analysis Group, Engineering \\ Lawrence Livermore National Laboratory \\ Livermore, California, 94551
}

December 15, 2004

\begin{abstract}
This paper summarizes an exercise carried out to validate the process of implementing LLNL's ALE3D to predict the permanent deformation and rupture of an air-backed steel plate subjected to underwater shock.

Experiments were performed in a shock tank at the Naval Science and Technology Laboratory in Visakhapatnam India, and the results are documented in reference [1] (Ramajeyathilagam, 2004). A consistent set of air-backed plates is subjected to shocks from increasing weights of explosives ranging from $10 \mathrm{~g}-80 \mathrm{~g}$. At $40 \mathrm{~g}$ and above, rupture is recorded in the experiment and, without fracture mechanics implemented in ALE3D, only the cases of $10 \mathrm{~g}, 20 \mathrm{~g}$, and $30 \mathrm{~g}$ are presented here.

This methodology applies the Jones-Wilkins-Lee (JWL) Equation of State (EOS) to predict the pressure of the expanding detonation products, the Gruneisein EOS for water under highly dynamic compressible flow - both on 1-point integrated 3-d continuum elements. The steel plates apply a bilinear elastic-plastic response with failure and are simulated with 3-point integrated shell elements. The failure for this exercise is based on effective (or equivalent) plastic strain.
\end{abstract}




\subsection{INTRODUCTION AND BACKGROUND}

Recent terrorist activities have brought attention to the vulnerability of the US infrastructure to underwater explosions. Scientists and engineers have been executing experiments and validating those experiments for decades and the literature has numerous examples of air-backed underwater explosions on sheet metal, as well as fewer experiments on the air-shocked sheet metal.

In general, the numerical simulations in the literature for validation with experiment employ a decoupled approach that begins with analytically attained approximations of the expected pressure time-history on the plate that is applied as a boundary condition to a finite element method with a 2-d Lagrangian shell element formulation. The de-coupled approach assumes that the shock is hitting a rigid (nondeforming) structure, thereby ignoring the shock energy absorbed in plastic deformation of the structure. This leads to a higher expected pressure pulse, and a conservatively large deformation.

There is added value to achieve a fully-coupled 3-d simulation that includes the significant effects of fluid-structure interaction and is flexible enough to account for multiple explosives, transmission media, and structures. This paper summarizes the first step: a validation of a particular case (plastic explosive, underwater, against steel). Although the simulation is fully coupled the "main events" of the simulation can be interchanged to account for differences in situation (i.e. a new EOS can be substituted to account for an Improvised Explosive Device, IED, or the parameters of the deviatoric response can be altered to account for aluminum or concrete). Future developments should also account for the non-continuum fracture response of the structure.

\subsection{COMPUTATIONAL Model}

The computational models used for this exercise assume that the explosive products expansion can be modeled using the Jones-Wilkins-Lee EOS for C-4, the shock propagation through water is modeled using a Gruneisen EOS, and the deviatoric/strength response is modeled by a $\mathbf{J} 2$ flow elastic-plastic bilinear curve with failure. The convenient units for the high pressures and length scale of this problem are centimeter [cm], gram [g], microsecond [ms], megabar [Mbar], and Kelvin [K].

\subsection{JONES-WILKINS-LEE EQUATION OF STATE FOR EXPLOSIVES}

The Jones-Wilkins-Lee (JWL) equation of state predicts the pressure-volume response of expanding detonation products at times after an explosion. This EOS approximates the energy release of the explosive in a shape independent way and assumes that all the energy released from the explosive spontaneously becomes expanding detonation products. This is often referred to as a volumetric burn model as opposed to an 
exact "burn" model that takes into account the shock front burning though the explosive. This can be a source of inaccuracy within the model. The JWL EOS takes the form (ALE3D manual, 2003):

$$
P=A\left(1-\frac{\omega}{R_{1} v}\right) e^{-R_{1} v}+B\left(1-\frac{\omega}{R_{2} v}\right) e^{-R_{2} v}+\frac{\omega E}{v}
$$

where $A B, R_{1}, R_{2}$, and $w$ are material constants, and $v$ and $E$ are the relative volume and internal energy of the material respectively. The material constants are determined by measuring the pressure on the case of cylindrically shaped explosives. Scaling of these parameters for the spherical explosive found in this experiment could be another source of uncertainty.

Furthermore, the source in this experiment is an Indian explosive named PEK-1, which is described as a plastic explosive with an energy 1.17 times that of TNT (Ramajeyathilagam, 2004). With little else to go on, the parameters of Composition-4 (C4) - a plasticized RDX (Research Development Explosive) with an energy density 1.2 times that of TNT - is used to describe PEK-1 at the ranges of explosive weight for this experiment. This assumption could cause the computed answer to diverge at larger weights where the energetics of C4 surpass those of PEK-1 (given what little we know about PEK-1).

\subsection{GRUNEISEN EQUATION OF STATE FOR WATER}

For the treatment of compressible fluid propagating the detonation shockwave, the Gruneisen Equation of State (EOS) is used within the framework of ALE3D. Explosive detonation and shock response of water is unlike that through air. Experiments have shown that there is a strong peak overpressure followed by a second peak from shock reflections within the boundaries of the detonating explosive (Cole, 1948). There is also a third peak at longer timescales as a result of vaporization of water under negative pressure that is termed cavitation. Theoretical derivations of the shock time history that are usually found in the literature as boundary conditions to a structural response calculations, correctly predict the impulse of the incoming shockwave, and these time histories take the form of exponential decay. The Gruneisen EOS has a cubic polynomial form that captures unique behavior of the second peak (not found in an exponential). The Gruneisen EOS takes the form [DYNA3D Manual/Woodruff, 1973]:

$$
P=\frac{\rho_{O} C^{2} \mu\left[1+\mu\left(1-\frac{\gamma_{O}}{2}\right)-\frac{a \mu^{2}}{2}\right]}{\left[1-\mu\left(S_{1}-1\right)-\frac{S_{2} \mu^{2}}{\mu+1}-\frac{S_{3} \mu^{3}}{(\mu+1)^{2}}\right]^{2}}+E\left(\gamma_{O}+a \mu\right)
$$

for: $\mathrm{m}>0$ (compression) 


$$
\begin{gathered}
P=\rho_{O} C^{2} \mu+E\left(\gamma_{O}+a \mu\right) \text { for: } \mathrm{m}<0 \text { (expansion) } \\
\mu=\frac{1-v}{v}
\end{gathered}
$$

where $C, S_{1}, S_{2}, S_{3}, g_{o}$, and $a$ are material constants, and $r_{o}, v$, and $E$ are the initial density, relative volume, and internal energy of the material respectively. Two different parameter sets to populate this EOS were found in the literature, and those two sets are used to create the pressure-volume response curves shown in Figure 1. The first set comes from a paper that documents a thorough validation of parameters for water based on analytical and experimental results (Molyneaux, et. al, 1994), and the second set of parameters come from a database used widely at Lawrence Livermore National Laboratory (LLNL).

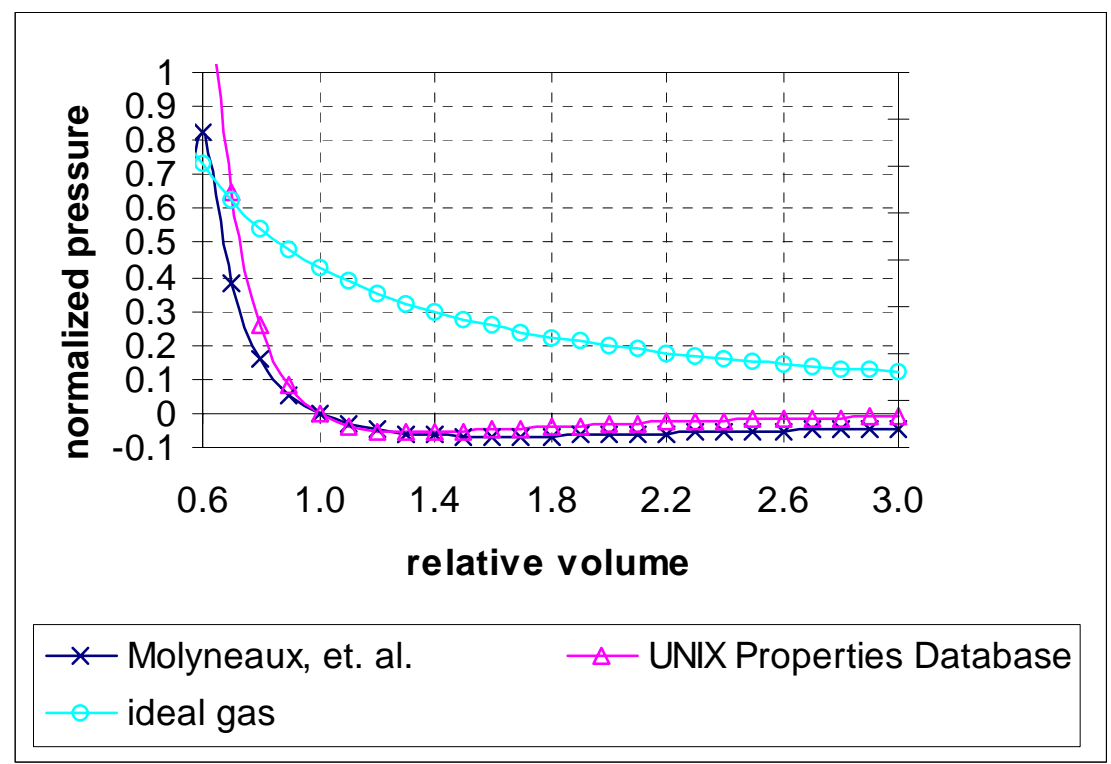

Figure 1: Comparison of different material constants in the Gruneisen Equation of State

It can be seen in the graph of the EOS for these parameters that the pressure response does not vary significantly for the two cases, and that the physics dictate that the there will be a positive pressure response in compression $(v<1)$ and a negative pressure response in expansion $(v>1)$. For comparison, the ideal gas equation of state pressure volume response is also included in Figure 1, and shows that there is no negative pressure response for shocks in air.

The PV response in Figure 1 is only valid for liquid water in the range $0.6<v<3$. At high compression and expansion, there are phase changes in water that are not accounted for in this model. Furthermore, water is a material that cannot handle tension from negative pressure. In fact, the literature suggests that the maximum negative pressure that could be sustained by water is one atmosphere (1e-6 Mbar) but is most likely zero (Cole, 1948; Clutter, 2004; Driels, 1980). This physical behavior commands that the 
pressure in the EOS must be "cut-off" at a reasonable value. Parameter studies in ALE3D indicate that there is no difference between the structural response when the cut-off is set to 0 or $1 \mathrm{e}-6 \mathrm{Mbar}$, so the cut-off is set to 0 atm to be consistent with the literature.

There have been studies in the literature (Driels, 1980) that look further into the assumption that there could be a significant negative pressure response in water. The reasoning for this argument suggests that the gas content of water causes water to "break" at effectively zero atmospheric pressure. Therefore if the water could be degassed, by either excessive hydrostatic pressure or from the dynamic pressure of another shock, then the water could sustain higher levels of negative pressure without cavitating. These findings are not applicable for this study because the depth of the change is only $2 \mathrm{~m}$, resulting in a hydrostatic pressure of less than 3 psi and there is no previous shock exposure.

\subsection{DEVIATORIC RESPONSE FOR STEEL}

The deviatoric (or strength) model of steel is modeled using an elastic-plastic response with a bilinear yield curve and effective plastic strain yield criterion. The Belytschko-Tsay shell element formulation is implemented with 3 integration points through the thickness. The parameters for the steel plate come directly from Ref. [1].

The advantage of using the shell element formulation over 3 - $d$ continuum solid elements is that dividing a thin plate $(0.2 \mathrm{~cm}$ thickness $)$ into a significant number of onepoint integrated solid elements will be Courant limiting to the point that a fully-coupled fluid-structure interaction solution could not be computed. Conversely, although the bending response of a single shell element is superior to that of a solid element, the shear response is not necessarily accurately represented. For the response of the plate for these experiments the bending response will dominate in the center of the clamped plate, but the shear response will dominate at the constraints. This develops uncertainty if the majority of the effective plastic strain (and rupture) is found at the boundaries.

\subsection{NumERICAL CONVERGENCE}

To check for numerical convergence of the fluid model, 4 computational cases (without the structure) were run, varying the ranges of mesh density. For each of these cases, the pressure time history and impulse are compared at a standoff of $25 \mathrm{~cm}$. The results for this convergence study are shown in Figure 2. Table 1 shows the impact of the computational burden for the increasing resolutions. Considering the balance between computational resources and accuracy, it is determined that the ideal the mesh density for this exercise is the medium range, where the calculated difference in impulse was only $4 \%$ off for the finest case.

Table 1: Comparison of computational effort for the numerical convergence studies 


\begin{tabular}{|c|c|c|c|c|c|}
\hline case & $\begin{array}{c}\text { No. of } \\
\text { continuum } \\
\text { elements }\end{array}$ & Run time & $\begin{array}{c}\text { No. of } \\
\text { processors }\end{array}$ & $\begin{array}{c}\text { Peak } \\
\text { Overpressure } \\
{[\text { Mbar] }}\end{array}$ & $\begin{array}{c}\text { Impulse } \\
\text { [Mbar-msec] }\end{array}$ \\
\hline Coarse & 88,000 & $3 \mathrm{~min}$ & 10 & $3.54 \mathrm{e}-4$ & 0.445 \\
\hline Medium & 648,000 & $15 \mathrm{~min}$ & 10 & $5.73 \mathrm{e}-4$ & 0.603 \\
\hline Fine & $5,585,000$ & $52 \mathrm{~min}$ & 10 & $6.99 \mathrm{e}-4$ & 0.606 \\
\hline Finest & $7,036,000$ & $1 \mathrm{hr} 24 \mathrm{~min}$ & 50 & $8.02 \mathrm{e}-4$ & 0.627 \\
\hline
\end{tabular}

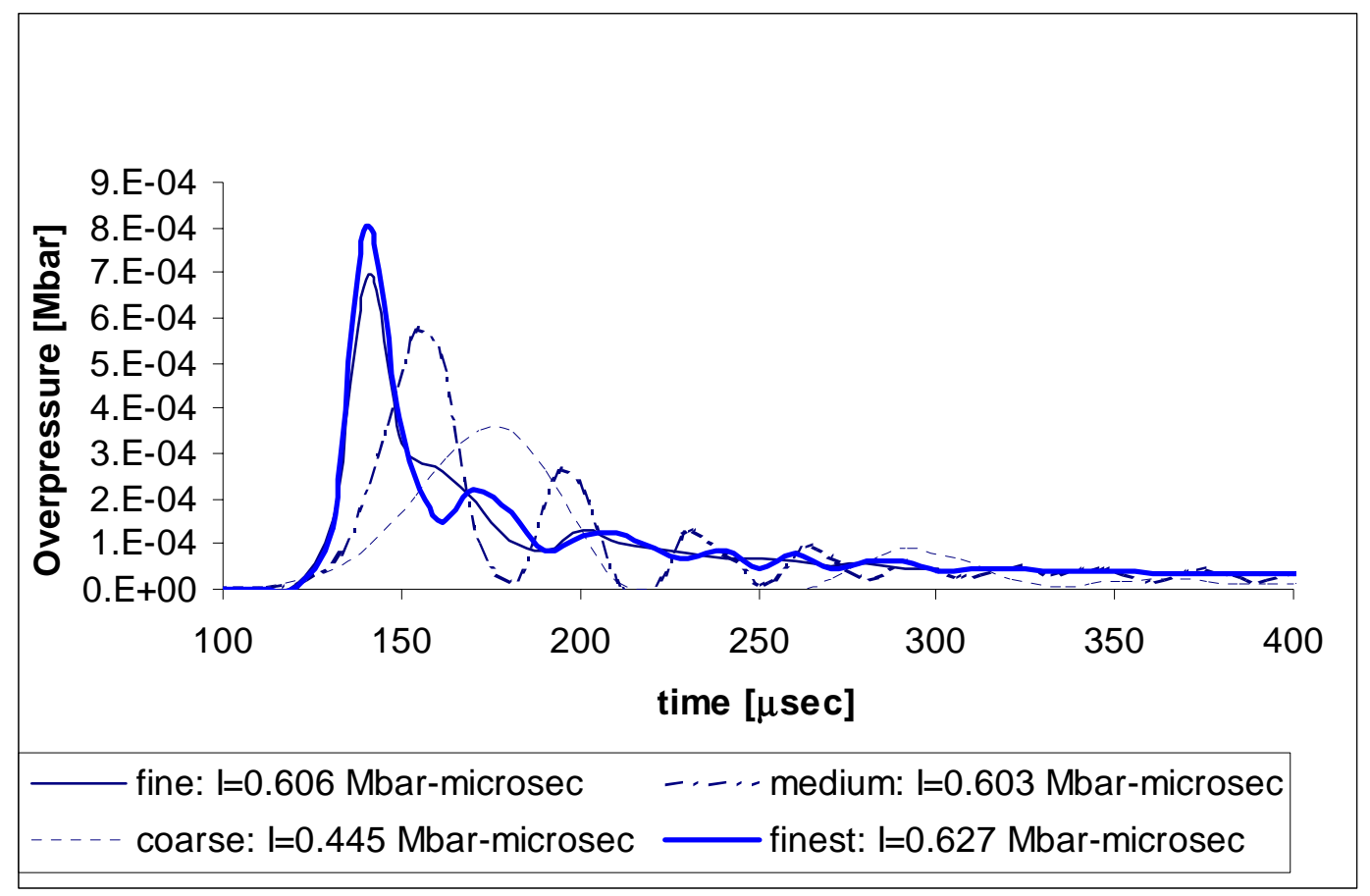

Figure 2: Mesh resolution cases for numerical convergence

\subsection{ALE3D RESUlts}

Figure 3 shows the finite element model used for the calculations in this exercise. The computed results are summarized in Table 2 and are also shown in Figures 4, 5, and 6 for the $10 \mathrm{~g}, 20 \mathrm{~g}$, and $30 \mathrm{~g}$ cases respectively. 


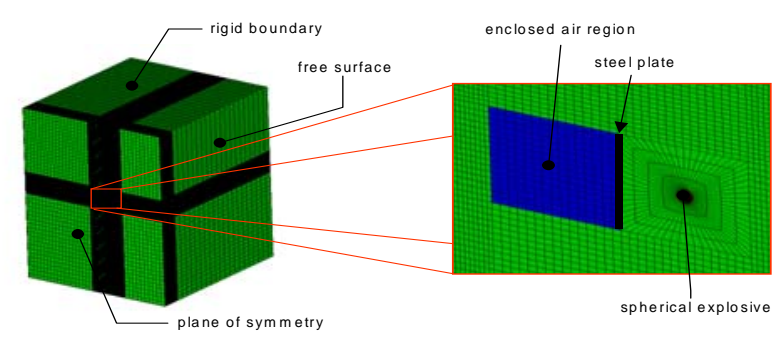

Figure 3: Finite Element Mesh used for exercise

As described in Section 2.1, the computational model uses an equation of state for the detonation products that is expected to predict larger plate deformation than the explosive used in the experiment. Furthermore, because of the non-linear nature of the volumetric burn EOS, this disparity between experiment and computation should grow larger as the weight of the explosive increases. Table 2 summarizes the computed displacements using the weight of PEK-1 as the input weight of C-4. As expected, the computed displacement diverges significantly at the highest weight.

Table 2: Comparison of computed and experimental obtained displacement at the center of the plate

\begin{tabular}{|c|c|c|c|}
\hline $\begin{array}{c}\text { Weight of PEK- } \\
\mathbf{1} \\
{[\mathbf{g}]}\end{array}$ & $\begin{array}{c}\text { Equivalent } \\
\text { weight of C-4 } \\
\text { [g] }\end{array}$ & $\begin{array}{c}\text { Computed } \\
\text { displacement } \\
\text { [cm] }\end{array}$ & $\begin{array}{c}\text { Experimental } \\
\text { displacement } \\
\text { [cm] }\end{array}$ \\
\hline $\mathbf{1 0}$ & 10 & 3.9 & 4.00 \\
\hline $\mathbf{2 0}$ & 20 & 6.3 & 5.78 \\
\hline $\mathbf{3 0}$ & 30 & 8.6 & 6.77 \\
\hline
\end{tabular}

To evaluate the relationship between the weight of PEK-1 used in the experiment and the equivalent weight of higher energy $\mathrm{C}-4$ that should be used in this exercise, a series of calculations were performed at various weights of $\mathrm{C}-4$ and the resulting permanent deformations were recorded. The recorded displacements from the $\mathrm{C}-4$ calculations are correlated to the displacements documented in the experiment, and an equivalent weight of $\mathrm{C}-4$ for each PEK-1 case is determined. Figure 4 shows the data points from this computational excursion, and the resulting linear relationship between the weight of PEK-1 and the equivalent weight of C-4. 


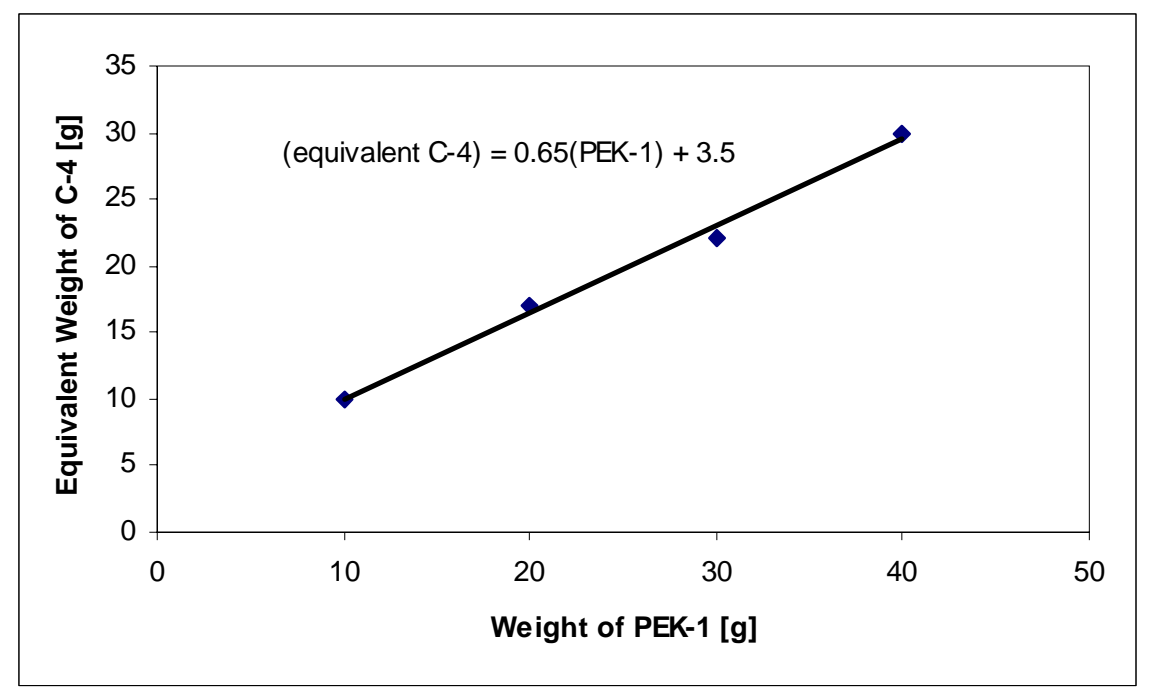

Figure 4: Linear relationship to determine equivalent weight of C-4 used in calculation (derived based on the structural deformation of the steel plate)

The aforementioned linear relationship reduces the input weight of the C-4 in the computational model. The scaling enables good agreement with experimental data, as shown in Table 3. Figures 4, 5, and 6 show detailed time histories for the scaled models.

Table 3: Comparison of computed and experimental obtained displacement at the center of the plate

\begin{tabular}{|c|c|c|c|}
\hline $\begin{array}{c}\text { Weight of PEK- } \\
\mathbf{1} \\
{[\mathbf{g}]}\end{array}$ & $\begin{array}{c}\text { Equivalent } \\
\text { weight of C-4 } \\
{[\mathbf{g}]}\end{array}$ & $\begin{array}{c}\text { Computed } \\
\text { displacement } \\
{[\mathbf{c m}]}\end{array}$ & $\begin{array}{c}\text { Experimental } \\
\text { displacement } \\
{[\mathbf{c m}]}\end{array}$ \\
\hline $\mathbf{1 0}$ & 10 & 3.9 & 4.00 \\
\hline $\mathbf{2 0}$ & 17 & 5.7 & 5.78 \\
\hline $\mathbf{3 0}$ & 22 & 6.6 & 6.77 \\
\hline
\end{tabular}




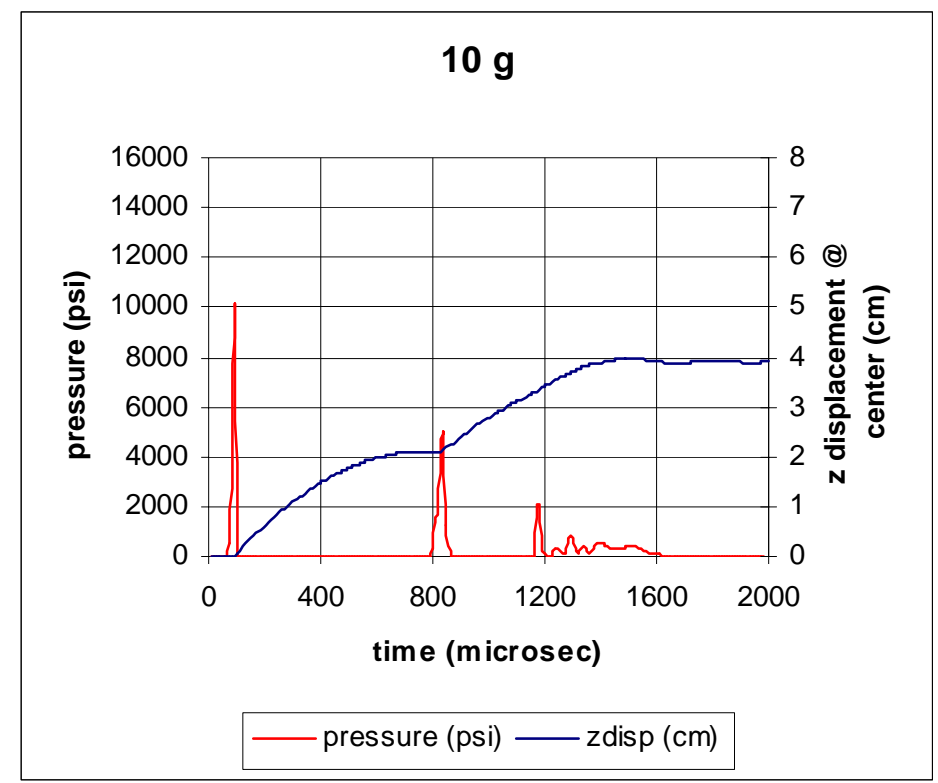

Figure 4: Pressure and displacement time history at the center of the plate

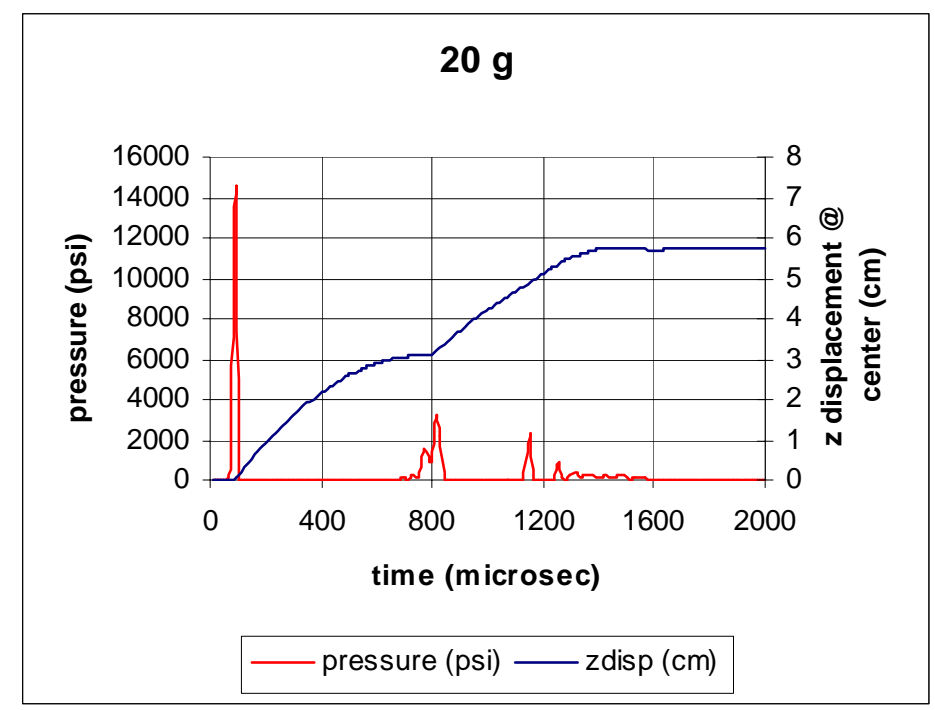

Figure 5: Pressure and displacement time history at the center of the plate 


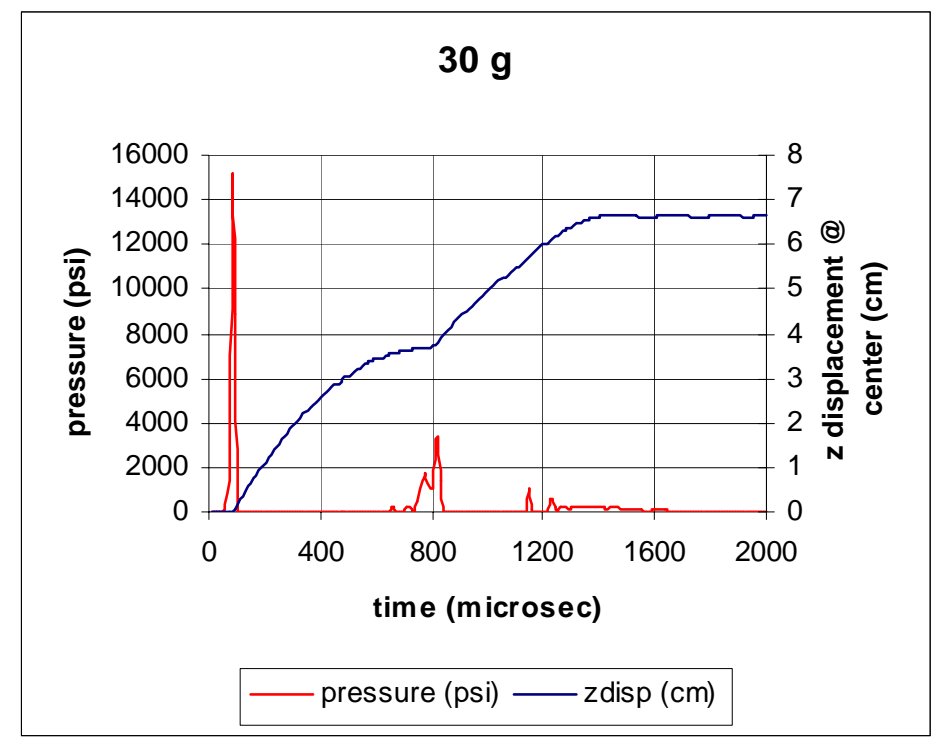

Figure 6: Pressure and displacement time history at the center of the plate

In addition to recording the magnitude of permanent deformation, the plates were inspected for visual cues that there would be rupture. For the $10 \mathrm{~g}, 20 \mathrm{~g}$, and $30 \mathrm{~g}$ cases, there were no indicators of rupture observed in the experiment. Figures 7, 8, and 9 show fringe plots of the computed effective plastic strain in the plates for the cases of $10 \mathrm{~g}, 20 \mathrm{~g}$, and $30 \mathrm{~g}$ of explosive all at $2 \mathrm{~ms}(2000 \mathrm{msec})$. The range of the fringe is $0 \%$ (blue) to $36 \%$ (red) effective plastic strain. As shown in the figures, no part of the steel plate has exceeded $36 \%$ effective plastic strain - which is the strain at rupture for this alloy (Ramajeyathilagam, 2004). This is computation is consistent with the experimental data that there will be no rupture in the plates.
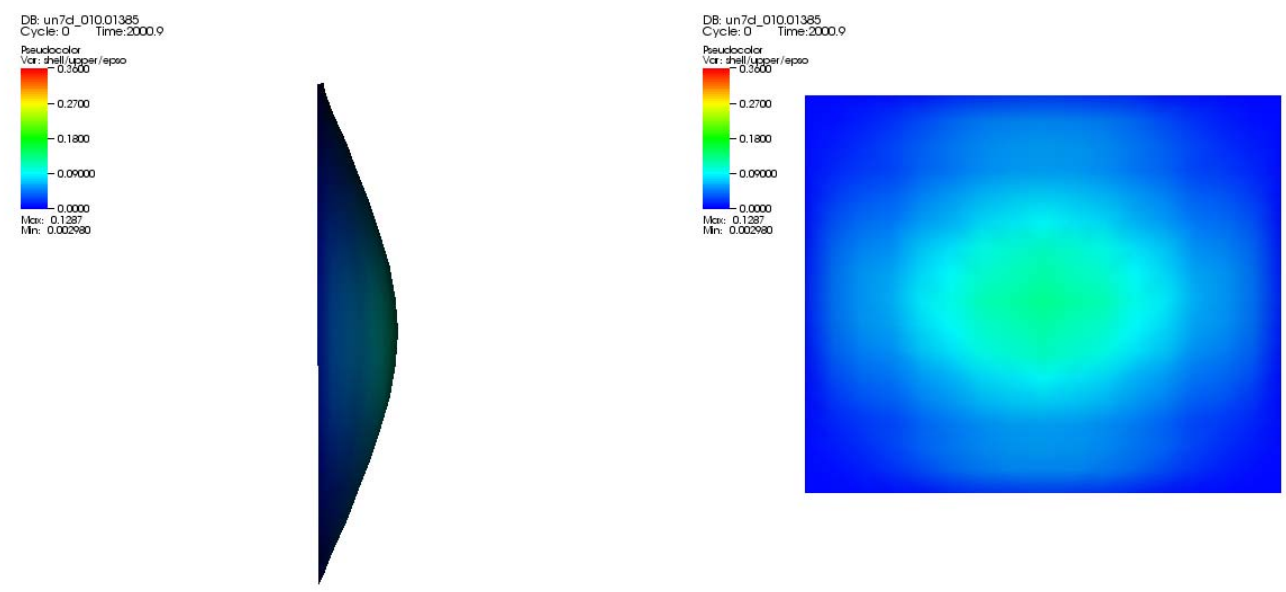

Figure 7: Computed fringe plot of effective plastic strain in the plate 

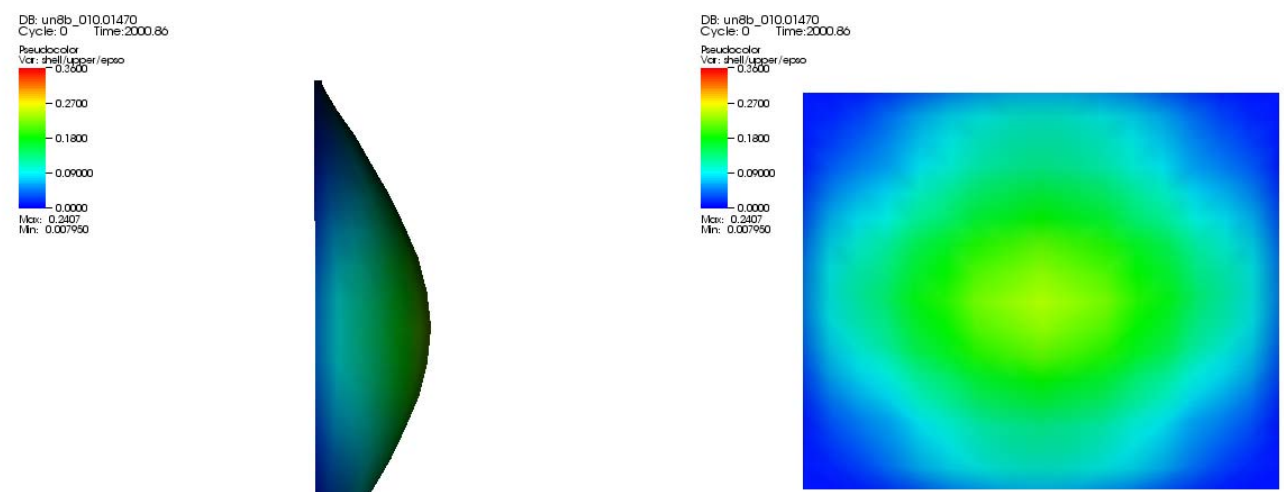

Figure 8: Computed fringe plot of effective plastic strain in the plate
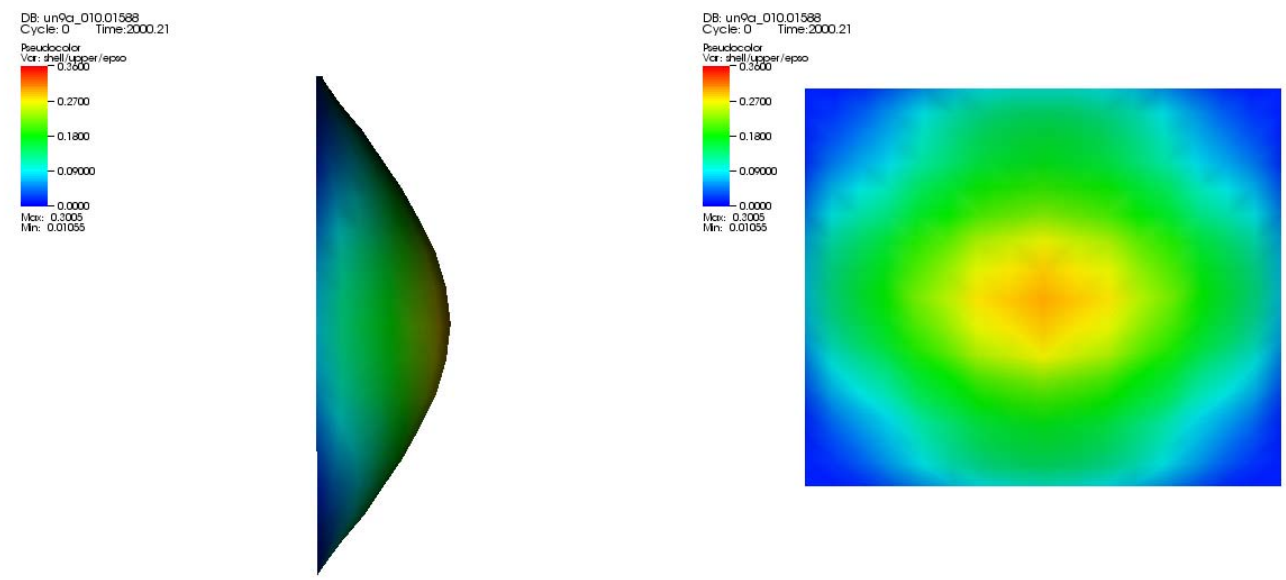

Figure 9: Computed fringe plot of effective plastic strain in the plate

\subsection{CONCLUSIONS}

Presented here is an exercise carried out to validate (with an experiment out of the literature) the process of implementing LLNL's ALE3D to predict the permanent deformation and rupture for an air-backed steel plate subjected to underwater shock. A computational model is built using the Jones-Wilkins-Lee equation of state (EOS) for the pressure-volume response of detonation products, the Gruneisen EOS for propagation of shock underwater, and a bilinear elasticplastic curve with failure for the deviatoric response of a steel plate. 
There was no available equation of state data for the explosive used in experiment, so properties were assumed based on the properties of a known plastic explosive. Initial results from the computation show that the computed magnitude of plastic deformation diverges from the experimentally obtained values, and that this divergence worsens as the explosive weight increases. It can be concluded that the results are sensitive to the energetics of the explosive and that the exponential terms in the JWL EOS influence this sensitivity and subsequent divergence. In this paper, a linear relationship is used to reduce the equivalent input weights for the calculations and this leads to good agreement with experimental data.

These computations clearly demonstrate the capability of computing fullycoupled, fluid-structure, interaction problems with LLNL's ALE3D, specifically for the structural response of underwater explosions. Although it remains to be demonstrated, it is assumed that this process can be implemented to robustly predict the response of any thin-walled structure to blast loading. 


\subsection{REFERENCES}

[1] Ramajeyathilagam, K. and C. P. Vendhan, "Deformation and rupture of thin rectangular plates subjected to underwater shock", International Journal of Impact Engineering, Vol. 30, pp.699-719, (2004).

[2] Anderson, A. et. al. "User Manual for ALE3D, An arbitrary Lagrange Eulerian System, Version 3.4” Lawrence Livermore National Laboratory, January 31, 2003.

[3] Cole, R. H., Underwater Explosions, Princeton University Press, 1948.

[4] Whirley, R.G. and B. E. Engelmann, "DYNA3D User Manual", UCRL-MA107254, November 1993.

[5] Molyneaux, T. C., L. Li, and N. Firth, "Numerical Simulations of Underwater Explosions”, Computers Fluids Vol. 23, No. 7, PP. 903-911 (1994).

[6] Clutter, J. K., and M. Stahl, "Hydrocode simulations of air and water shocks for facility vulnerability assessments”, Journal of Hazardous Materials, vol. 9, no. 24, pp. 9-24, (2004).

[7] Driels, M. R., "The effect go a non-zero cavitation tension on the damage sustained by a target plate subject to an underwater explosion” Journal of Sound and Vibration, vol. 73, no. 4, pp. 533-545, (1980). 


\title{
19.0 Bubble Collapse Phenomenology
}

\section{SIMULATION OF UNDERWATER EXPLOSION BUBBLE DYNAMICS USING ALE3D}

\author{
Timothy A. Dunn
}

\section{Introduction}

The goal of this project was to evaluate the computer code ALE3D for simulation of underwater detonations of high explosives. Special attention was paid to the evolution and dynamics of the explosive bubble, including bubble collapse. Impulse loading on nearby structures was also investigated. This is not the first time ALE3D has been used to model these phenomena. Earlier versions of ALE3D have successfully predicted underwater bubble dynamics and their impact on structures (Couch et. al. [1]). This study attempts to reproduce some of those results using the current version of ALE3D. This study is expected to provide insight into modeling requirements such as grid refinement and proper initialization steps.

The physics of an underwater explosion can be divided into phases. First, the explosive is detonated, where chemical reactions convert the HE into a high-temperature, high-pressure gas bubble. The high pressure in the gas begins the next phase by causing the bubble to expand. Thus, the bubble "pushes" the water out of the way. The outward motion of the water is accompanied by a large pressure wave, i.e. shock. The pressure inside the bubble decreases as its volume increases. Ultimately the pressure drops to hydrostatic levels, i.e. the pressure inside the bubble is equal to the pressure in the surrounding fluid. However, the bubble continues to expand due to inertia. As the bubble pressure continues to drop, the pressure outside becomes increasingly greater than the pressure inside and the expansion slows down, until ultimately the expansion stops.

The pressure in the gas bubble is now lower than that of the surrounding water. This starts the next phase of the process. The high water pressure pushes in on the gas bubble, causing it to contract inward. This phenomenon is known as bubble collapse. As the bubble shrinks, the gas pressure increases. Once again, inertia will cause the bubble to overshoot the equilibrium point. The motion will finally stop when the bubble reaches its minimum size, resulting in another high-pressure bubble.

Left with another high-pressure bubble, the system is in a state similar to the one just after the detonation. Therefore, we can see that the bubble will undergo a number of cycles of expansion and contraction. At the beginning of each cycle, the initiation of outward motion by the gas bubble and surrounding liquid is accompanied by a pressure pulse propagating into the liquid. The pressure pulse is generated from a much slower phenomenon that the original detonation. Therefore, the peak pressure in the pulse is much lower than the original shock wave. However, the duration of this pulse can be much longer than the leading shock, and thus the overall impulse of the pressure pulse may be even greater than the impulse resulting from the primary shock. Since the density of the gas in the bubble is much smaller than the surrounding liquid, the bubble is affected by buoyancy and the bub- 
ble will migrate to the surface. The motion of an explosive bubble and the accompanying pressure time-history is shown in Figure 38 as taken from Swisdak [3].

In addition to buoyancy, the motion of the explosive bubble may be influenced by its proximity to other surfaces. As the pressure waves emitted from the explosive reflect off nearby surfaces, refraction waves propagate from the surfaces relieving the pressure and creating a non-isotropic pressure field. This results in a non-uniform pressure distribution on the bubble surface and can cause the gas bubble to migrate or jet towards the adjacent surface.

The ability of ALE3D to correctly simulate and predict the aforementioned behavior was analyzed with a series of test cases.

- Underwater Spherical Explosion Shock

- Underwater Spherical Bubble Collapse

- Underwater Explosion Bubble Collapse Against a Flat Plate

- Bubble-Cylinder Interaction

ALE3D version 3.9.x was used for the current simulations.

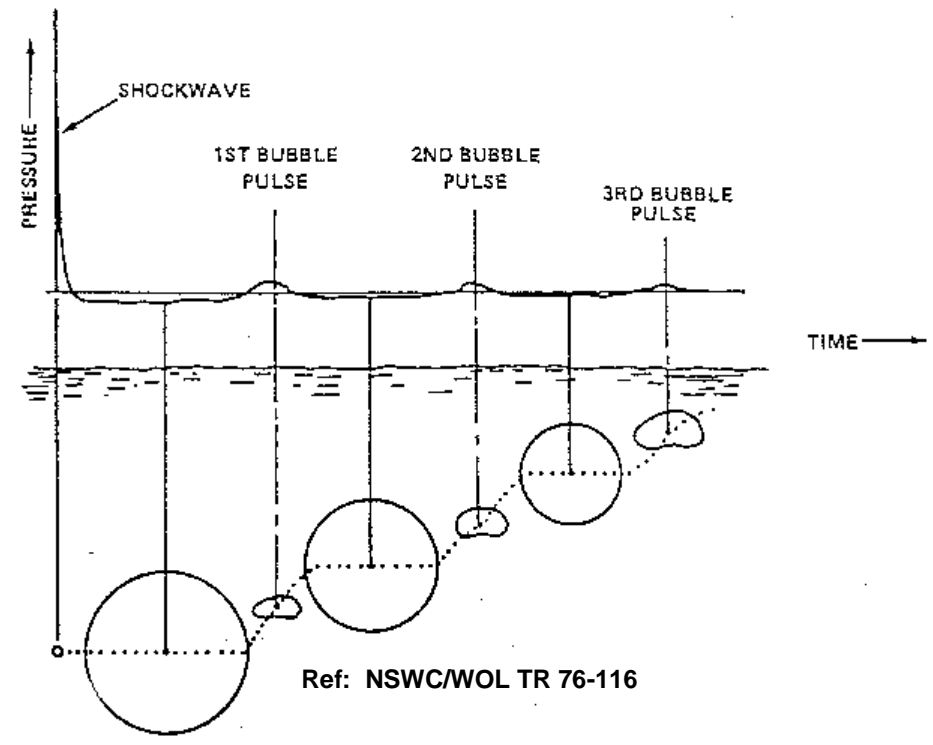

FIGURE 38. Pressure time-history and bubble evolution of an underwater explosion. Figure taken from Ref. NSWC/WOL TR 76-116.

\section{Underwater Spherical Explosion and Bubble Collapse}

The first test cases are compared with data from Wardlaw [2]. Wardlaw used a 1-D Eulerian code to simulate spherical explosion shocks in water using highly resolved meshes. The tests used a sphere of high explosive with a radius of $16 \mathrm{~cm}$ surrounded by water. Wardlaw used JWL and Tait equations of state to simulate the HE and water respectively. 
The ALE3D simulations used a 3-D mesh with 1/8-symmetry. They were performed on 4 grids with 11072, 21632, 42752, and 84992 grid elements. The outer boundary was constrained and utilized a non-reflective boundary condition. The following material models were used:

- Water: Gruneisen EOS with coefficients: .148e6 2.56 -1.986 .2268 0.50 .

- HE: JWL EOS with coefficients: 5.484e12 0.09375e12 4.94 1.21 0.28

The first test looked at the expansion of the HE bubble. The initial radius of the bubble was $16 \mathrm{~cm}$ and the outer boundary was located $1000 \mathrm{~cm}$ from the center. The outer boundary is far enough away that the pressure wave does not propagate to the boundary before the simulation is terminated at $5 \mathrm{msec}$. This test looked at the pressure variation within the flow-field, paying special attention to the peak pressures. Figure 39 shows the pressure time-history curves taken at a location $121 \mathrm{~cm}$ from the origin. The predicted pressurewave arrival time is found to be approximately the same for each of the 4 grids. The peak pressure increases with grid refinement, indicating that very fine grids are required to accurately predict the peak values of pressure. The peak pressure predicted with the finest grid is approximately $1.8 \mathrm{E} 9$ dyne/cm2, compared to a value of $1.9 \mathrm{E} 9 \mathrm{dyne} / \mathrm{cm} 2$ predicted in Wardlaw. Although the coarse-grid simulations underestimate the peak-pressure values, the overall impulse of the pressure wave (the integrated value of pressure over time) is similar for all grid solutions. Therefore, it is expected that the overall impact of an explosive detonation on near-by structures can be accurately predicted by a reasonably coarse mesh.

The next test used a similar geometry, but the simulation was extended out to $150 \mathrm{msec}$ in order to observe the collapse of the bubble. To eliminate the effect of the far-field, the outer boundary was moved out to $10,000 \mathrm{~cm}$. Figure 40 shows the variation of the bubble radius with time. The four grids provide similar results. The Wardlaw data indicates a maximum bubble radius of approximately $220 \mathrm{~cm}$ and a minimum radius after collapse of $30 \mathrm{~cm}$, which occurs around $130 \mathrm{msec}$ after the HE is lit. 


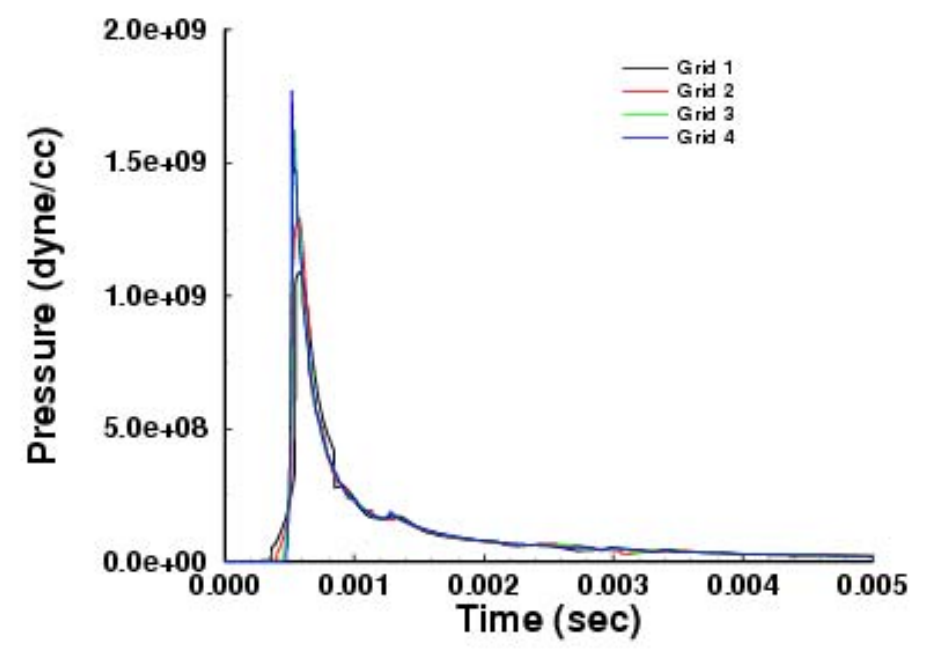

FIGURE 39. Pressure time-history for an underwater spherical explosion. Pressures data taken $121 \mathrm{~cm}$ from the center of the HE.

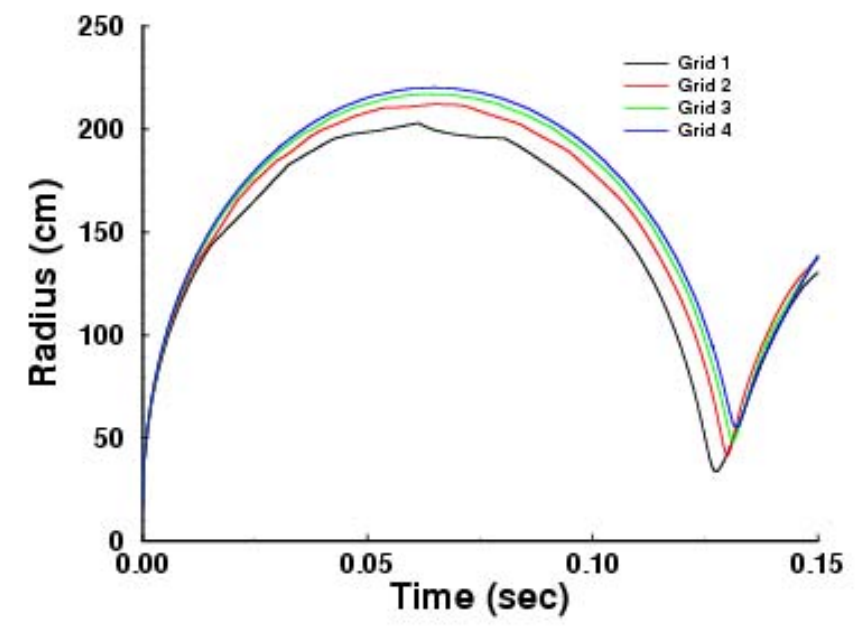

FIGURE 40. Bubble radius for an underwater spherical explosion with bubble collapse.

\section{Underwater Explosion Bubble Collapse Against a Flat Plate}

The next test problem looked at the interaction of an underwater explosion bubble with a flat plate. Experiments were performed at the Naval Undersea Warfare Center (NUWC) Seneca Lake Sonar Test Facility at Dresden, New York. The experimental results are documented in Thrun, et. al. [4]. ALE3D was used to simulate the experiment denoted as "Shot \#3" in the report. 
In the experiment, a 14-gram charge of $\mathrm{CH}-6$ was detonated 5.12 inches below a flat circular plate. The steel plate was 1-inch thick and 70 inches in diameter. In the center of the plate was a 12-inch diameter, 6-inch thick aluminum plug, which housed 11 pressure gages spaced 1 inch apart. The target was designed to be essentially rigid. The entire apparatus, along with its support structure was lowered to a depth of 317.2 feet below the water surface for the experiment. The experimental setup is shown in Figure 41.

The ALE3D simulation modeled the flat plate, plug, water, and the explosive charge. It is not believed that including the support structure would modify the results significantly. The computational setup is shown in Figure 42. Two lines of symmetry were utilized in the vertical directions to reduce the problem size. The computational setup was chosen to closely resemble the simulations reported by Couch et. al. [1]. Our simulation used a total of 188,388 brick elements. The steel plate and aluminum plug were modeled with a Lagrangian mesh, while the fluid used ALE techniques with mesh relaxation. The water was divided into near- and far-field regions, with identical material properties, to better control the mesh relaxation. The fluid-solid boundary was separated with a slide interface with slip conditions on the surface. Transition zoning (9:1) was utilized in the water to reduce the number of far-field elements. Gravity was turned on in the simulation, but the initial hydrostatic equilibrium condition was not initialized. The pressure was initialized with a value consistent with the charge depth. The far-field boundaries were constrained in the $\mathrm{x}, \mathrm{y}$, and $\mathrm{z}$ directions. Non-reflecting boundary conditions were specified on the outer boundaries to help reduce the effect of reflected pressure waves. The following material models were used:

- Steel: SGEOS \#28

- Aluminum: SGEOS \#89

- CH-6: JWL EOS with coefficients: 5.37360 .20914 .51 .50 .3

- Water: LEOS \#2010

A constant pressure gas was also used at the top of the computational domain. In the presented solutions an LEOS equation of state was used for the water. On earlier simulations a Gruneisen form was used. Comparisons of the results using the two equations of state revealed negligible differences.

Figure 43 shows various stages of the bubble evolution. The first stage $(0 \mathrm{msec})$ shows the initial configuration. At $6 \mathrm{msec}$ the bubble has reached its maximum diameter. At 10 msec the bubble has reduced in size and is in the process of collapsing. By $11 \mathrm{msec}$ a jet has formed and is striking the plate. Note that these images reveal a slight bending of the plate for each snapshot.

Figure 44 shows a pressure time-history at the centerline of the plate surface. These timehistories are just showing the time frame during the bubble collapse and jetting (i.e. the initial pressure shock is not seen in these plots). Computational and experimental results are shown in separate plots. Two separate lines are given for the computational results; one obtained from a Lagrangian tracer particle and the other from an Eulerian tracer particle. Neither tracer is expected to give the actual pressure in the simulation, as their loca- 
tions will both drift away from the plate surface. However, the tracers do give an estimate of the predicted pressure history. Both the experimental and computational graphs show the peak pressure is about 10,000 psi and the duration of the pulse is approximately 1 msec. Figure 45 shows plots for pressure probes located 1 inch off the centerline from which similar conclusions may be drawn.
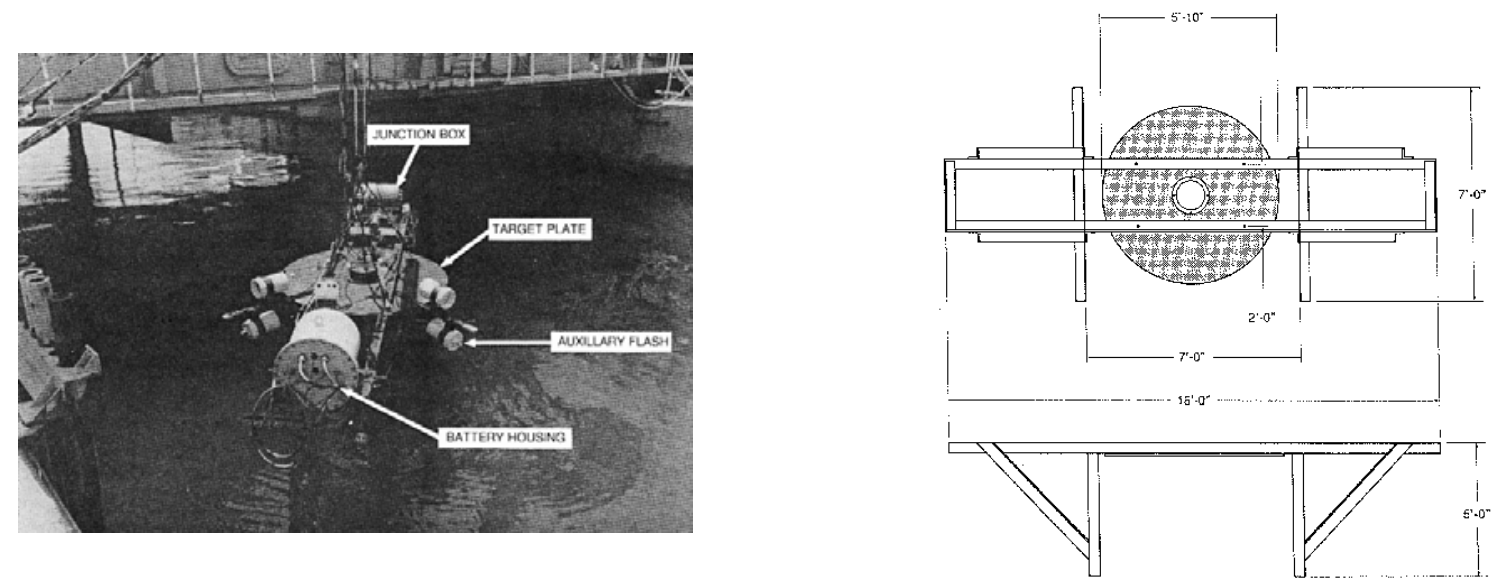

FIGURE 41. Experimental setup of underwater explosion bubble collapse against a flat plate. Figure taken from Ref. NSWCDD/TR-92/482.
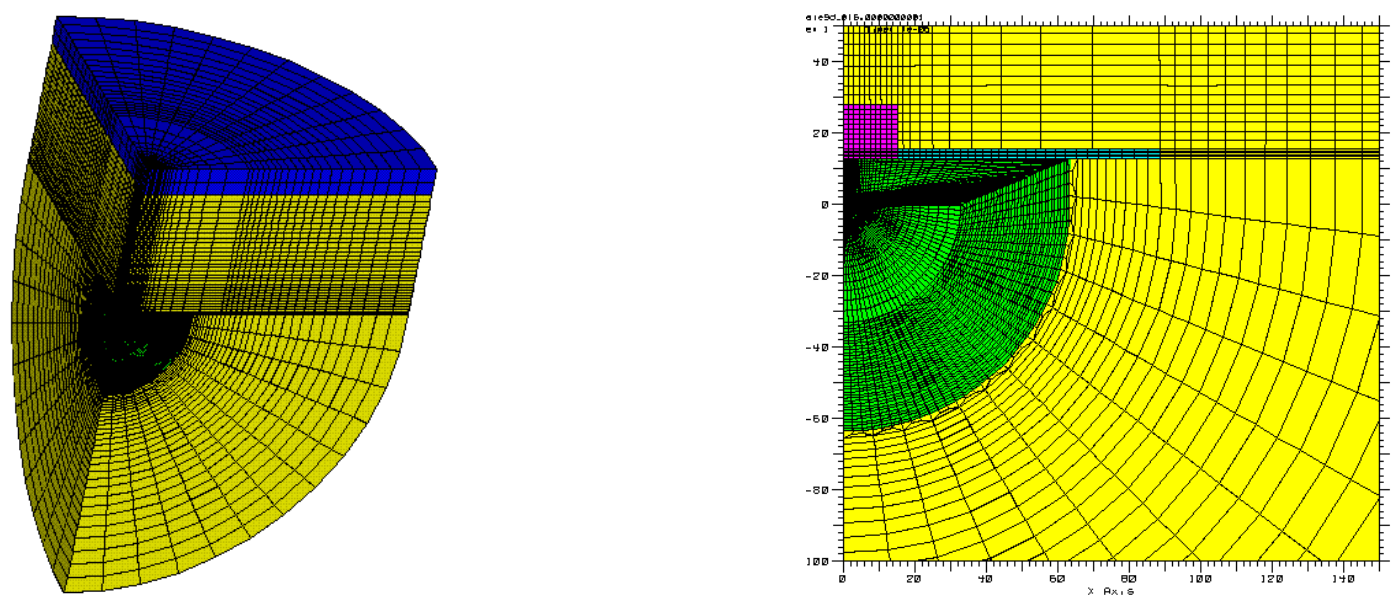

FIGURE 42. Computational setup and initial mesh of underwater explosion bubble collapse against a flat plate. 

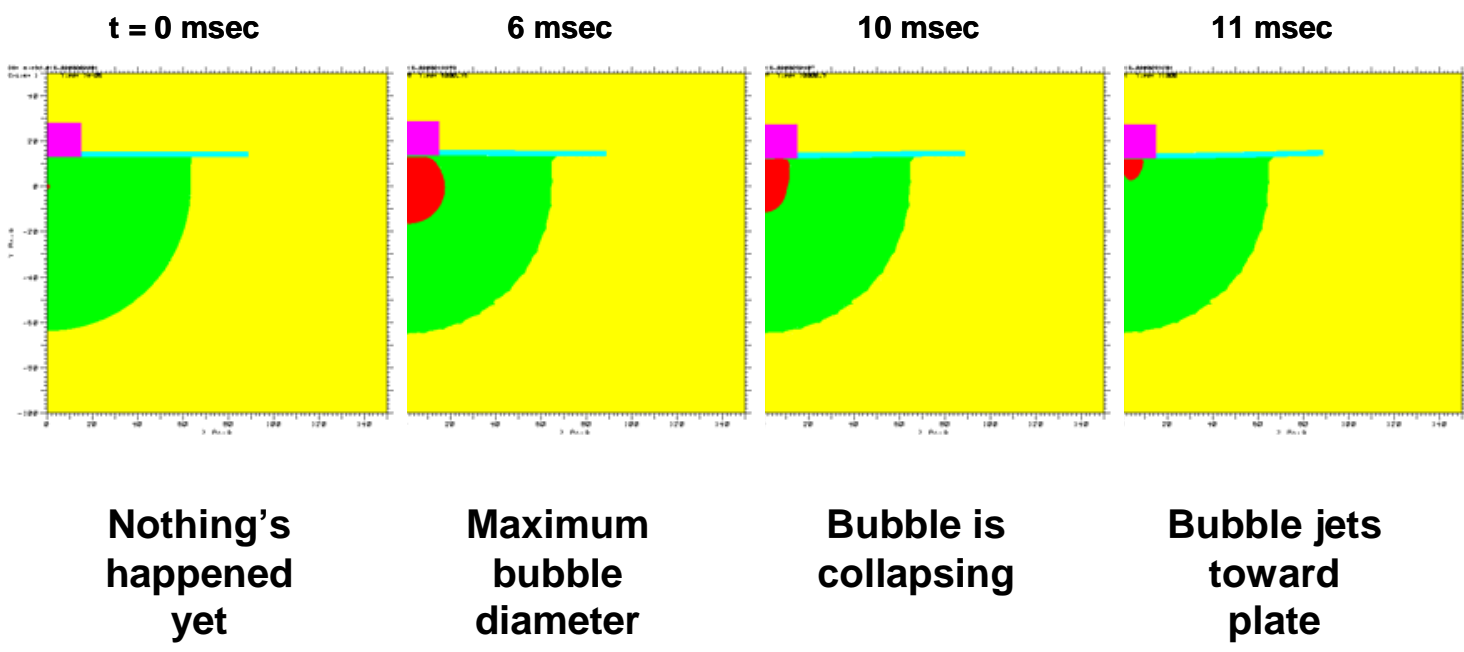

\section{Bubble is \\ collapsing}
Bubble jets
toward
plate

FIGURE 43. Stages in a bubble collapsing near a flat plate.
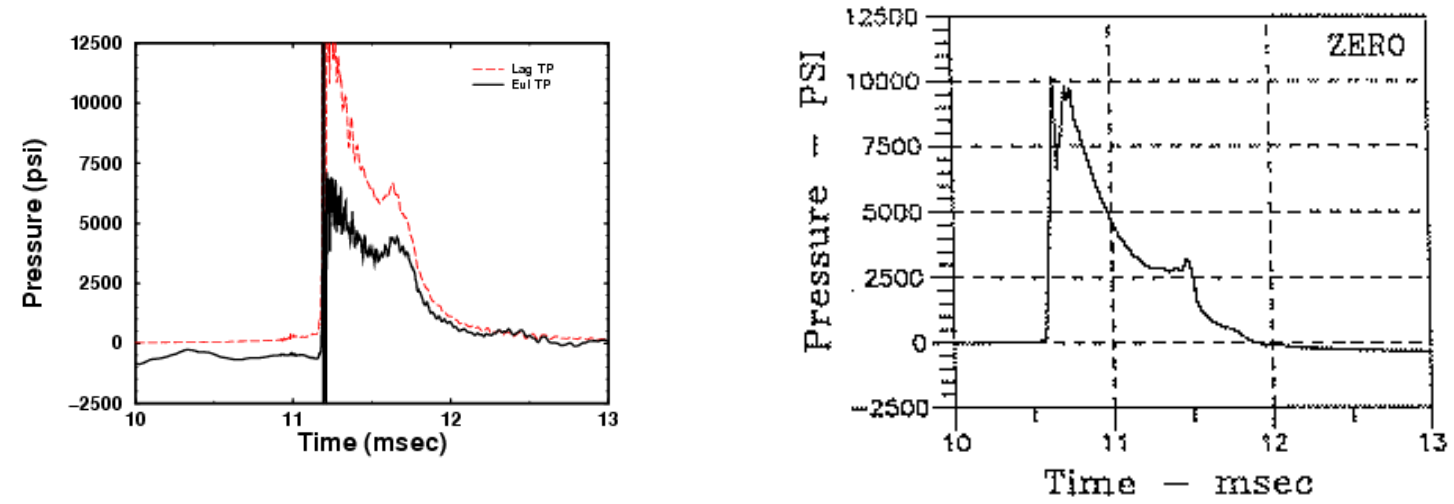

FIGURE 44. Pressure time history taken at the surface of the plate at the centerline. A) Computational Prediction, B) Experimental Data (Ref. NSWCDD/TR-92/482). 

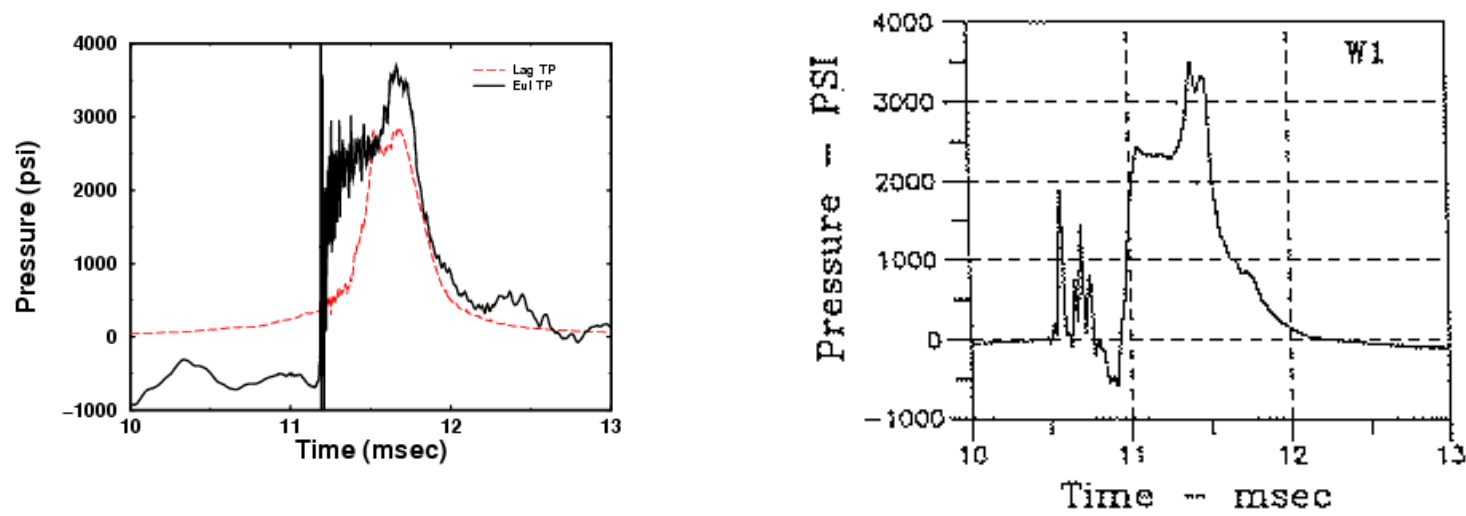

FIGURE 45. Pressure time history taken on the surface of the plate at a radial location 1 inch away from the centerline. A) Computational Prediction, B) Experimental Data (Ref. NSWCDD/TR-92/482).

\section{Bubble-Cylinder Interaction}

The final test case presented here involves a charge detonated near a rigid cylinder. Experiments were performed in the NSWC hydro-ballistic tank and are described in NSWCDD/TR-93/162 [5]. The experiments provided high-speed camera images of the bubble evolution. ALE3D was used to model the experiment and the simulated bubble shapes were compared to the data. This test case was also modeled with an earlier version of ALE3D as described in Couch et. al. [1]. The current ALE3D simulations were in good agreement with both the experimental data and the previous ALE3D model.

This simulation used 451,548 brick elements. One symmetry plane was used to cut the problem size in half. The initial geometry and mesh is shown in Figure A-9. The problem consisted of a 1.1-gram charge of PETN, which was detonated 12.71 inches to the side of a rigid cylinder with a diameter of 21.375 inches. The charge and cylinder were placed at a depth of 3.94 feet and the air in the tank was set at a pressure equivalent to 2.05 feet of water. The following materials were used:

- Water: Gruneisen EOS with coefficients: .148e0 2.56 -1.986.2268 0.5 0.

- PETN: JWL EOS with coefficients: 6.30040 .20664 .51 .50 .29

- Air: Constant pressure gas (i.e. polynomial with coefficients: 0.06e-6 000000 )

The rigid cylinder was modeled as a boundary condition with the surface nodes constrained in the $\mathrm{x}, \mathrm{y}$, and $\mathrm{z}$ directions. Symmetry boundary conditions were used to enforce a no-penetration type boundary on all external boundaries. Gravity was turned on in the simulations. The pressure was initialized to hydrostatic levels using the variable density initialization capabilities in ALE3D. Mesh relaxation was turned on for all nodes in the problem, but a relax hold option was used in the far field to help keep adequate mesh refinement near the charge and cylinder.

Figure A-10 shows the experimental data for the problem. This data shows that the bubble reaches its maximum diameter at $77.3 \mathrm{msec}$ after the detonation. It then collapses and 
migrates up and toward the cylinder. Originally, the bubble is fairly spherical in shape, but as it shrinks, it becomes more oblong and "bean" shaped. Figures A-11--16 show the computational results for the bubble shape. As in the experimental data, the simulation shows the bubble migrates up and toward the cylinder as it collapses. The computations also exhibit a final oblong shape of the bubble. It is important to note that the bubble shapes shown in the computational plots are obtained by taking an orthogonal slice down the center of the bubble, while the experimental shapes are acquired from photographs and thus show the shape of the external surface and not the shape at the centerline.

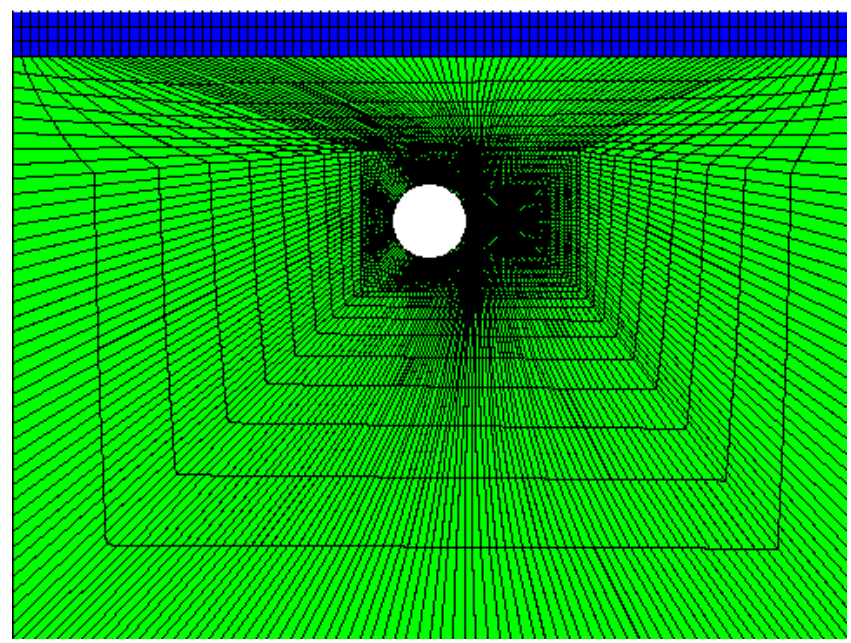

FIGURE 46. Computational setup and initial mesh for the Bubble-Cylinder Interaction test case.

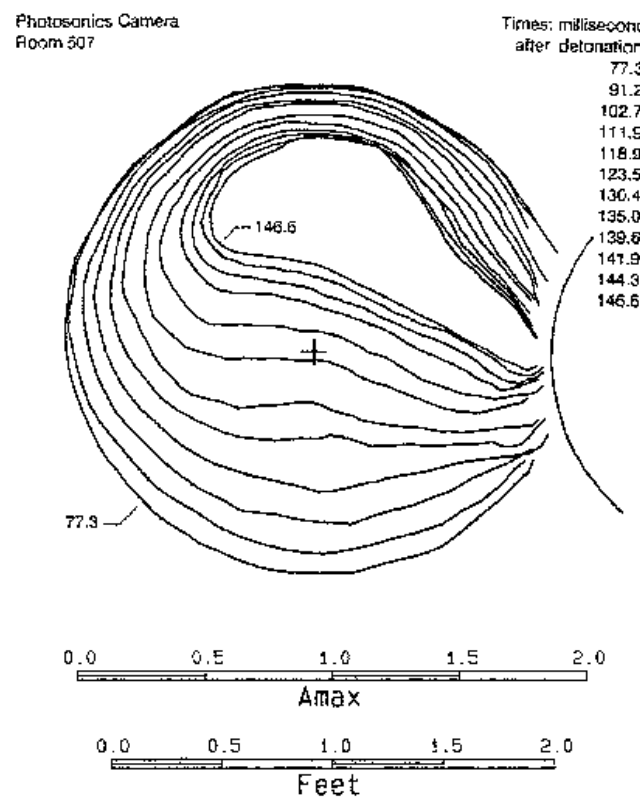

FIGURE 47. Experimental data for bubble-cylinder interaction. Shows outlines of bubble shapes obtained from high-speed camera images. Figure taken from Ref. NSWCDD/TR-93/ 162. 


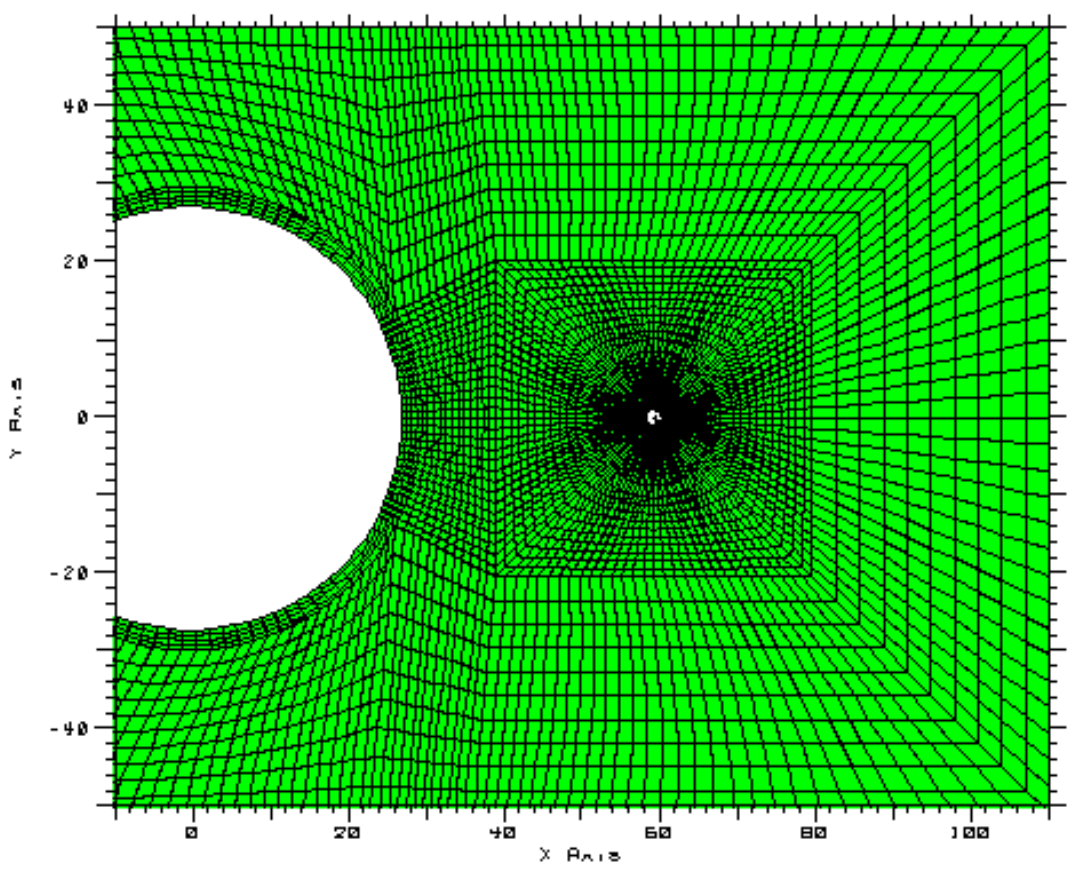

FIGURE 48. Computational grid and material geometry along bubble centerline showing bubble-cylinder interaction. Taken at 0 msec.

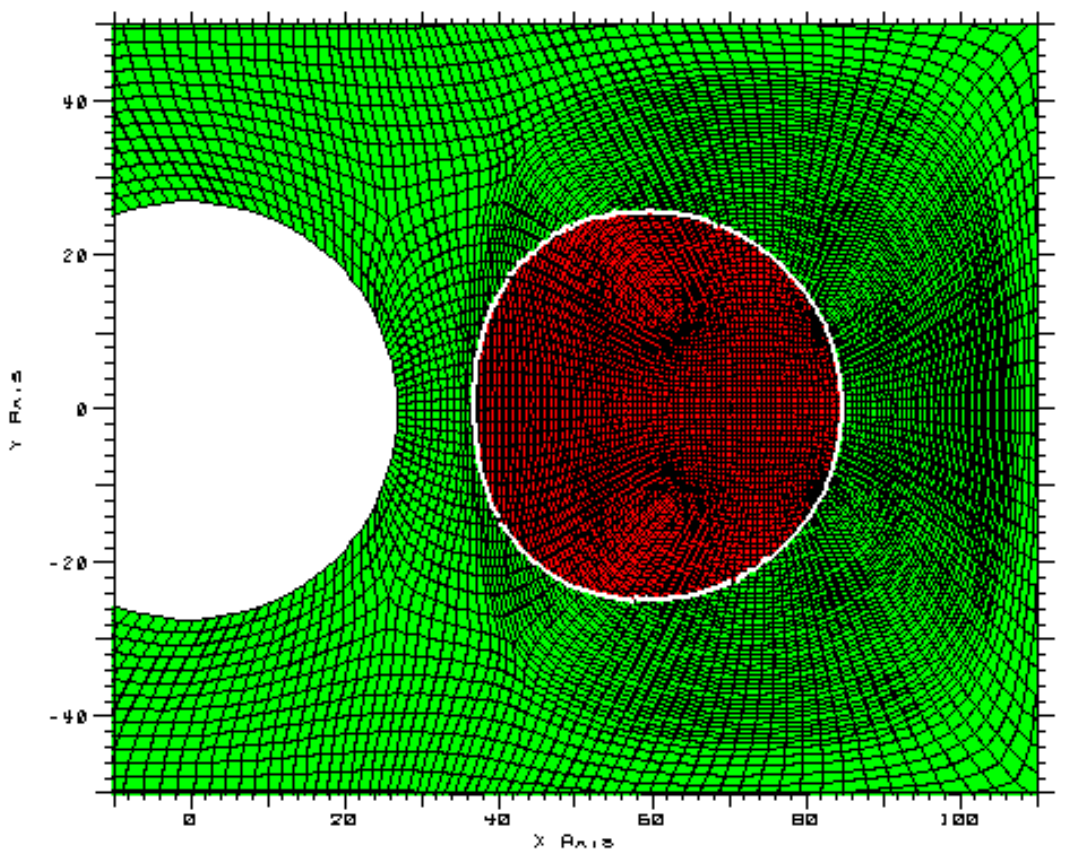

FIGURE 50. Computational grid and material geometry along bubble centerline showing bubble-cylinder interaction. Taken at 23.2 msec. 


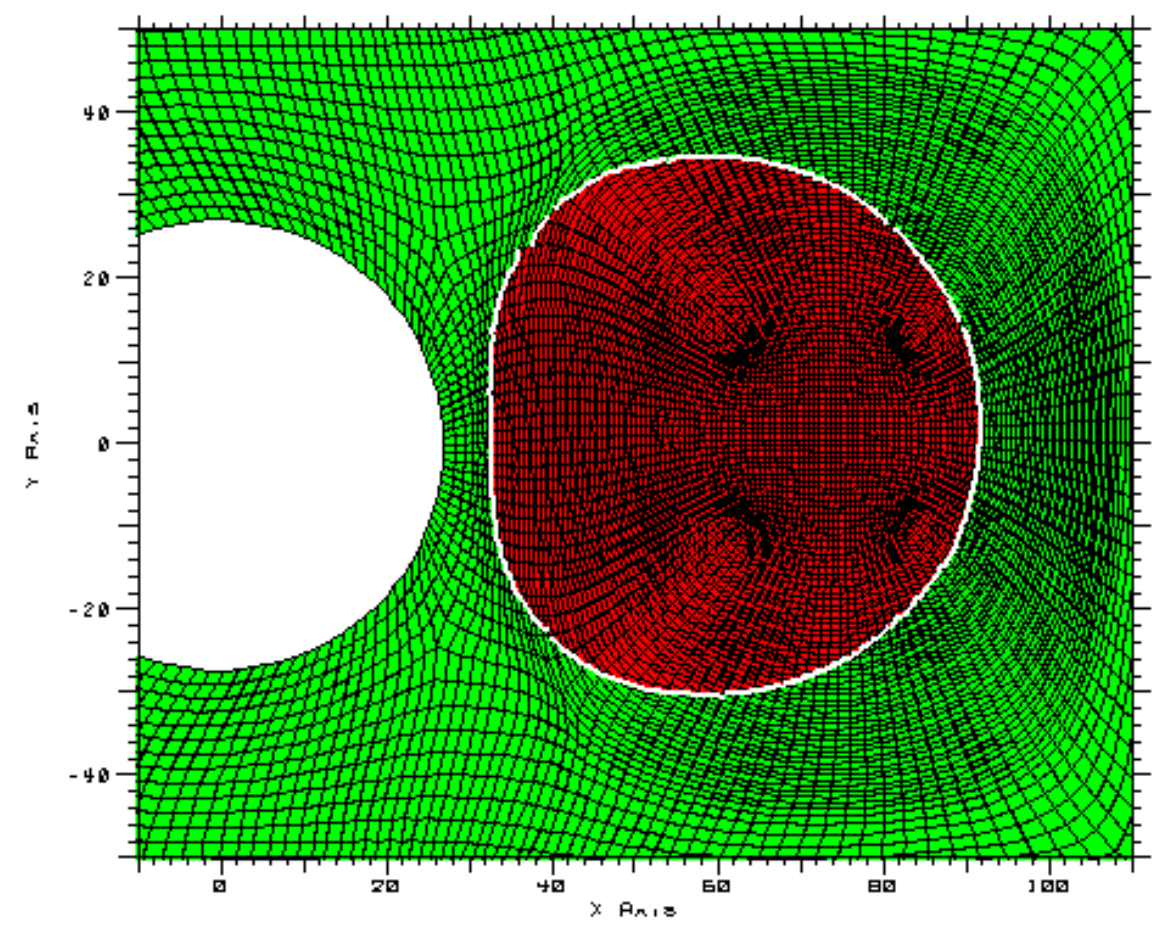

FIGURE 51. Computational grid and material geometry along bubble centerline showing bubble-cylinder interaction. Taken at 65.0 msec.

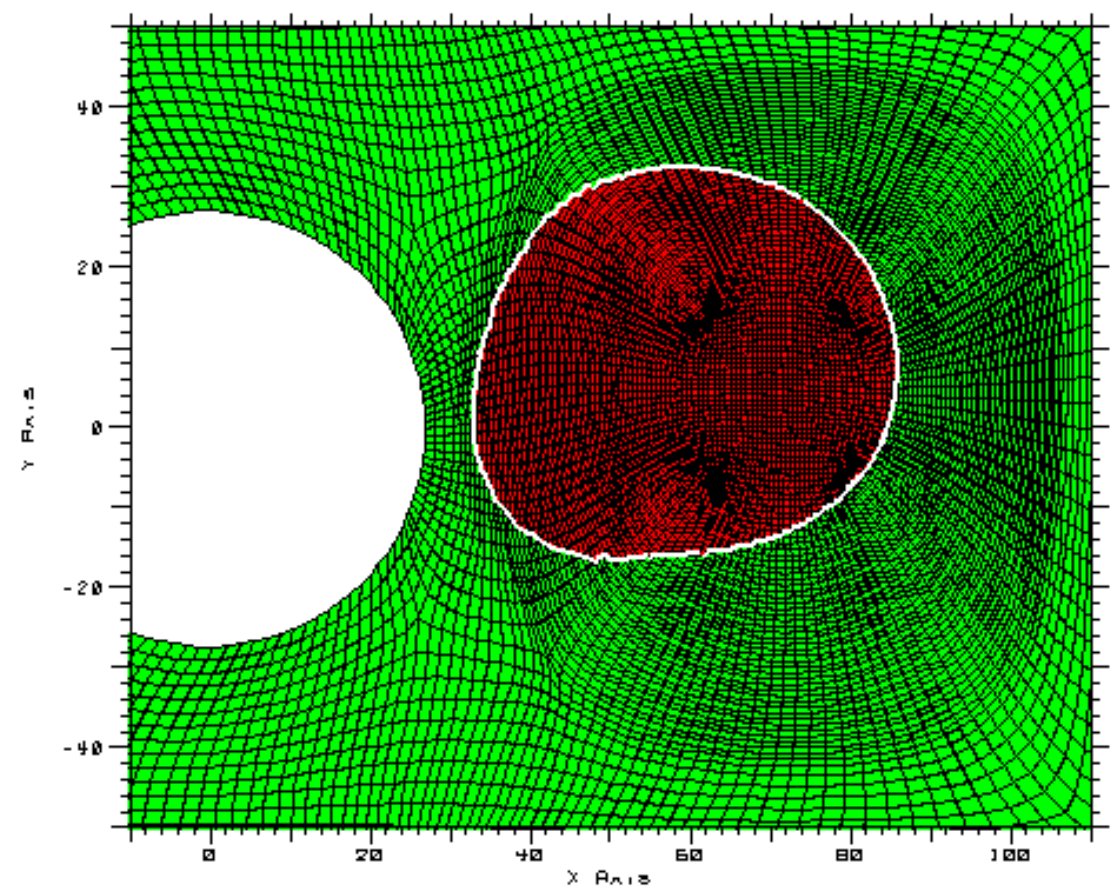

FIGURE 52. Computational grid and material geometry along bubble centerline showing bubble-cylinder interaction. Taken at 115.0 msec. 


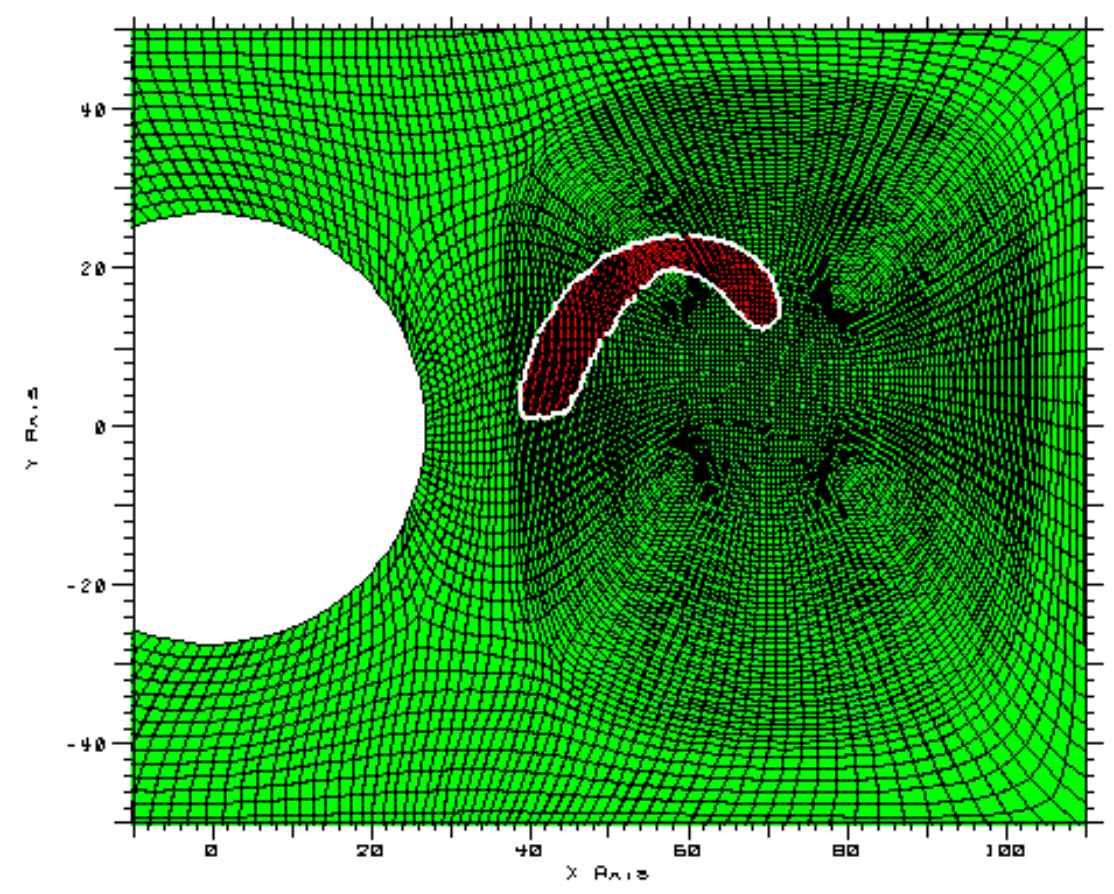

FIGURE 53. Computational grid and material geometry along bubble centerline showing bubble-cylinder interaction. Taken at 141.0 msec.

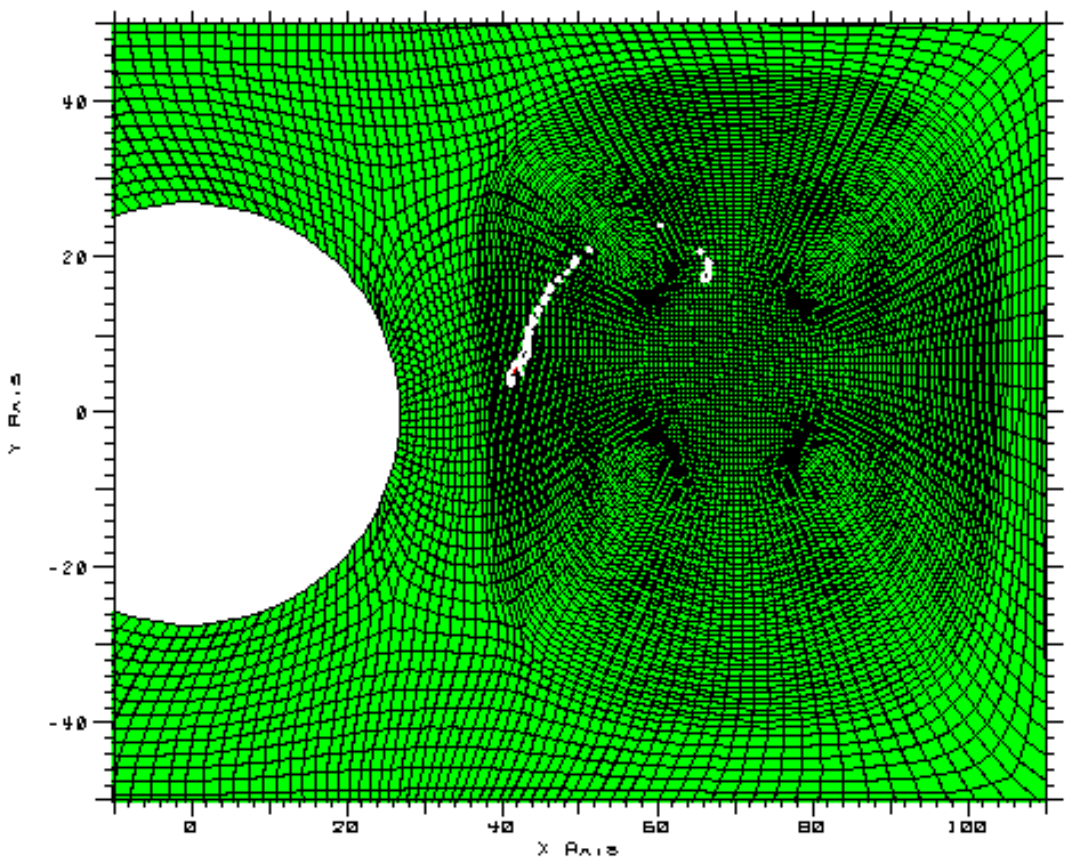

FIGURE 54. Computational grid and material geometry along bubble centerline showing bubble-cylinder interaction. Taken at 144.1 msec. 


\section{References}

1. 1.R Couch, D Faux, "Simulation of Underwater Explosion Benchmark Experiments with ALE3D", 1996, UCRL-CR-123819.

2. 2.AB Wardlaw, "Underwater Explosion Test Cases", 1998, NSWC/IHTR 2069.

3. 3.MM Swisdak, ed. "Explosion Effects and Properties: Part II - Explosion Effects in Water", 1978, NSWC/WOL/TR 76-116.

4. 4.R Thrun, JF Goertner, GS Harris, "Underwater Explosion Bubble Collapse Against a Flat Plate. 1992 Seneca Lake Test Series Data Report", 1993, NSWCDD/TR-92/482.

\section{5.1993, NSWCDD/TR-93/162}

\subsection{Concrete Benchmark Experiment}

These benchmark experiments, called the "Precision Panel Concrete Breach Benchmark Tests", were completed in 1997 by the U.S. Army Corps of Engineers Waterways Experiment Station (WES) located in Vicksburg, now called the Engineering Research and Development Center (ERDC). The test configuration is shown in Figure 55. The test consisted of a 1"x4.85" comp C-4 charge placed inside a 1.0"diameter by 8.4 "deep hole located in the center of a 6' $\times 6$ ' reinforced concrete wall. The rebar detail is \#5 rebar with 5 " spacing and a 1.5 " cover.

The ALE3D finite element model used for this benchmark experiment used approximately 120,000 8-node brick elements to model the air, HE, rebar, and concrete. The ALE3D porous crush concrete material was used to model the concrete, an elastic-plastic material model for the steel reinforcement, a JWL equation of state for the high explosive, and a Gamma Law gas EOS for air. Due to the high deformation of the concrete and steel, an advection method - equipotential relaxation - was used to relax all materials within the mesh. Figure 56 and Figure 57 show a comparison between experimental results and ALE3D simulation. The radius of concrete damage, or the radius of the red region in the center of the panel, was calculated by ALE3D to be approximately $33 \mathrm{~cm}$. The radius of concrete damage on the back side of the panel was calculated to be approximately $30 \mathrm{~cm}$. A plot of concrete damage and relative volume for a slice through the center of the concrete panel is also shown in Figure 56. By studying the regions of red for concrete damage and concrete relative volume greater than 1.2, it appears that ALE3D predicts possible cratering between 30 and $40 \mathrm{~cm}$ for the back and front sides of the concrete panel. The average back crater radius for the experiment was $31.75 \mathrm{~cm}$ and the average front crater radius was $35.56 \mathrm{~cm}$. The cratering and extent of damage computed with the ALE3D program is in good agreement with the experimental observations. 

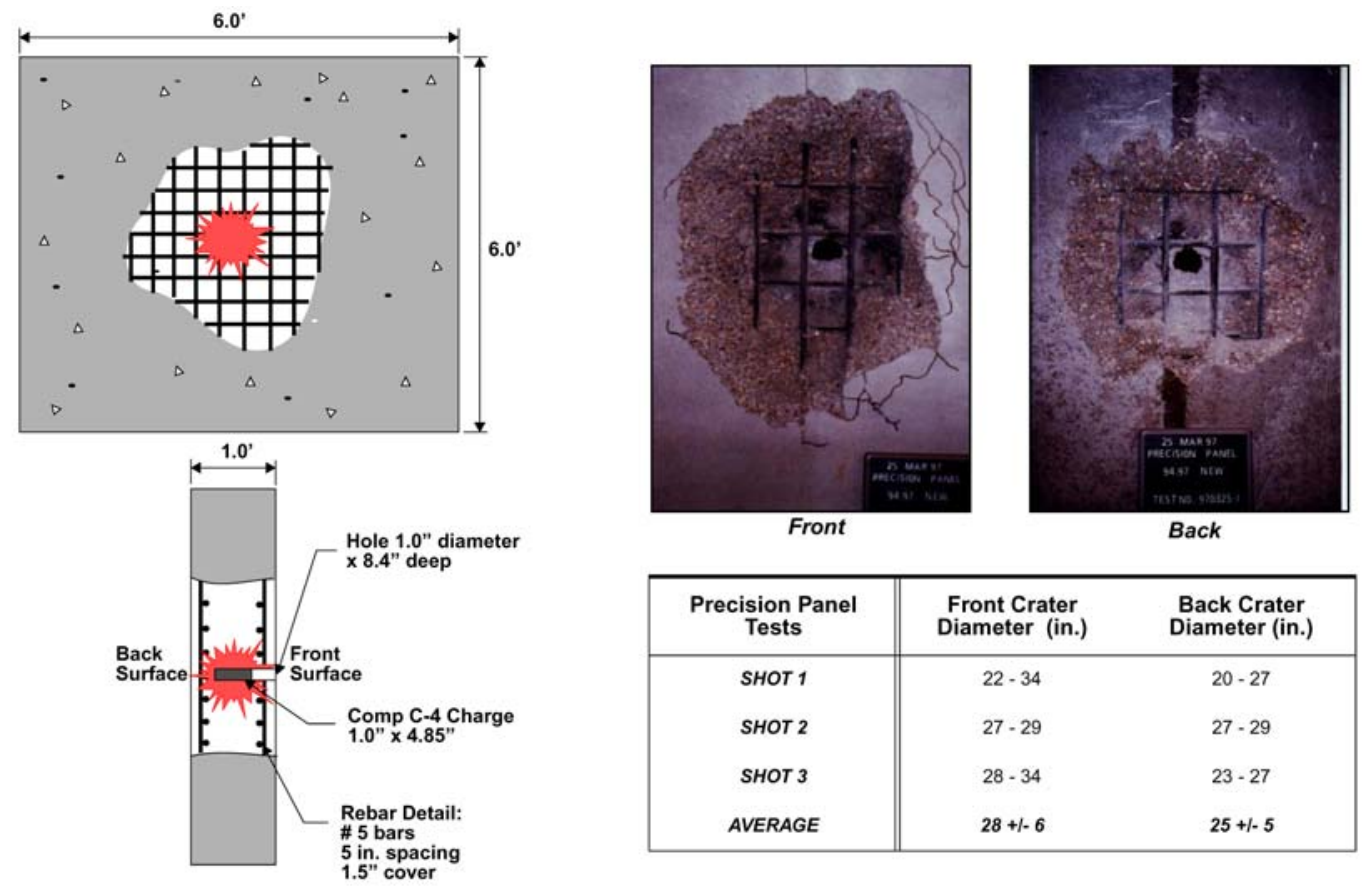

\begin{tabular}{|c||cc|}
\hline $\begin{array}{c}\text { Precision Panel } \\
\text { Tests }\end{array}$ & $\begin{array}{c}\text { Front Crater } \\
\text { Diameter (in.) }\end{array}$ & $\begin{array}{c}\text { Back Crater } \\
\text { Diameter (in.) }\end{array}$ \\
\hline SHOT 1 & $22-34$ & $20-27$ \\
SHOT 2 & $27-29$ & $27-29$ \\
SHOT 3 & $28-34$ & $23-27$ \\
AVERAGE & $28+1-6$ & $25+1-5$ \\
\hline
\end{tabular}

FIGURE 55. Description of concrete benchmark experiment. 


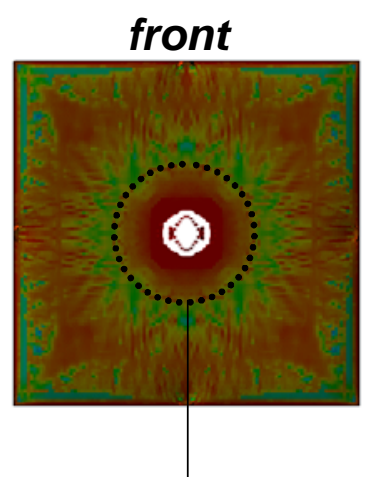

$33 \mathrm{~cm}$ radius

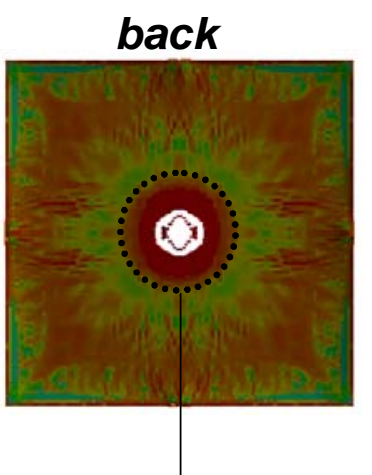

$30 \mathrm{~cm}$ radius

\begin{tabular}{|c|c|c|}
\hline $\begin{array}{c}\text { Precision Panel } \\
\text { Tests }\end{array}$ & $\begin{array}{l}\text { Front Crater } \\
\text { Radius (cm) }\end{array}$ & $\begin{array}{l}\text { Back Crater } \\
\text { Radius }(\mathbf{c m})\end{array}$ \\
\hline Shot 1 & $27.94-43.18$ & $25.4-34.29$ \\
\hline Shot 2 & $34.29-36.83$ & $34.29-36.83$ \\
\hline Shot 3 & $35.56-43.18$ & $29.21-34.29$ \\
\hline Average & $35.56(+/-7.62)$ & $31.75(+/-6.35)$ \\
\hline
\end{tabular}

Slice through center of panel (quarter symmetry used for calculation)

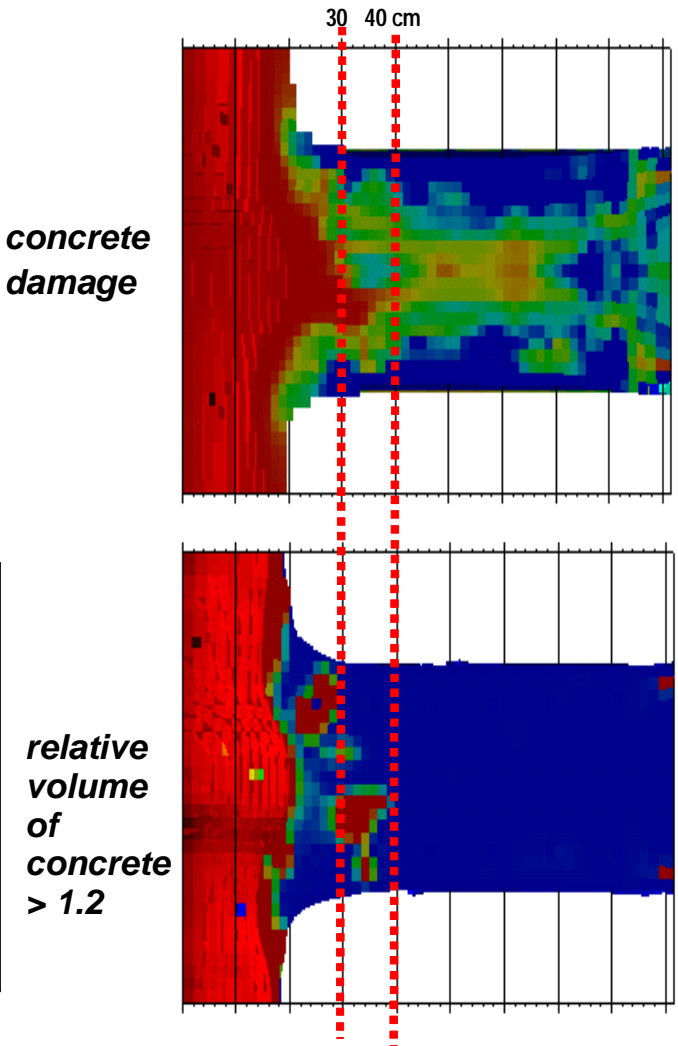

FIGURE 56. Comparison between experimental results and ALE3D simulation. 

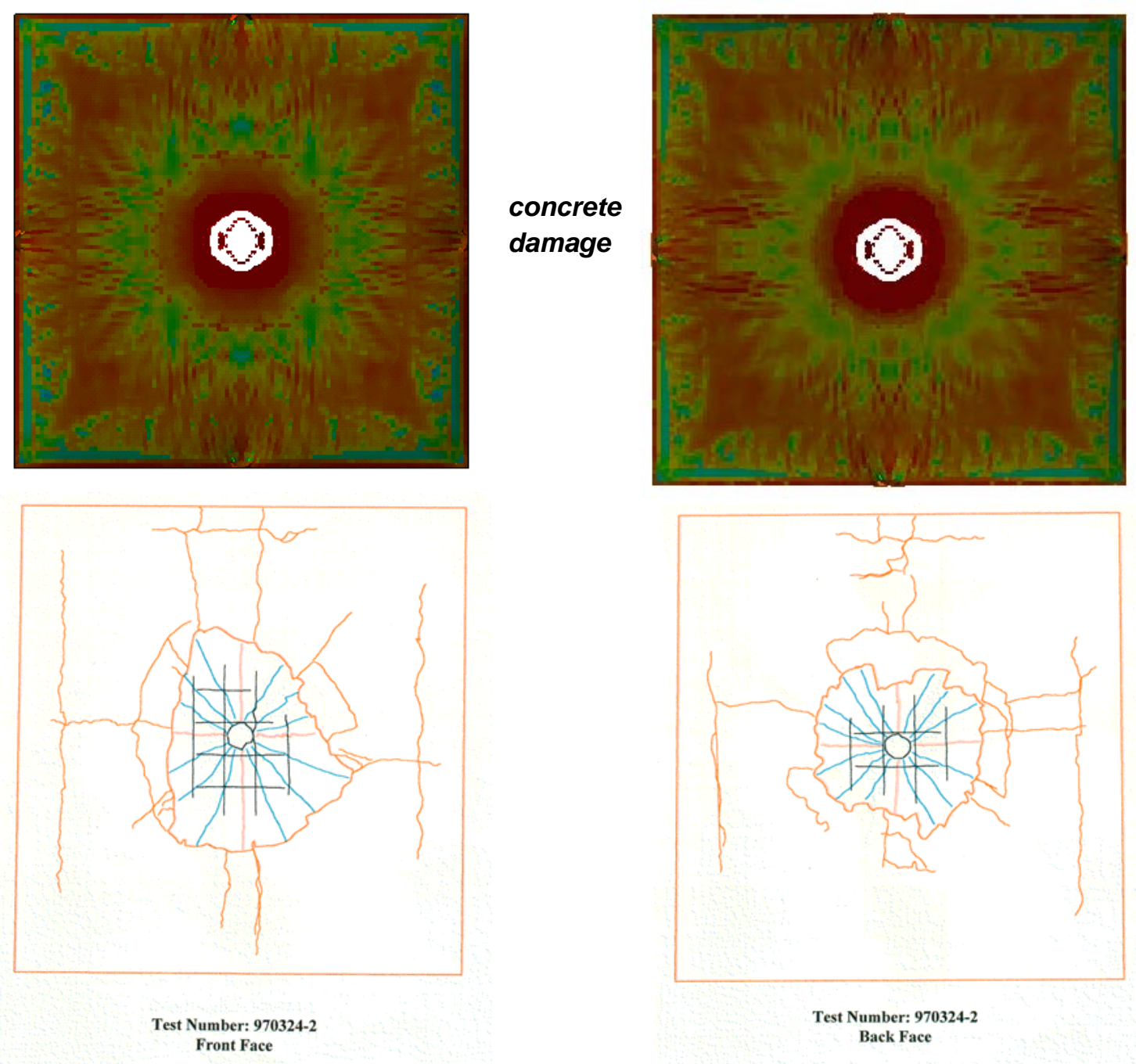

FIGURE 57. Comparison between experimental results and ALE3D simulation.

For the model and results described above, the rebar was simulated by explicitly meshing the rebar using brick elements. A second model was generated in order to evaluate the usefulness of the new homogenized rebar formulation and FiberGrid, which is a pre-processor for GEN3D/ALE3D used to insert volume fractions and directionality of the homogenized rebar into the concrete zones which contain steel reinforcement. Figure 58 shows the ALE3D model with the homogenized rebar shown as black lines.

A comparison of the concrete damage between the two finite element models was completed and is shown in Figure 59. The main difference between the two finite element simulations is that the homogenized rebar model shows more concrete damage where the rebar exists.

In addition to validating that the homogenized rebar model is working properly, the usefulness of a new spall or damage criterion was evaluated. The spall or damage criterion is 
a very simple idea. The idea is that concrete spallation might be able to be predicted in these complicated concrete plasticity models if a certain portion of a concrete structure (subjected to very large blast pressures or impact) has both tensile or compressive damage and a very large velocity. For this simulation, the concrete damage threshold was 0.85 (from a scale of 0 to 1 where 1 is complete tensile or compressive damage of concrete) and the velocity threshold was chosen to be 20 inches/sec. Figure 60 shows the fringe plot of this spall/damage criterion. As a result of using these two threshold values, the predicted spall was approximately $30 \mathrm{~cm}$, which matches experiment reasonably well.

The problem with this spall criterion is how arbitrary it is with regards to choosing a velocity magnitude. To gain more understanding of what velocities to use, a suite of velocity time histories were extracted across the cross-section of the concrete wall panel. These time histories are shown in Figure 60. By closely examining the velocity time histories, one can see a significant change in the velocity profiles at around $30 \mathrm{~cm}$ from where the charge was placed. At the $30 \mathrm{~cm}$ position, there is still significant velocities in the concrete, whereas after $30 \mathrm{~cm}$ the velocities are virtually zero after 0.005 seconds. By looking at the velocity profile at $30 \mathrm{~cm}$, one could see that $20 \mathrm{in} / \mathrm{sec}$ might not be a bad choice for a velocity threshold for the spall criterion.

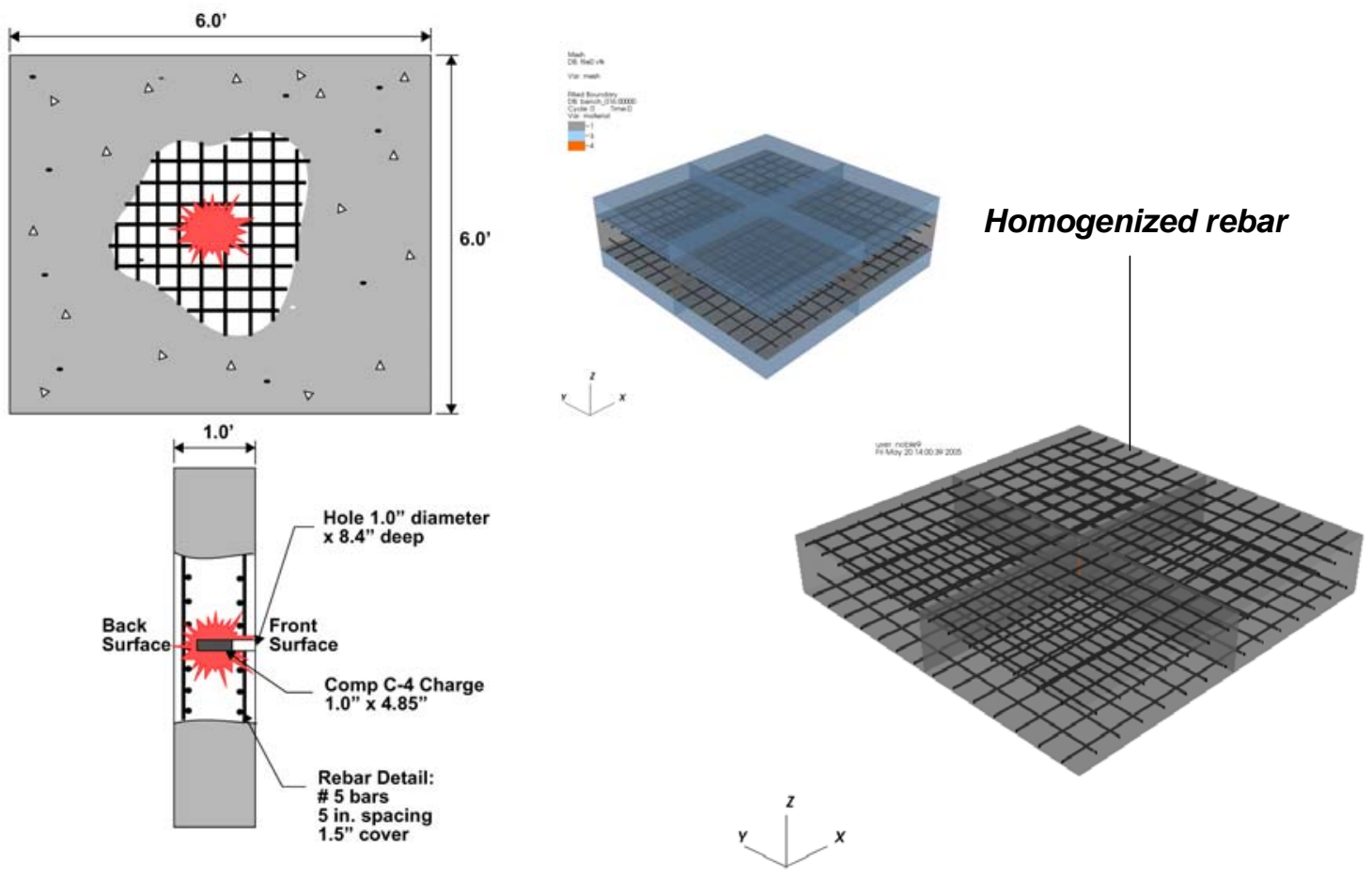

FIGURE 58. ALE3D finite element model of precision wall panel using homogenized rebar. 

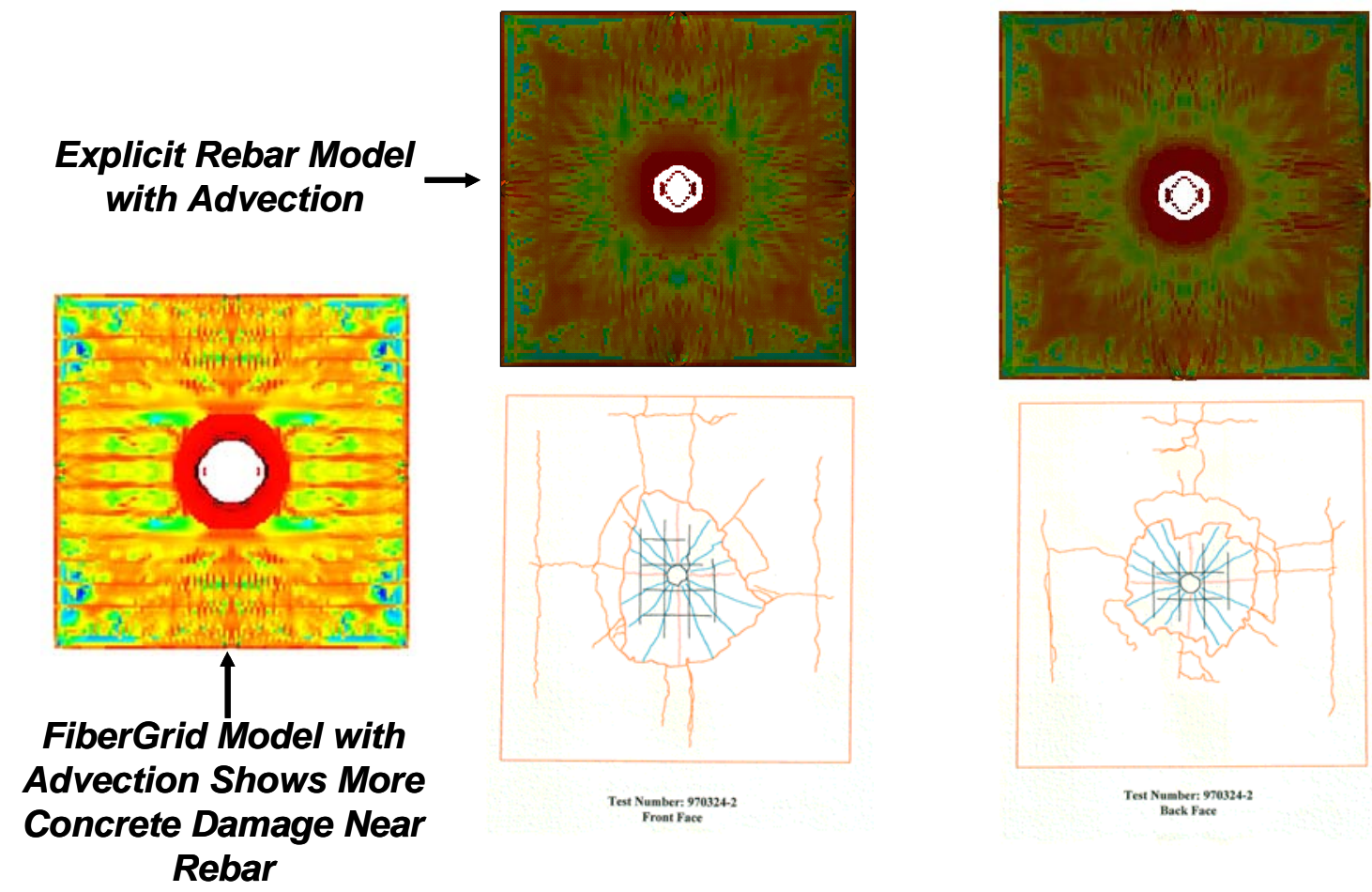

Test Number: 970324-2
Back Face

Rebar

FIGURE 59. Results comparison between the ALE3D model using brick elements for rebar and the ALE3D model using homogenized rebar.

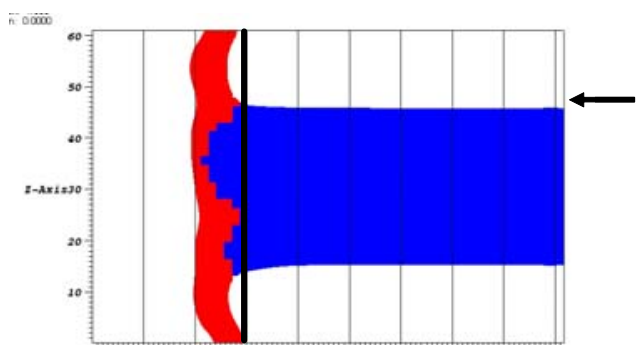

Concrete damage $>0.85$;

speed (velocity) > $20 \mathrm{in} / \mathrm{sec}$

Significant change in velocity profile at $x=30 \mathrm{~cm}$
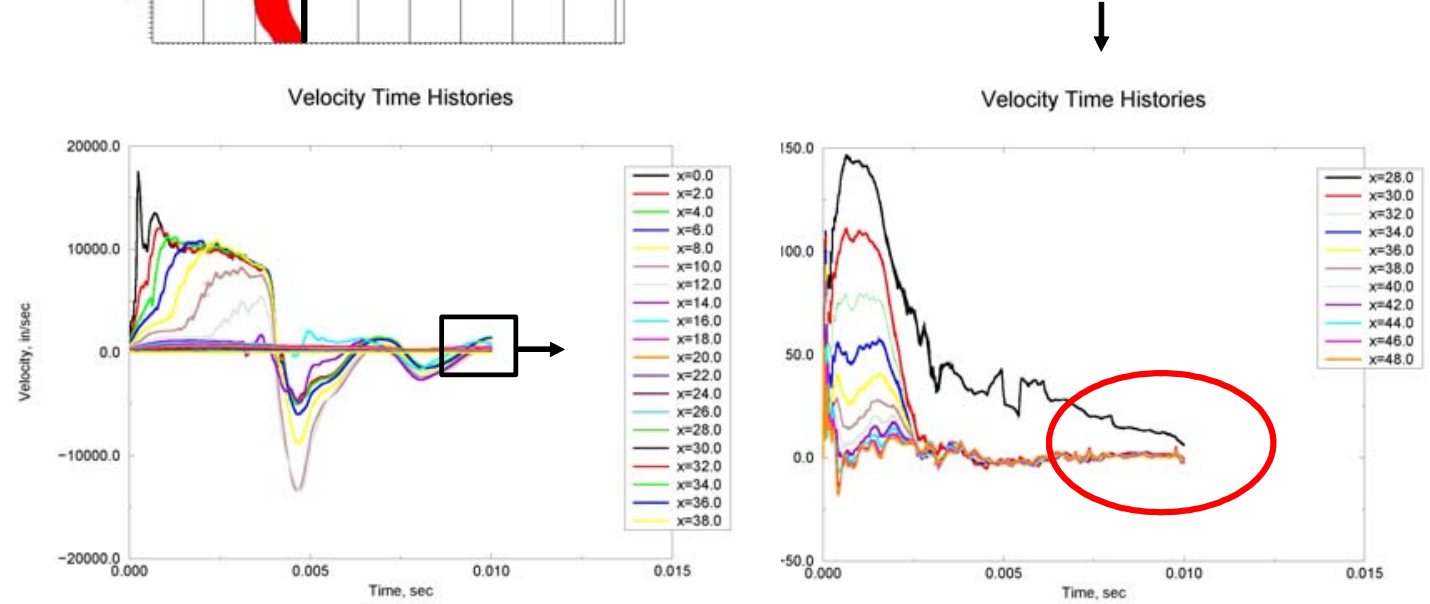

FIGURE 60. Results from homogenized rebar model using new damage visualization. 


\subsection{Explosively Formed Projectile Validation Experiment}

An explosively formed projectile (EFP) experiment conducted by LLNL scientists was used to validate the vast number of CALE simulations that were performed for studying concrete damage or breach by platter charges impacting reinforced concrete targets. The experimental set-up and results are shown in Figure 61. The top damage plot shows the concrete breach from two EFP's (see Figure 61) impacting the $6 \mathrm{ft}$ thick concrete target, and the bottom damage plot shows the concrete breach from the first EFP impacting the 6 $\mathrm{ft}$ thick concrete target. The EFP consists of unconfined HE (4.8 lbs LX-14) backing a spherically shaped copper liner that is $1 / 8$ inches thick. In the experiment, the EFP had been positioned at two different stand-off distances, 2.0 and 1.16 charge diameters from the concrete wall. Therefore, two CALE simulations were completed for both stand-off distances. Figure 62 shows the CALE finite element model used for this validation study, and Figure 63 shows the damage resulting from the EFP impact into an unreinforced concrete block for the two standoff distances. The breach or penetration distance of the EFP was calculated to be approximately $20 \mathrm{~cm}$. The experimental hole profiles from the first EFP impacting the concrete target (Figure 61) show that the breach or penetration distance was approximately $21-24 \mathrm{~cm}$ depending on the experiment one compares to. The CALE finite element results are in reasonable agreement with the test data. 


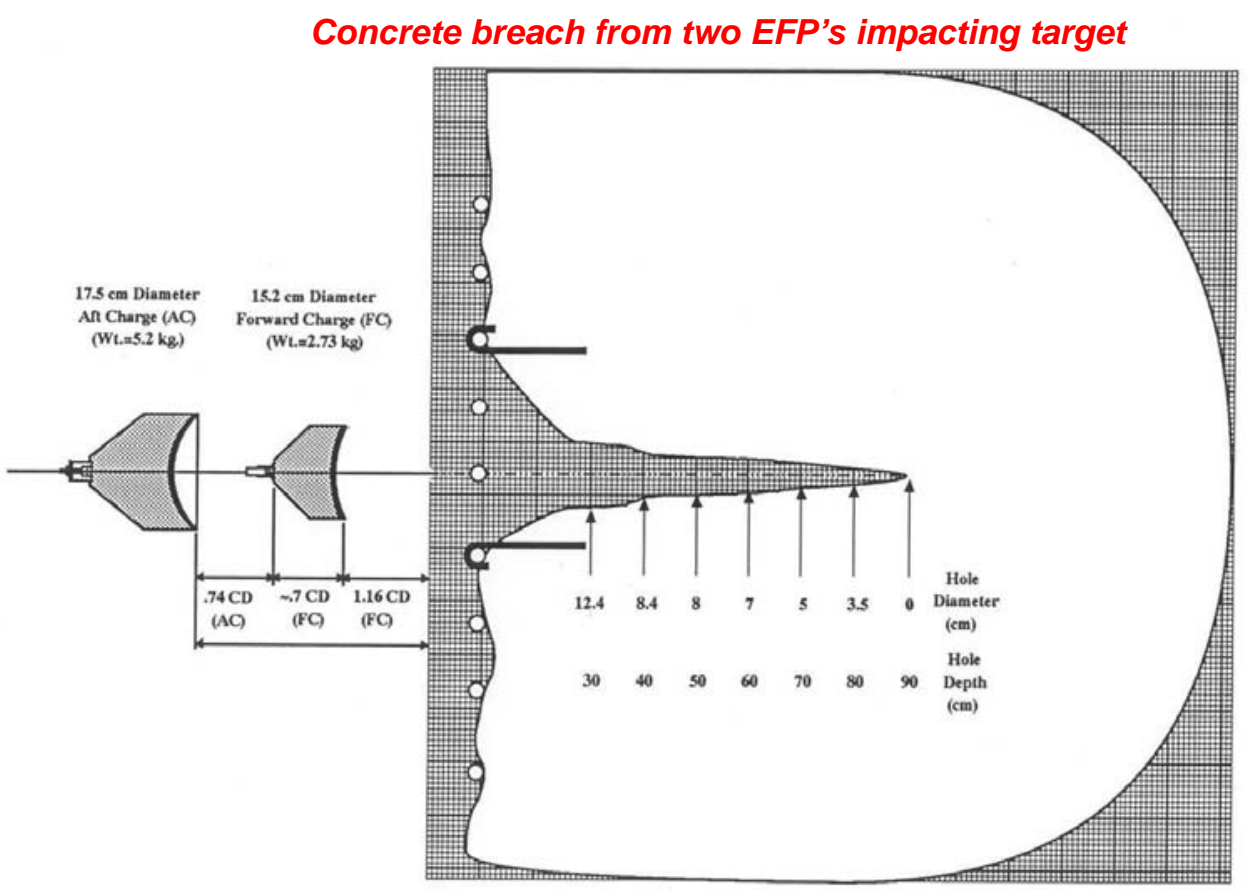

Concrete breach from first EFP impacting target

Horizontal Hole Profiles [Grid Spacing = 1-cm]
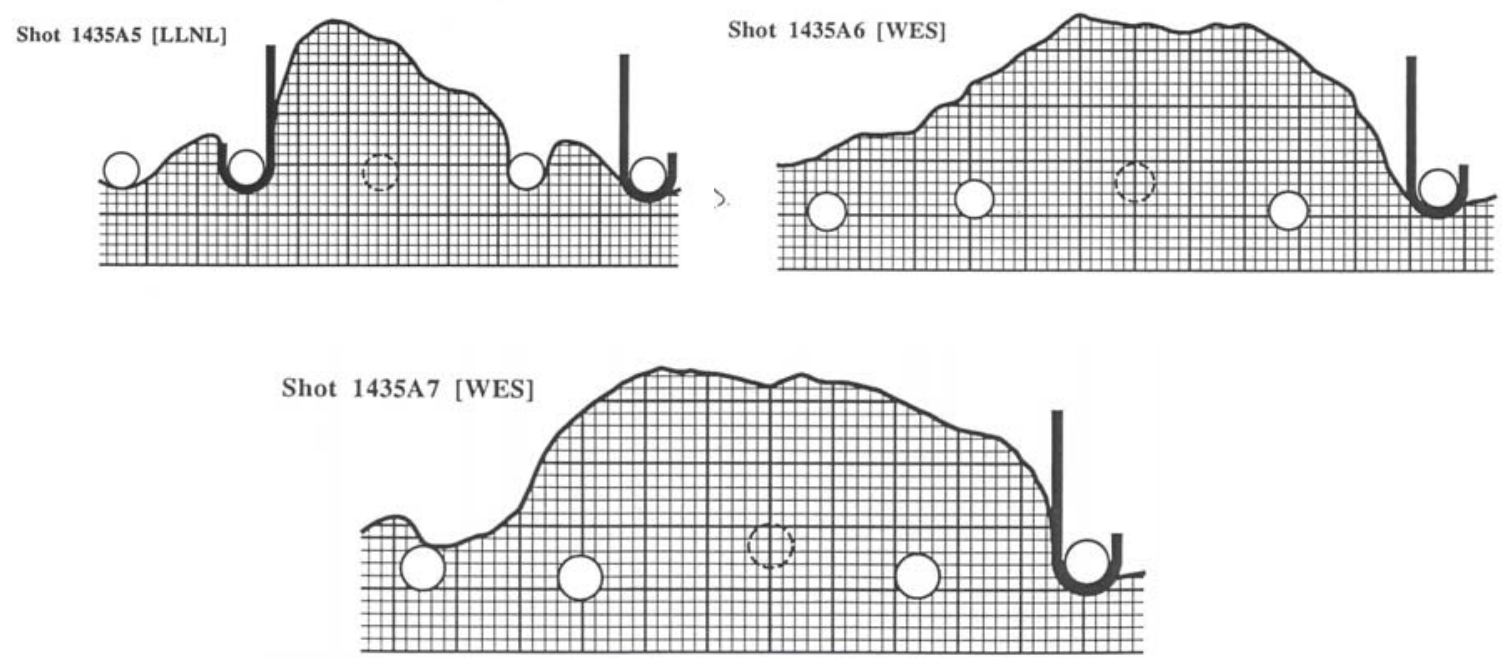

FIGURE 61. Experimental set-up and results for explosively formed projectile impacting a reinforced concrete block. 


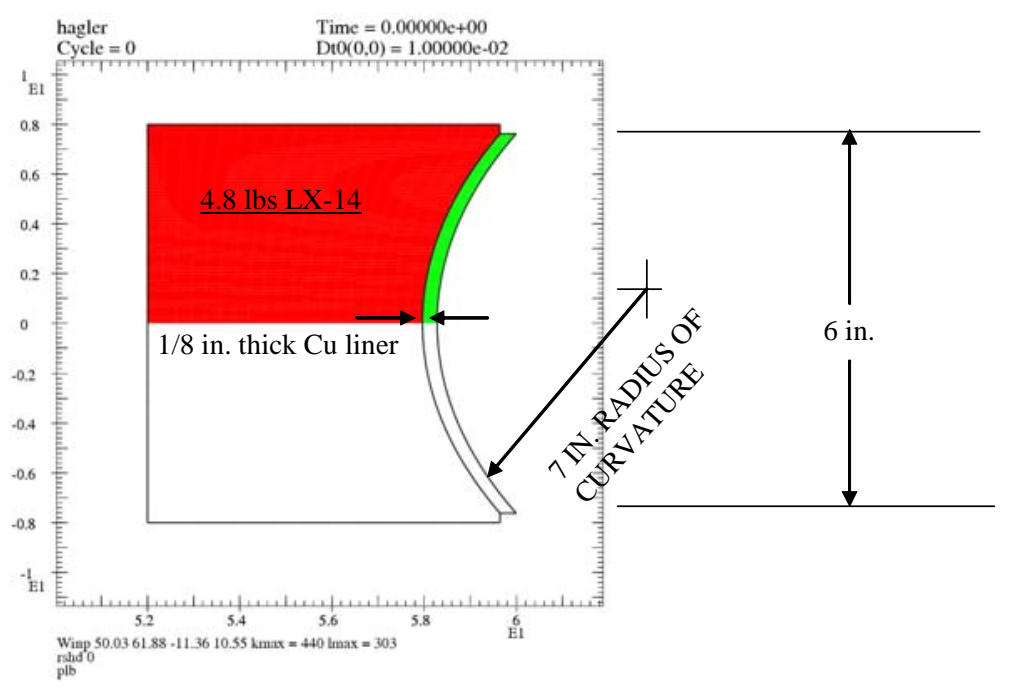

FIGURE 62. CALE finite element model of explosively formed projectile.
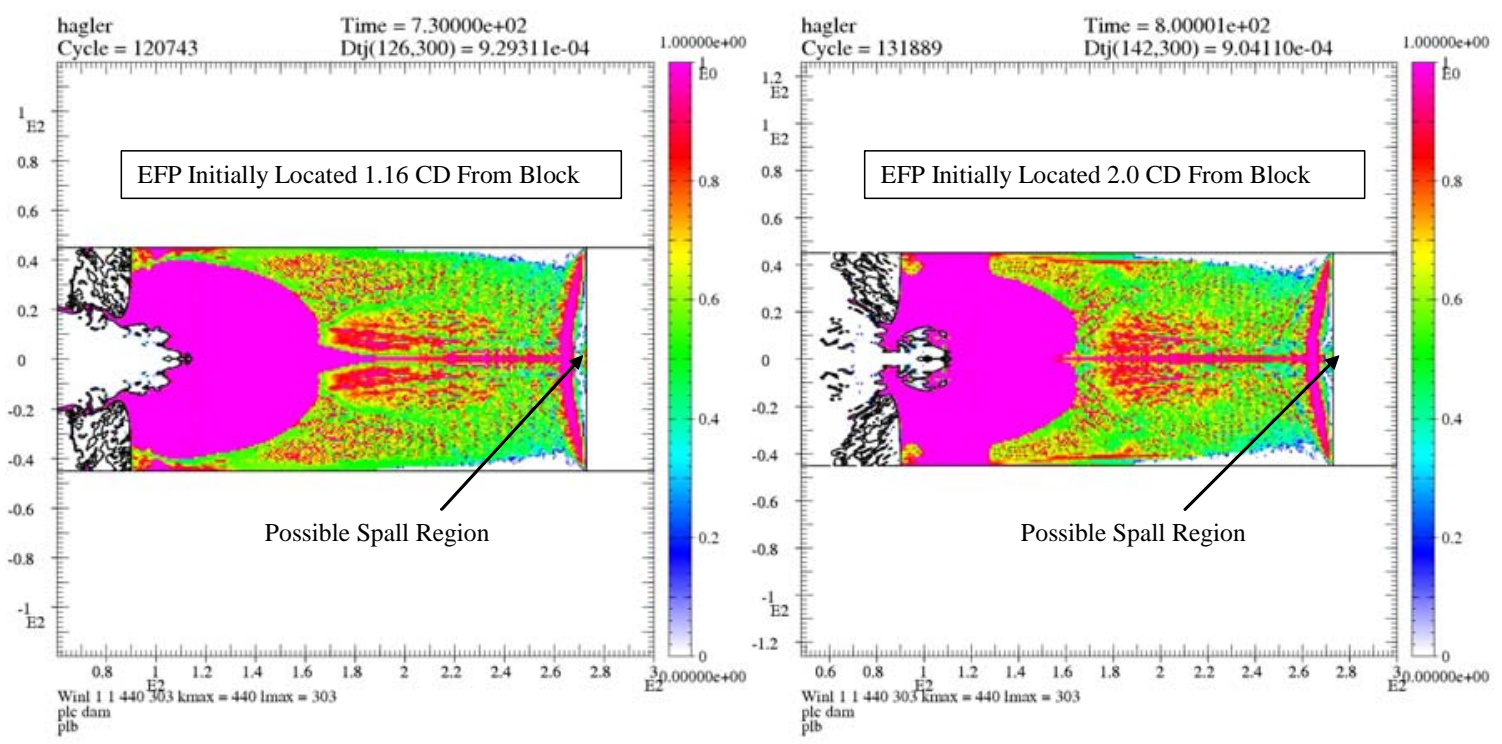

FIGURE 63. Damage resulting from EFP (Copper) impact into unreinforced concrete block.

\subsection{ALE3D/TM5-1300 Comparison Study}

The ALE3D program pressure calculations have been checked by comparison with idealized explosive configurations for which simple analytical formulas are available. In the case of a simple idealized spherical charge for example, the overpressure at a specified distance from the source can be computed from analytical formulas provided in the mili- 
tary blast manual TM5-1300. For the case of a one pound TNT equivalent spherical charge, the overpressures computed with the TM5-1300 manual and with ALE3D are shown in Figure 64. The ALE3D simulation agrees well with the analytical military services blast calculation. The differences between the two are attributable to the finite dimensions of the three dimensional explosive source modeled in the ALE3D simulation (as opposed to a point source in the idealized calculations), and potentially energy differences between the ALE3D characterization of the explosive material versus the assumed material energy in the TM5-1300 formulas. 

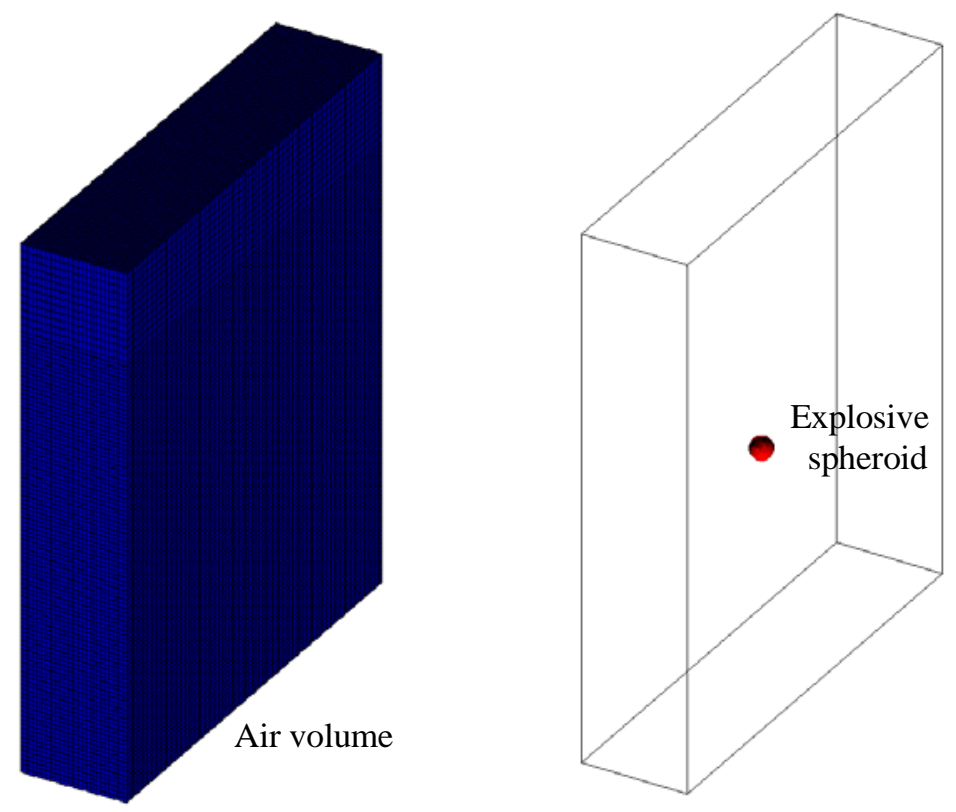

ALE3D \& TM5-1300 Comparison

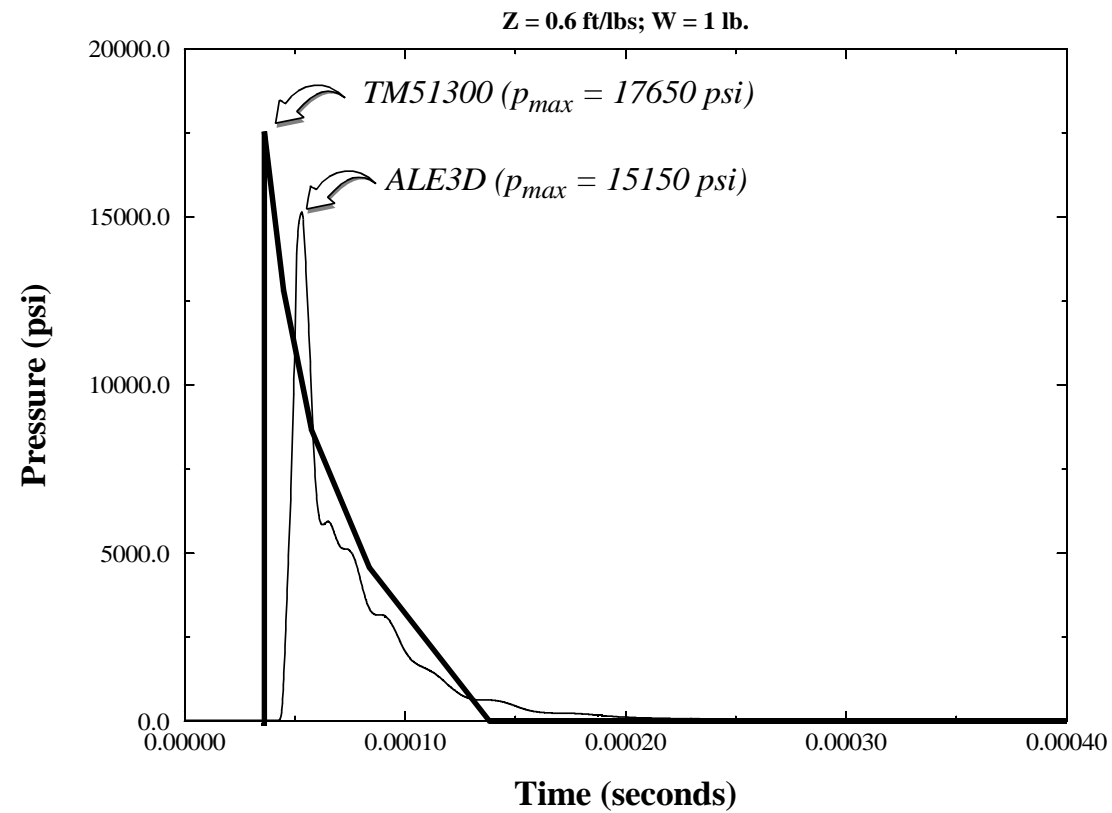

FIGURE 64. Comparison of overpressures from an idealized spherical charge as obtained from the military services TM5-1300 manual and ALE3D simulations. 


\subsection{ALE3D Underwater Shock Validation Study}

Submergence of an explosive underwater can have a significant effect on the peak overpressures achieved with a given explosive. Empirical data indicates that for dam destruction, "a surface detonation will produce only about one-tenth of the peak overpressure and impulse produced by a submerged explosion". The peak overpressure obtained with submerged explosives has been briefly documented in Meyer $^{2}$ and Cole ${ }^{3}$. For various bombs, the explosive pressure as a function of standoff distance is indicated in Figure 65. Figure 65 also shows the pressure prediction for a submerged spherical charge as computed with the ALE3D program for an explosive weight equivalent to the M118 warhead. The ALE3D simulation exhibits a good correlation with the submerged warhead data. The propagation of the shock wave in the ALE3D simulation is shown in Figure 66 for an underwater burst and the 10,50 and 100 meter distances highlighted in the graph of Figure 65 are indicated with dashed lines. A similar plot in Figure 67 shows the shock propagation in air.

1. Davis, L.K., Vulnerability of Dams to Conventional Munitions, Department of the Army, Waterways Experiment Station, Corps of Engineers, December 1990.

2. Meyer, J.W., Davis, L.K., Rooke, A.D., Vulnerability of Man-Made Inland Waterways to Conventional Air-Delivered Bombs, U.S. Army Engineer Waterways Experiment Station, April 1971.

3. Cole, R.H., Underwater Explosions, Princeton University Press, Princeton, New Jersey, 1948. 
Peak incident pressure as a function of standoff distance

a)
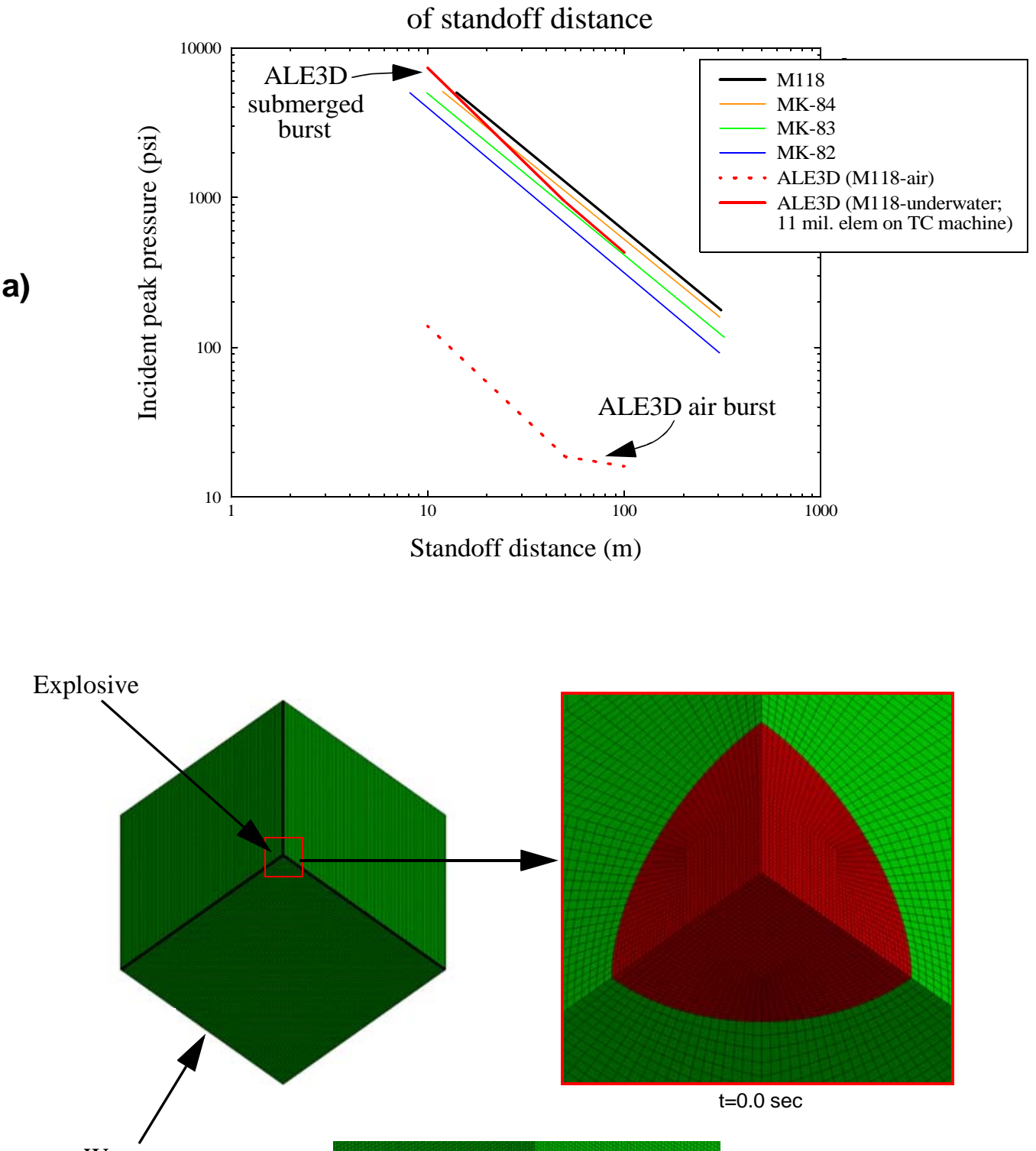

b) Water

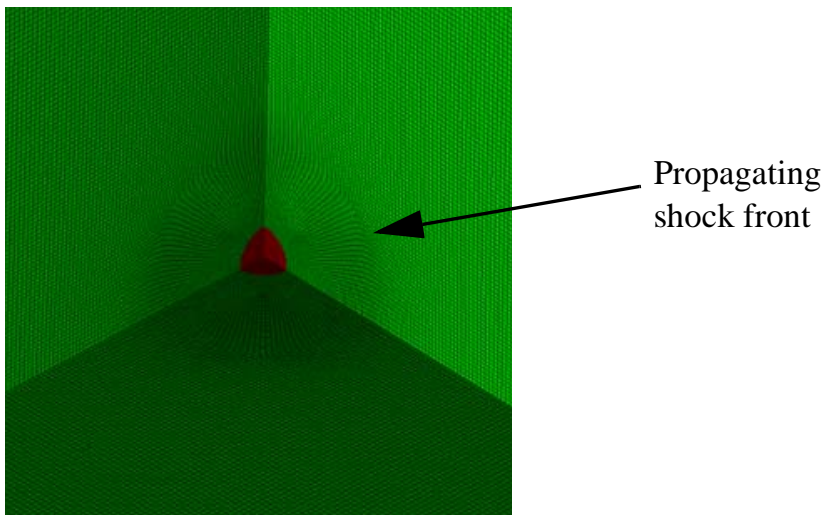

$\mathrm{t}=0.25 \mathrm{sec}$

FIGURE 65. Peak overpressures for a submerged explosive. a) Data from reference * and ALE3D simulations; b) ALE3D model of a submerged spherical explosive. 

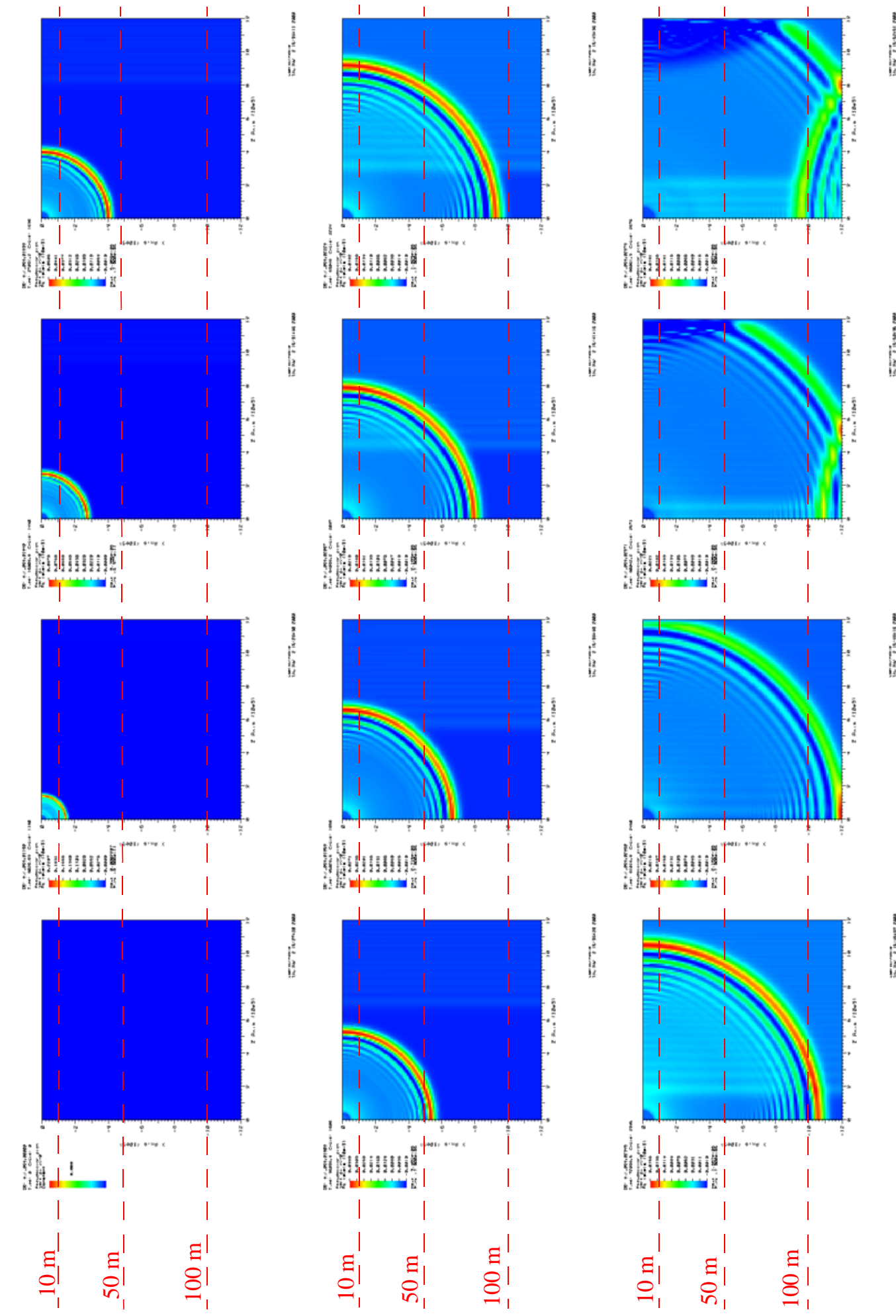

完

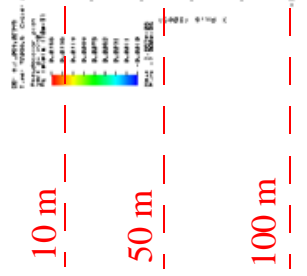




\subsection{Gravity Initialization}

The typical methodology for taking gravity loads into account is to dynamically turn on gravity at initialization or by using the ALE3D implicit solver to pre-stress the structure. Both of these methods have shortcomings. It was found that dynamcially turning on gravity at initialization the structure in many cases would not see a pre-load before the explosive has already damaged the structure. It was also found that if the model were allowed to run without an explosive load and without mass damping, the stress levels could reach peaks much higher than expected and potentially initiate damage in the concrete. An alternate solution to this would be to use the ALE3D implicit solver to pre-stress the structure although the solver will not work in models with shell elements or in models where shaped-in material regions exist.

An alternate method for pre-stressing the structure was evaluated due to the issues mentioned above. The approach outlined in Figure 68 involves dynamically turning on gravity for a period of time and using mass proportional damping to control the amplification effect of stress waves reflecting off of free surfaces in the model. The procedure proved effective on representative one and two-dimensional models and will be evaluated for the full three-dimensional model in the future (Figure 69).

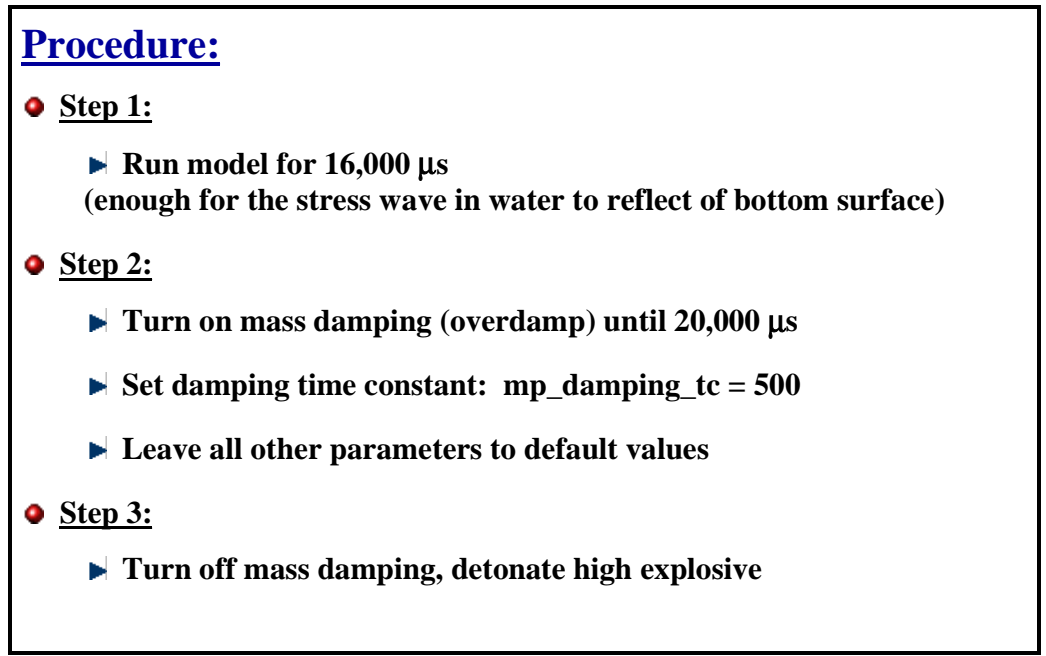

FIGURE 68. Steps in the alternate gravity initialization scheme 

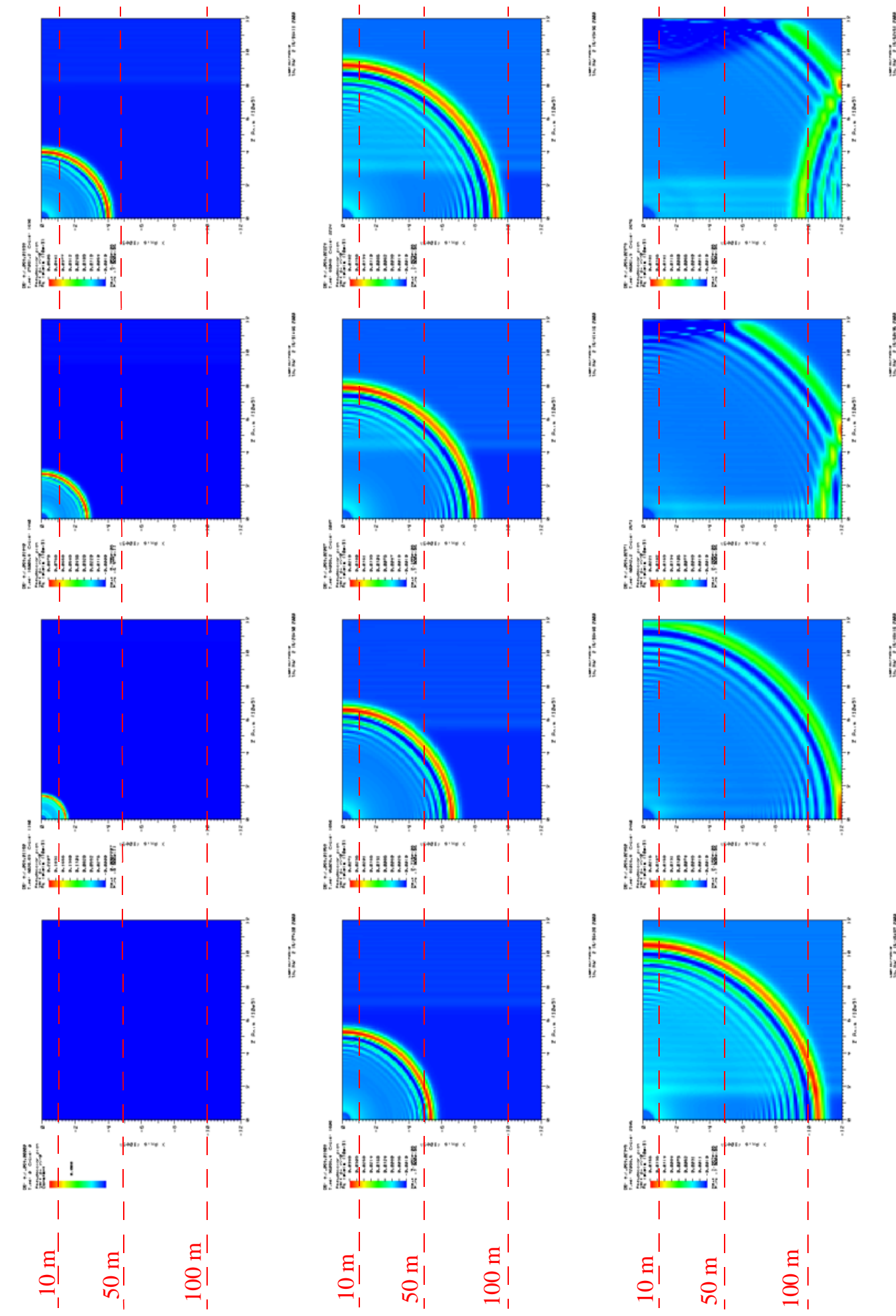

完

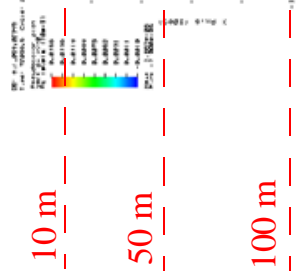




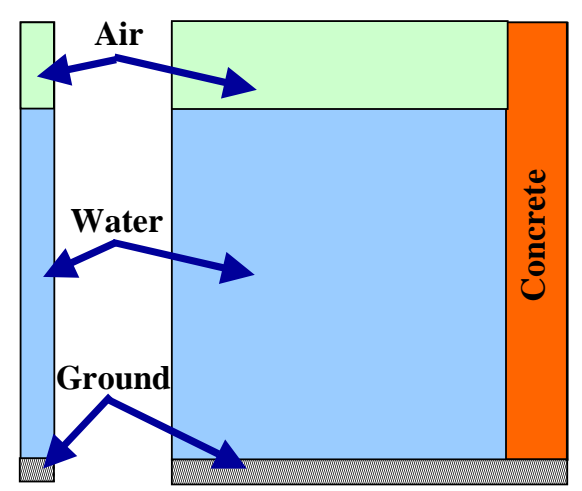

Case 1: Column

Case 2: Plane

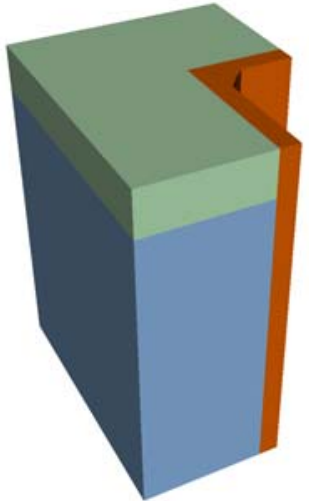

Case 3: Full Corner

FIGURE 69. Three analysis models considered for alternate gravity initialization scheme.

To verify the that the alternate gravity initialization scheme produces reasonable results, a series of calculations were completed for the one-dimensional column and two-dimensional plane geometries (Figure 69). The water pressure and concrete vertical stress as a function of depth are plotted in Figure 70. Both implicit and explicit scheme were compared to what a hand calculation predicts. The results showed very little variation in the pressure as a function of position in the water and somewhat larger variations in the concrete vertical stress for each of the evaluated cases.

The variations in concrete vertical stresses as a function of depth can be linked to a few sources. The deviation in slope between the code calculated values (for the explicit formulation) and the hand calculated values can be attributed to a non-zero concrete porosity resulting in a reduced effective density. In addition, the deviation from linearity in the two-dimensional plane cases is caused by the bending in the wall due to the adjacent volume of water. And to some level, deviations between the implicit and explicit schemes in the two-dimensional plane examples can also be affected by the water material properties required in the implicit calculation (i.e. ALE3D implicit solver requires water strength for convergence). 


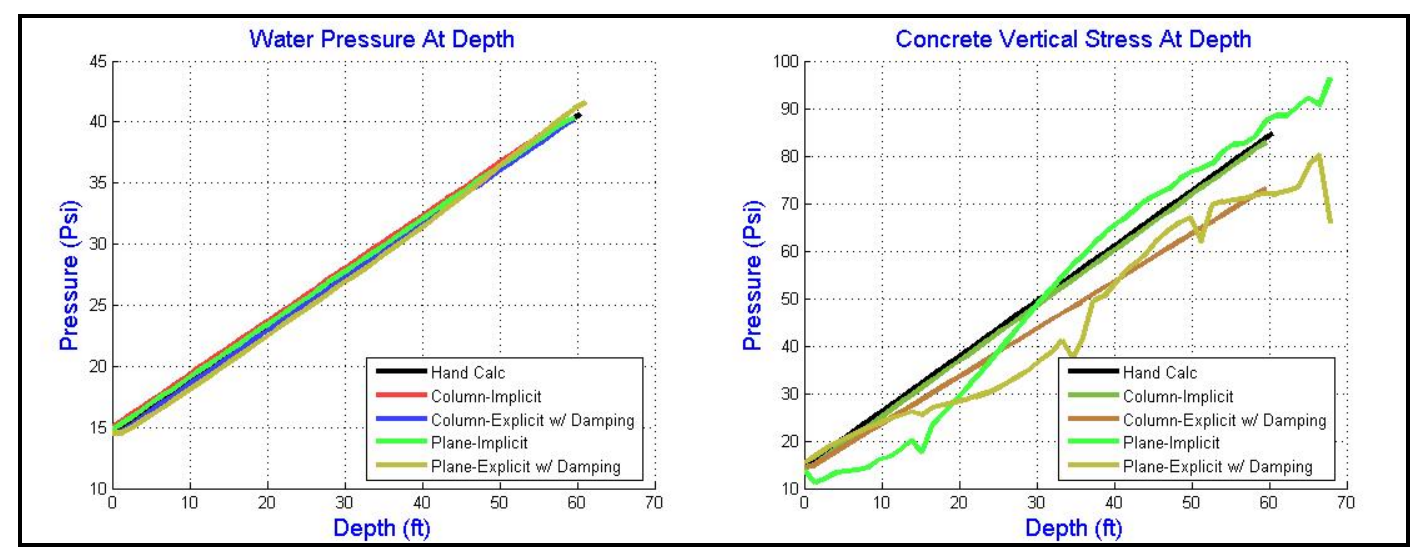

FIGURE 70. Water pressure and concrete vertical stress as a function of depth

For each calculation listed above, the first two steps of the process outlined in Figure 68 were followed. Note that the velocity and pressure in the water have effectively reached steady state values by 20,000 microseconds in to the simulation (Figure 71). Similarly, most of the ringing of stress waves in the concrete have ceased and are slowly damping out to a steady state value.

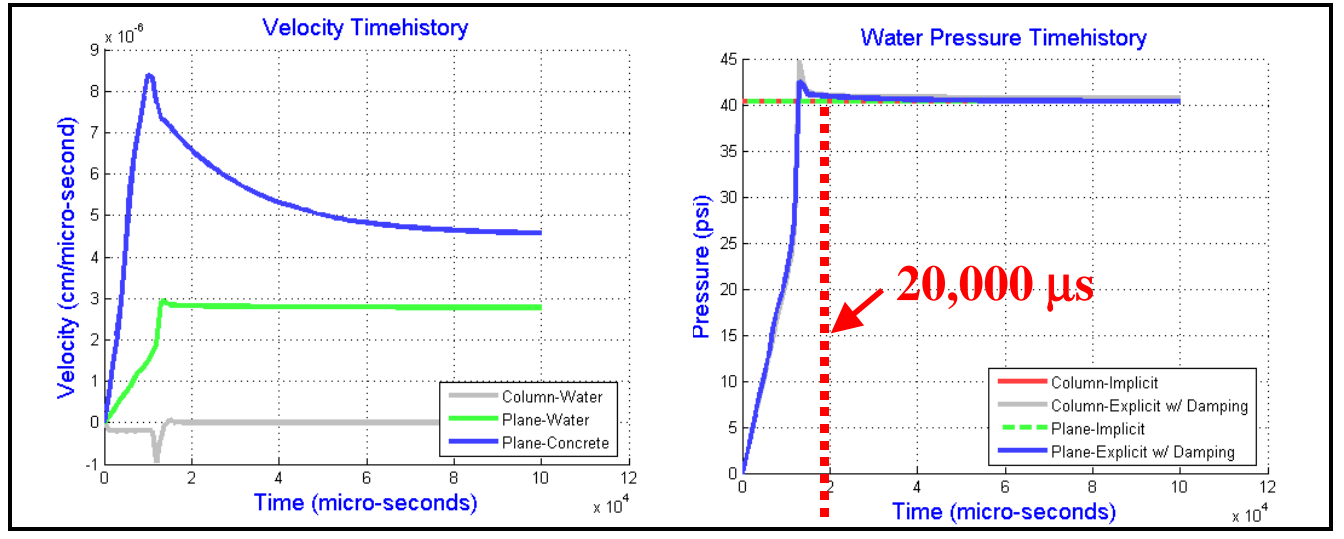

FIGURE 71. Pressure and velocity time history plots for water and concrete

\subsection{Acknowledgements}

This work was performed under the auspices of the U.S. Department of Energy by the University of California, Lawrence Livermore National Laboratory under contract No. W7405-Eng-48. 